UNIVERSIDADE DE SÃO PAULO

INSTITUTO DE QUÍMICA DE SÃO CARLOS

\title{
AMINAS ACÍCLICAS COMO LIGANTES ANCILARES EM CATALISADORES DE RUTÊNIO PARA POLIMERIZAÇÃO VIA METÁTESE DE OLEFINAS CÍCLICAS
}

\section{Tiago Breve da Silva}

\author{
Dissertação apresentada ao Instituto \\ de Química de São Carlos, da \\ Universidade de São Paulo, para \\ obtenção do Título de Mestre em \\ Química
}

Orientador: Prof. Dr. Benedito dos Santos Lima-Neto 
Nenhum homem realmente produtivo pensa

como se estivesse escrevendo uma

dissertação.

\section{Albert Einstein}

À Deus, que me permite acordar todos os dias, me proporcionando uma nova chance de fazer tudo diferente; e pelo amparo que........bem, só ele sabe o que se passa em nossa mente, em nosso coração, e supriu-me do que precisei para a realização deste trabalho 
Os nossos pais amam-nos porque somos seus filhos,

é um fato inalterável. Nos momentos de sucesso,

isso pode parecer irrelevante, mas nas ocasiões de fracasso,

oferecem um consolo e uma segurança

que não se encontram em qualquer outro lugar.

\section{Bertrand Russell}

Aos meus pais, Narciso e Lúcia, que sempre me deram apoio quando mais precisei, e que ainda, se for pra fazer tudo novamente, ali estarão eles.

Amo vocês. 
Quem é

mais amigo de um irmão

do que seu irmão?

Salústio

Ao meu irmão, Gustavo,

pelo incentivo, apoio, e pela força que sempre me deu. 
Há 2 espécies de chatos: os chatos propriamente ditos e os amigos, que são os nossos chatos prediletos.

\section{Mário Quintana}

\section{Agradecimentos}

Agradeço a Deus pela saúde, pelos amigos e pela família. Agradeço por cada dia vivido em São Carlos e por tudo que pude aprender.

Agradeço ao Professor Benedito pela orientação e pelo apoio para a realização desse trabalho. O "Zé Tiago" agradece imensamente.

Aos professores Douglas e Daniel, pelo convívio e pelo aprendizado.

E agradeço também, como diria "Zé Luiz": A cada membro da família São Carlense: Magão (papagaiada!!!), Zé Luiz ( Cadê as cabritas?!?), Henrique (Little boy), Camila (Esse Tiaguinho...), Evânia ( Presta atenção, porque tem gente que não presta), Danizinha (Paciência, cadê?), Larissa (E esse GPC hein?!?), Marcela ( Bora começar?), Ricardo (Baininho), Guilherme (Buda).

Aos amigos que me aturam todos os dias no laboratório de inorgânica: Gustavo, Naná (Nalbert), André (Barbie), Thiago Abraão, Maycon, Silvia, Dani Truzzi, Natalinha, Andressa (Olga Maria), Aline (Elaine), Leandro (Boi), Thiago (Papa), Alexandre (Itapira), Felipe (Felipão), Juliana (Grippa)

Aos amigos de "batalha": Flávio (baixinho), Pedro Ivo (baiano), Carol. Aos amigos de república: Denivaldo (Tô te devendo uma, hein!!!), Alanzão, Marcelo Vale, Dudu.

Aos técnicos da CAQI que eu tanto torrei a paciência: Silvana (RMN), Carlinhos (A.E. e ICP), André (FTIR) 


\section{LISTA DE TABELAS}

Tabela 1 - Tolerância e reatividade em reações de metátese de catalisadores de metais de transição frente a alguns grupos funcionais em ordem decrescente de reatividade.

Tabela 2 - Resultados de ROMP de norborneno (NBE) com $\left[\mathrm{RuCl}_{2}\left(\mathrm{PPh}_{3}\right)_{2} \mathrm{~L}_{\mathrm{x}}\right] ;[\mathrm{Ru}]=1 \mu \mathrm{mol}$, $[\mathrm{NBE}] /[\mathrm{Ru}]=5.000,5 \mu \mathrm{LEDA}$ em $\mathrm{CHCl}_{3}{ }^{41}$ 38

Tabela 3 - Valores de $\mathrm{pK}_{\mathrm{a}}$ e ângulo de cone para fosfina e ligantes nitrogenados ${ }^{42}$ .40

Tabela 4 - Dados da análise elementar para os complexos de Ru" sintetizados.

Tabela 5 - Bandas dos espectros de FTIR dos complexos $\left[\mathrm{RuCl}_{2}\left(\mathrm{PPh}_{3}\right)_{2}\left(\mathrm{~N}_{\mathrm{III}}\right)_{\mathrm{x}}\right]$, para $\mathrm{N}_{\mathrm{III}}=$ $\mathrm{NH}_{2} \mathrm{Ph}, \mathrm{NH}_{2} \mathrm{CH}_{2} \mathrm{Ph}$ e $\mathrm{NH}^{\mathrm{n}} \mathrm{BuPh}$ com $\mathrm{x}=2$ para $\mathrm{NH}_{2} \mathrm{Ph}, \mathrm{NH}_{2} \mathrm{CH}_{2} \mathrm{Ph}$ e $\mathrm{x}=1$ para $\mathrm{NH}^{\mathrm{n}} \mathrm{BuPh} .^{45,46} .53$

Tabela 6 - Dependência do rendimento, $M_{w}$ e IPD em relação ao volume de EDA, para a ROMP de NBE com $\left[\mathrm{RuCl}_{2}\left(\mathrm{PPh}_{3}\right)_{2}\left(\mathrm{NH}_{2} \mathrm{Ph}\right)_{2}\right] ;[\mathrm{NBE}] /[\mathrm{Ru}]=5000 ;[\mathrm{Ru}]=1 \mu \mathrm{mol}$ em $2 \mathrm{~mL}$ de $\mathrm{CHCl}_{3}$ à $25^{\circ} \mathrm{C}$ por 5 minutos. 70

Tabela 7 - Dependência do rendimento, $M_{w}$ e IPD em relação à temperatura, para a ROMP de NBE com 1, 2 e 3; $[\mathrm{NBE}] /[\mathrm{Ru}]=5000 ;[\mathrm{Ru}]=1 \mu \mathrm{mol}$ em $2 \mathrm{~mL}$ de $\mathrm{CHCl}_{3}$ à $25^{\circ} \mathrm{C}$ e $50^{\circ} \mathrm{C}$ por 5 minutos.

Tabela 8 - Dependência do rendimento em relação ao tempo e a temperatura, para a ROMP de DCPD com 3; [DCPD $] /[\mathrm{Ru}]=5000 ;[\mathrm{Ru}]=1 \mu \mathrm{mol}$ em $2 \mathrm{~mL}$ de $\mathrm{CHCl}_{3}$ à $50^{\circ} \mathrm{C}$ por 60 e 120 minutos.

Tabela 9 - Dependência do rendimento, $M_{w}$ e IPD em relação à temperatura, tempo e razão molar para a ROMP de NBE com 1 em $2 \mathrm{~mL}$ de $\mathrm{CHCl}_{3}$. 80

Tabela 10 - Dependência do rendimento, $M_{w}$ e IPD em relação à temperatura, tempo e razão molar para a ROMP de NBE com 2 em $2 \mathrm{~mL}$ de $\mathrm{CHCl}_{3}$. 
Tabela 11 - Dependência do rendimento, $M_{w}$ e IPD em relação à temperatura, tempo e razão molar para a ROMP de NBE com 3 em $2 \mathrm{~mL}$ de $\mathrm{CHCl}_{3}$ em 5 minutos.

Tabela 12 - Rendimentos da copolimerização de DCPD com NBE e NBD com 3 a $50^{\circ} \mathrm{C}$ por 60 minutos 87

Tabela 13 - Deslocamento químico, atribuições e área relativa dos picos (\%) e $\sigma_{c}$ do polímero formado utilizando 1 . 90

Tabela 14 - Deslocamento químico, atribuições e área relativa dos picos (\%) e $\sigma_{c}$ do polímero formado utilizando 2 . 92

Tabela 15 - Deslocamento químico, atribuições e área relativa dos picos (\%) e $\sigma_{c}$ do polímero formado utilizando 3. 


\section{LISTA DE FIGURAS}

Figura 1. Exemplo geral de metátese.

Figura 2. Síntese de neohexeno a partir de 2,2,4-trimetil-2-penteno usando uma mistura catalítica de $\mathrm{WO}_{3} / \mathrm{SiO}_{2}$ e $\mathrm{MgO}(1: 3)$ à $370{ }^{\circ} \mathrm{C}$ e 30 bar através de Metátese Cruzada ( $\mathrm{CM}$ Cross Metathesis).

Figura 3. Os principais tipos de metátese de olefinas. 20

Figura 4. Mecanismo carbeno/ciclometalobutano proposto por Chauvin e Hérisson em 1971

Figura 5. Ilustração do mecanismo de polimerização de olefinas via ROMP . 22

Figura 6. Ilustração do mecanismo de polimerização de olefinas via ROMP. Etapa de iniciação. .23

Figura 7. Coordenação da (a) olefina ao centro metálico e (b) formação do ciclometalobutano em termos de orbitais moleculares ${ }^{13,14}$. 24

Figura 8. Ilustração do mecanismo de polimerização de olefinas via ROMP. Etapa de propagação. 25

Figura 9. Reações secundárias intermoleculares (a) e intramoleculares (b). 25

Figura 10. Ilustração do mecanismo de polimerização de olefinas via ROMP. Etapa de terminação. 26

Figura 11. Ilustração do mecanismo de polimerização de olefinas via ROMP. Período de indução. .26

Figura 12. Copolímero de Polinorborneno funcionalizado com $\varepsilon$-caprolactana e norborneno com grupo ciano ${ }^{17}$

Figura 13. Catalisadores para metátese de olefinas baseados em $\mathrm{Ti}, \mathrm{Mo}, \mathrm{W}$ e $\mathrm{Ru}^{3,4}$. 28 
Figura 14. Catalisadores para metátese de olefinas de Grubbs, Grubbs-Hoyeda e modificações ${ }^{22,23}$ 30

Figura 15. Exemplos de fosfinas e fosfito. 32

Figura 16. Ligação- $\sigma$ e ligação- $\pi$ entre metal e ligantes fosforados (retrodoação). 33

Figura 17. Complexos sintetizados pelo grupo ${ }^{42}$ 36

Figura 18. Ligantes ancilares nitrogenados utilizados neste trabalho. 39

Figura 19. Rota para obtenção do complexo precursor $\left[\mathrm{RuCl}_{2}\left(\mathrm{PPh}_{3}\right)_{3}\right](\mathbf{P})$ 43

Figura 20. Rota para obtenção do complexo $\left[\mathrm{RuCl}_{2}\left(\mathrm{PPh}_{3}\right)_{2}\left(\mathrm{NH}_{2} \mathrm{Ph}\right)_{2}\right](\mathbf{1})$. 43

Figura 21. Rota para obtenção do complexo $\left[\mathrm{RuCl}_{2}\left(\mathrm{PPh}_{3}\right)_{2}\left(\mathrm{NH}_{2} \mathrm{CH}_{2} \mathrm{Ph}\right)_{2}\right](2)$. 44

Figura 22. Rota para obtenção do complexo $\left[\mathrm{RuCl}_{2}\left(\mathrm{PPh}_{3}\right)_{2}\left(\mathrm{NH}^{\mathrm{n}} \mathrm{BuPh}\right)\right](3)$. 45

Figura 23. Monômeros utilizados. .46

Figura 24. Espectro vibracional na região do infravermelho em pastilha de Csl do complexo precursor $\left[\mathrm{RuCl}_{2}\left(\mathrm{PPh}_{3}\right)_{3}\right](\mathbf{P})$ e do complexo[RuCl$\left.{ }_{2}\left(\mathrm{PPh}_{3}\right)_{2}\left(\mathrm{NH}_{2} \mathrm{Ph}\right)_{2}\right](\mathbf{1})$ em vermelho. 52

Figura 25. Espectro vibracional na região do infravermelho em pastilha de CsI do complexo precursor $\left[\mathrm{RuCl}_{2}\left(\mathrm{PPh}_{3}\right)_{3}\right](\mathbf{P})$ e do complexo $\left[\mathrm{RuCl}_{2}\left(\mathrm{PPh}_{3}\right)_{2}\left(\mathrm{NH}_{2} \mathrm{Bz}\right)_{2}\right](2)$ em verde...... 52

Figura 26. Espectro vibracional na região do infravermelho em pastilha de Csl do complexo precursor $\left[\mathrm{RuCl}_{2}\left(\mathrm{PPh}_{3}\right)_{3}\right](\mathbf{P})$ e do complexo $\left[\mathrm{RuCl}_{2}\left(\mathrm{PPh}_{3}\right)_{2}\left(\mathrm{NH}^{\mathrm{n}} \mathrm{BuPh}\right)\right](3)$ em azul. 52

Figura 27. Espectro de $\mathrm{RMN}{ }^{31} \mathrm{P}\left\{{ }^{1} \mathrm{H}\right\}$ em $\mathrm{CDCl}_{3}$ para o complexo $\left[\mathrm{RuCl}_{2}\left(\mathrm{PPh}_{3}\right)_{2}(\text { anilina })_{2}\right](\mathbf{1}) . .55$ Figura 28. Espectro de $\mathrm{RMN}{ }^{31} \mathrm{P}\left\{{ }^{1} \mathrm{H}\right\}$ em $\mathrm{CDCl}_{3}$ para o complexo $\left[\mathrm{RuCl}_{2}\left(\mathrm{PPh}_{3}\right)_{2}(\text { anilina })_{2}\right](\mathbf{1})$ após irradiação de luz branca por 60 minutos. 55

Figura 29. Proposta mecanística para o complexo $\left[\mathrm{RuCl}_{2}\left(\mathrm{PPh}_{3}\right)_{2}(\text { anilina })_{2}\right](\mathbf{1})$ em solução e na presença de ligantes. 56

Figura 30. Espectro de $\mathrm{RMN}{ }^{31} \mathrm{P}\left\{{ }^{1} \mathrm{H}\right\}$ em $\mathrm{CDCl}_{3}$ para o complexo $\left[\mathrm{RuCl}_{2}\left(\mathrm{PPh}_{3}\right)_{2}(\text { anilina })_{2}\right](\mathbf{1})$ após irradiação de luz branca por 60 minutos e adição de excesso de $\mathrm{NH}_{2} \mathrm{Ph}$. 
Figura 31. Espectro de $\mathrm{RMN}{ }^{31} \mathrm{P}\left\{{ }^{1} \mathrm{H}\right\}$ em $\mathrm{CDCl}_{3}$ para o complexo $\left[\mathrm{RuCl}_{2}\left(\mathrm{PPh}_{3}\right)_{2}(\text { anilina })_{2}\right](\mathbf{1})$ na presença de $\mathrm{NH}_{2} \mathrm{Ph}$. 58

Figura 32. Espectro de $\mathrm{RMN} \quad{ }^{31} \mathrm{P}\left\{{ }^{1} \mathrm{H}\right\}$ em $\mathrm{CDCl}_{3}$ para $\mathrm{o}$ complexo $\left[\mathrm{RuCl}_{2}\left(\mathrm{PPh}_{3}\right)_{2}(\text { benzilamina })_{2}\right](2)$ em 6 minutos. 58

Figura 33. Espectro de $\mathrm{RMN} \quad{ }^{31} \mathrm{P}\left\{{ }^{1} \mathrm{H}\right\}$ em $\mathrm{CDCl}_{3}$ para $\mathrm{o}$ complexo $\left[\mathrm{RuCl}_{2}\left(\mathrm{PPh}_{3}\right)_{2}(\text { benzilamina })_{2}\right](2)$ em 6 minutos. Espécies contendo metal. 59

Figura 34. Proposta mecanística para o complexo $\left[\mathrm{RuCl} 2\left(\mathrm{PPh}_{3}\right)_{2}\left(\mathrm{NH}_{2} \mathrm{CH}_{2} \mathrm{Ph}\right)_{2}\right](2)$ em solução $^{47,49}$. 59

Figura 35. Espectro de $\mathrm{RMN}{ }^{31} \mathrm{P}\left\{{ }^{1} \mathrm{H}\right\}$ em $\mathrm{CDCl}{ }_{3}$ para o complexo $\left[\mathrm{RuCl}_{2}\left(\mathrm{PPh}_{3}\right)_{2}\left(\mathrm{NH}^{\mathrm{n}} \mathrm{BuPh}\right)\right](3)$ em 5 minutos e em 12 horas. 60

Figura 36. Isomerização para o complexo 3 de pirâmide de base quadrada em bipirâmide trigonal ${ }^{38}$ 61

Figura 37. Espectro de UV-vis em $\mathrm{CHCl}_{3}$ para o complexo $\left[\mathrm{RuCl}_{2}\left(\mathrm{PPh}_{3}\right)_{2}\left(\mathrm{NH}_{2} \mathrm{Ph}\right)_{2}\right](\mathbf{1})$. O complexo não apresenta variação espectral por 12 horas. $\mathrm{Ru}^{\prime \prime}=10^{-4} \mathrm{~mol} \cdot \mathrm{L}^{-1}$ à $25^{\circ} \mathrm{C}$. 62

Figura 38. Espectro de UV-vis em $\mathrm{CHCl}_{3}$ para o complexo $\left[\mathrm{RuCl}_{2}\left(\mathrm{PPh}_{3}\right)_{2}\left(\mathrm{NH}_{2} \mathrm{Ph}\right)_{2}\right](\mathbf{1})$ após 30 minutos de irradiação. $\mathrm{Ru}^{\prime \prime}=10^{-4} \mathrm{~mol} \cdot \mathrm{L}^{-1}$ à $25^{\circ} \mathrm{C}$. 62

Figura 39. Espectro de UV-vis em $\mathrm{CHCl}_{3}$ para o complexo $\left[\mathrm{RuCl}_{2}\left(\mathrm{PPh}_{3}\right)_{2}\left(\mathrm{NH}_{2} \mathrm{Ph}\right)_{2}\right](\mathbf{1})$ após 30 minutos de irradiação e posterior adição de $\mathrm{NH}_{2} \mathrm{Ph}$. A linha azul é correspondente ao espectro inicial da solução pura; linha vermelha é correspondente ao espectro após irradiação e as linhas pretas pontilhadas são correspondentes a evolução espectral após adição de excesso de $\mathrm{NH}_{2} \mathrm{Ph}$. $\mathrm{Ru}^{\prime \prime}=10^{-4} \mathrm{~mol}^{-\mathrm{L}^{-1}}$ à $25^{\circ} \mathrm{C}$. 63

Figura 40. Espectro de UV-vis em $\mathrm{CHCl}_{3}$ para o complexo $\left[\mathrm{RuCl}_{2}\left(\mathrm{PPh}_{3}\right)_{2}\left(\mathrm{NH}_{2} \mathrm{Ph}\right)_{2}\right](\mathbf{1})$ na presença de NBD por 60 minutos. Ru" $=10^{-4} \mathrm{~mol}^{-1} \mathrm{~L}^{-1}$ à $25^{\circ} \mathrm{C}$ 64 
Figura 41. Espectro de UV-vis em $\mathrm{CHCl}_{3}$ para o complexo $\left[\mathrm{RuCl}_{2}\left(\mathrm{PPh}_{3}\right)_{2}\left(\mathrm{NH}_{2} \mathrm{CH}_{2} \mathrm{Ph}\right)_{2}\right](2)$ a $25^{\circ} \mathrm{C}$ (a) e $50^{\circ} \mathrm{C}$ (b) após 60 minutos. $\mathrm{Ru}^{\prime \prime}=10^{-4} \mathrm{~mol} \cdot \mathrm{L}^{-1}$. 64

Figura 42. Espectro de UV-vis em $\mathrm{CHCl}_{3}$ para o complexo $\left[\mathrm{RuCl}_{2}\left(\mathrm{PPh}_{3}\right)_{2}\left(\mathrm{NH}_{2} \mathrm{CH}_{2} \mathrm{Ph}\right)_{2}\right](2)$ a $25^{\circ} \mathrm{C}$ por 60 minutos na presença de luz branca (a) e na presença de $\operatorname{EDA}(\mathrm{b}) . \mathrm{Ru}^{\prime \prime}=10^{-4} \mathrm{~mol} . \mathrm{L}^{-1} \ldots 65$ Figura 43. Espectro de UV-vis em $\mathrm{CHCl}_{3}$ para o complexo $\left[\mathrm{RuCl}_{2}\left(\mathrm{PPh}_{3}\right)_{2}\left(\mathrm{NH}_{2} \mathrm{CH}_{2} \mathrm{Ph}\right)_{2}\right](2)$ por 60 minutos na presença de 20 vezes de excesso de $\mathrm{PPh}_{3}$ a $25^{\circ} \mathrm{C}$ (a) e a $50^{\circ} \mathrm{C}(\mathrm{b}) \cdot \mathrm{Ru}^{\prime \prime}=10^{-4}$ mol. $L^{-1}$ 66

Figura 44. Espectro de UV-vis em $\mathrm{CHCl}_{3}$ para o complexo $\left[\mathrm{RuCl}_{2}\left(\mathrm{PPh}_{3}\right)_{2}(\text { benzilamina })_{2}\right](2)$ por 60 minutos na presença de 20 vezes de excesso de $\mathrm{NH}_{2} \mathrm{CH}_{2} \mathrm{Ph}$ a $25^{\circ} \mathrm{C}$ (a) e a $50^{\circ} \mathrm{C}$ (b). $\mathrm{Ru}{ }^{\prime \prime}=$ $10^{-4} \mathrm{~mol} \cdot \mathrm{L}^{-1}$ 66

Figura 45. Espectro de UV-vis em $\mathrm{CHCl}_{3}$ para o complexo $\left[\mathrm{RuCl}_{2}\left(\mathrm{PPh}_{3}\right)_{2}\left(\mathrm{~N}-{ }^{\mathrm{n}}\right.\right.$ butilanilina $\left.)\right](3)$ por 60 minutos a $25^{\circ} \mathrm{C} . \mathrm{Ru}^{\prime \prime}=10^{-4} \mathrm{~mol} \cdot \mathrm{L}^{-1}$ .67

Figura 46. Voltamograma para o complexo $\left[\mathrm{RuCl}_{2}\left(\mathrm{PPh}_{3}\right)_{2}\left(\mathrm{NH}_{2} \mathrm{Ph}\right)_{2}\right](1)$ em $\mathrm{CHCl}_{2}$ a TA. Velocidade de varredura: $200 \mathrm{mV} / \mathrm{s}$ .68

Figura 47. Voltamograma para o complexo $\left[\mathrm{RuCl}_{2}\left(\mathrm{PPh}_{3}\right)_{2}\left(\mathrm{NH}_{2} \mathrm{CH}_{2} \mathrm{Ph}\right)_{2}\right](2)$ em $\mathrm{CHCl}_{2}$ a $\mathrm{TA}$. Velocidade de varredura: $200 \mathrm{mV} / \mathrm{s}$. 68

Figura 48. Voltamograma para o complexo $\left[\mathrm{RuCl}_{2}\left(\mathrm{PPh}_{3}\right)_{2}\left(\mathrm{NH}^{\mathrm{n}} \mathrm{BuPh}\right)\right](3)$ em $\mathrm{CHCl}_{2}$ a $\mathrm{TA}$. Velocidade de varredura: $200 \mathrm{mV} / \mathrm{s}$ 69

Figura 50. Evolução espectral por 20 minutos na região do UV-vis do complexo $\left[\mathrm{RuCl}_{2}\left(\mathrm{PPh}_{3}\right)_{2}\left(\mathrm{NH}_{2} \mathrm{Ph}\right)_{2}\right]$ em $\mathrm{CHCl}_{3}[\mathrm{Ru}]=1,0 \times 10^{-4} \mathrm{~mol} . \mathrm{L}^{-1}, \mathrm{~T} . \mathrm{A}$. 70

Figura 51. Dependência do rendimento em relação ao volume de EDA, para a ROMP de NBE $\operatorname{com}\left[\mathrm{RuCl}_{2}\left(\mathrm{PPh}_{3}\right)_{2}\left(\mathrm{NH}_{2} \mathrm{Ph}\right)_{2}\right] ;[\mathrm{NBE}] /[\mathrm{Ru}]=5000 ;[\mathrm{Ru}]=1 \mu \mathrm{mol}$ em $2 \mathrm{~mL}$ de $\mathrm{CHCl}_{3}$ à $25^{\circ} \mathrm{C}$ por 5 minutos 
Figura 52. Reações concorrentes provenientes da formação da espécie carbeno em solução.

Figura 53. Competição entre olefina e EDA pelo centro metálico na presença de excesso de EDA.

Figura 54. Dependência do rendimento em relação à temperatura, para a ROMP de NBE com 1, 2 e 3; $[\mathrm{NBE}] /[\mathrm{Ru}]=5000 ;[\mathrm{Ru}]=1 \mu \mathrm{mol}$ em $2 \mathrm{~mL}$ de $\mathrm{CHCl}_{3}$ à $25^{\circ} \mathrm{C}$ e $50^{\circ} \mathrm{C}$ por 5 minutos. .. 73 Figura 55. Dependência do rendimento em relação à temperatura, para a ROMP de NBD com 1, 2 e 3; $[\mathrm{NBD}] /[\mathrm{Ru}]=5000 ;[\mathrm{Ru}]=1 \mu \mathrm{mol}$ em $2 \mathrm{~mL}$ de $\mathrm{CHCl}_{3}$ à $25^{\circ} \mathrm{C}$ e $50^{\circ} \mathrm{C}$ por 30 minutos. 75

Figura 56. Dependência do rendimento em relação ao tempo, para a ROMP de NBD com 1 e 2; $[\mathrm{NBD}] /[\mathrm{Ru}]=5000 ;[\mathrm{Ru}]=1 \mu \mathrm{mol}$ em $2 \mathrm{~mL}$ de $\mathrm{CHCl}_{3}$ à $25^{\circ} \mathrm{C}$ e $50^{\circ} \mathrm{C}$. 76

Figura 57. Ilustração de dupla coordenação que pode ocorrer em complexos de rutênio. ...77 Figura 58. Formação de entrecruzamento na ROMP de diciclopentadieno ${ }^{53}$. 78 Figura 59. Dependência do rendimento em relação à temperatura, para a ROMP de NBE com $1 \mathrm{em} 2 \mathrm{~mL}$ de $\mathrm{CHCl}_{3}$ por 5 minutos. 79

Figura 60. Dependência do rendimento em relação ao tempo e a temperatura, para a ROMP de NBE com 1 em $2 \mathrm{~mL}$ de $\mathrm{CHCl}_{3}$. 79

Figura 61. Dependência do rendimento em relação ao tempo e a temperatura, para a ROMP de NBE com 2 em $2 \mathrm{~mL}$ de $\mathrm{CHCl}_{3}$. 81

Figura 62. Dependência do rendimento em relação ao tempo e a temperatura, para a ROMP de NBE com 3 em $2 \mathrm{~mL}$ de $\mathrm{CHCl}_{3}$.

Figura 63. Dependência do rendimento em relação ao aumento da razão molar de NBD para a ROMCP de NBE/NBD com 3 em $2 \mathrm{~mL}$ de $\mathrm{CHCl}_{3}$ a $50^{\circ} \mathrm{C}$ por 30 minutos. 85 
Figura 64. Dependência do rendimento em relação ao aumento da razão molar de NBE para a ROMCP de NBD/NBE com 3 em $2 \mathrm{~mL}$ de $\mathrm{CHCl}_{3}$ a $50^{\circ} \mathrm{C}$ por 30 minutos. 86

Figura 65. Rendimentos para ROMP na presença de luz branca, a $25^{\circ} \mathrm{C}$ por 5 minutos na presença de EDA, comparativo com amostra envelhecida. ?]: 1 m: 2; linha sólida: fotólise, linha tracejada: solução envelhecida. 89

Figura 67. Numeração dada aos carbonos do polinorborneno para uso nos cálculos de integral para obtenção do valor de $\sigma_{\mathrm{c}}^{39,55}$ 91

Figura 68. Espectro de $\mathrm{RMN}^{13} \mathrm{C}$ para polinorborneno formado com 2 ............................... 91

Figura 69. Espectro de $\mathrm{RMN}^{13} \mathrm{C}$ para polinorborneno formado com 3. 92

Figura 70. Cromatogramas com IPD para ROMP de NBE utilizando 1 em: (a) EDA; (b) $25^{\circ} \mathrm{C}$ em $5 \mathrm{~min}$; (c) $50^{\circ} \mathrm{C}$ em $5 \mathrm{~min}$ e (d) $50^{\circ} \mathrm{C}$ em $30 \mathrm{~min}$. 102

Figura 71. Cromatograma com IPD para ROMP de NBE utilizando 2 a $50^{\circ} \mathrm{C}$ em $5 \mathrm{~min}$. 103

Figura 72. Cromatograma com IPD para ROMP de NBE utilizando 3 a $25^{\circ} \mathrm{C}$ em 5 min. 103 


\section{LISTA DE SÍMBOLOS E ABREVIATURAS}

$\theta$ : Ângulo de cone

$\sigma_{c}$ : Fração cis no polímero

EDA: Etildiazoacetato

$\mathrm{M}_{\mathrm{n}}$ : Massa molecular numérica media

$\mathrm{M}_{\mathrm{w}}$ : Massa molecular ponderada média

IPD: Índice de polidispersidade

pip: Piperidina

$\mathrm{PC}_{3}$ : Tricicloexilfosfina

$\mathrm{PPh}_{3}$ : Trifenilfosfina

NBE: Norborneno

NBD: Norbornadieno

DCPD: Diciclopentadieno

COD: 1,5-cicloctadieno

poliNBE: Polinorborneno

poliNBD: Polinorbornadieno

poliDCPD: Polidiciclopentadieno

ROMP: Ring Opening Metathesis Polymerization (polimerização por abertura de anel)

ROMCP: Ring Opening Metathesis Copolymerization (copolimerização por abertura de anel)

GPC: Gel permeation cromatograph (cromatografia de permeação em gel) 


\section{RESUMO}

As moléculas à base de nitrogênio, $\mathrm{NH}_{2} \mathrm{Ph}, \mathrm{NH}_{2} \mathrm{CH}_{2} \mathrm{Ph}$ e $\mathrm{NH}^{\mathrm{n}} \mathrm{BuPh}$ foram investigadas como ligantes ancilares nos novos complexos do tipo $\left[\mathrm{RuCl}_{2}\left(\mathrm{PPh}_{3}\right)_{2}(\operatorname{amina})_{\mathrm{x}}\right]$ para a polimerização via metátese por abertura de anel (ROMP) de norborneno (NBE), norbornadieno (NBD) e diciclopentadieno (DCPD). Os complexos foram obtidos da síntese com $\left[\mathrm{RuCl}_{2}\left(\mathrm{PPh}_{3}\right)_{3}\right]$ com as respectivas moléculas. E eles foram caracterizados por análise elementar de $\mathrm{CHN}, \mathrm{FT}-\mathrm{IR}, \mathrm{RMN}{ }^{31} \mathrm{P}\left\{{ }^{1} \mathrm{H}\right\}$, Espectroscopia eletrônica na região do uv-vis e voltametria cíclica. Os complexos isolados foram hexacoordenados $(x=2)$ com $\mathrm{NH}_{2} \mathrm{Ph}$ e $\mathrm{NH}_{2} \mathrm{CH}_{2} \mathrm{Ph}$, e pentacoordenado com $\mathrm{NH}^{\mathrm{n}} \mathrm{BuPh}(\mathrm{x}=1)$. Além disso, os resultados sugerem que todos os ligantes estão trans-posicionados no caso do complexo com $\mathrm{NH}_{2} \mathrm{Ph}$ (complex 1) e cis no caso do complexo com $\mathrm{NH}_{2} \mathrm{CH}_{2} \mathrm{Ph}$ (complex 2). O complexo com $\mathrm{NH}^{\mathrm{n}} \mathrm{BuPh}$ ( complex 3 ) é sugerido estar na geometria pirâmide de base quadrada, com a amina no eixo axial. Quantitativos rendimentos foram obtidos na ROMP de NBE a $50^{\circ} \mathrm{C}$ com 1 por 30 min e com 2 por 5 minutos. Similar resultado foi obtido $\operatorname{com} 3$ at $25^{\circ} \mathrm{C}$ por $5 \mathrm{~min}$. O valor de $\mathrm{M}_{\mathrm{w}}$ foram na faixa de $10^{4}$ e $10^{5} \mathrm{~g} / \mathrm{mol}$,com valores de IPD entre 1,6 e 3,5. Os valores de $\mathrm{o}_{\mathrm{c}}$ foram em torno de 0,40 a 0,52. ROMP de NBE e DCPD, bem como copolimerizações foram também realizadas com melhores resultados com 3.Os resultados são discutidos em termos de densidade eletrônica e impedimento estérico das aminas como ligantes ancilares nos complexos. As reações com o complexo 2 são favoráveis pelo caráter $\sigma$-doador, enquanto que o grande ângulo de cone da $\mathrm{NH}^{\mathrm{n}} \mathrm{BuPh}$ prove a reatividade de 3. 


\section{ABSTRACT}

The nitrogen-based molecules, $\mathrm{NH}_{2} \mathrm{Ph}, \mathrm{NH}_{2} \mathrm{CH}_{2} \mathrm{Ph}$ and $\mathrm{NH}^{\mathrm{n}} \mathrm{BuPh}$ were investigated as ancillary ligands in the new $\left[\mathrm{RuCl}_{2}\left(\mathrm{PPh}_{3}\right)_{2}(\text { amine })_{\mathrm{x}}\right]$ complex types for Ring Opening Metathesis Polymerization (ROMP) of norbornene (NBE), norbornadiene (NBD) and dicyclopentadiene (DCPD). The complexes were obtained from syntheses with $\left[\mathrm{RuCl}_{2}\left(\mathrm{PPh}_{3}\right)_{3}\right]$ of and the respectively molecules and they were characterized by elementar analysis of $\mathrm{CHN}, \mathrm{FT}-\mathrm{IR}, \mathrm{NMR}{ }^{31} \mathrm{P}\left\{{ }^{1} \mathrm{H}\right\}$, uv-vis spectroscopy and cyclic voltammetry. The isolated complexes were sixcoordinated $(x=2)$ with $\mathrm{NH}_{2} \mathrm{Ph}$ and $\mathrm{NH}_{2} \mathrm{CH}_{2} \mathrm{Ph}$ and pentacoordinated with $\mathrm{NH}^{\mathrm{n}} \mathrm{BuPh}(\mathrm{x}=1)$. Moreover, the data suggest that all the ligands are trans-positioned in the case of $\mathrm{NH}_{2} \mathrm{Ph}$ (complex 1) and cis-positioned in the case of $\mathrm{NH}_{2} \mathrm{CH}_{2} \mathrm{Ph}$ (complex 2). The complex with $\mathrm{NH}^{\mathrm{n}} \mathrm{BuPh}(\mathbf{3})$ was suggested to present a square pyramidal geometry with the amine in the axial axis. Quantitative yields were obtained in the ROMP of NBE at $50{ }^{\circ} \mathrm{C}$ with 1 for $30 \mathrm{~min}$ and with 2 for $5 \mathrm{~min}$. Similar result was obtained with 3 at $25^{\circ} \mathrm{C}$ for $5 \mathrm{~min}$. The $\mathrm{M}_{\mathrm{w}}$ values were in the range of $10^{4}$ to $10^{5} \mathrm{~g} / \mathrm{mol}$ with PDI values between 1.6 and 3.5. The $\sigma_{\mathrm{c}}$ values were 0.40 to 0.52 . ROMP of NBD and DCPD, as well copolymerizations with NBE, NBD and DCPD, were also performed with better results with $\mathbf{3}$. The results are discussed in terms of the electronic density and steric hindrance from the amines as ancillary ligands in the complexes. The reactions with complex 2 are favored by the $\sigma$-donor character of $\mathrm{NH}_{2} \mathrm{CH}_{2} \mathrm{Ph}$, whereas the large cone angle of $\mathrm{NH}^{\mathrm{n}} \mathrm{BuPh}$ provided the reactivity with 3. 


\section{SUMÁRIO}

1. INTRODUÇÃO ......................................................................................................

1.1. Alguns Aspectos da Metátese de Olefinas ....................................................19

1.2. ROMP - Ring-Opening Metathesis Polymerization .......................................22

1.3. Desenvolvimento de catalisadores para polimerizações via ROMP .....................28

1.4. Alguns aspectos sobre ligantes ancilares ....................................................31

1.5. A pesquisa sobre Metátese de Olefinas no IQSC ..........................................34

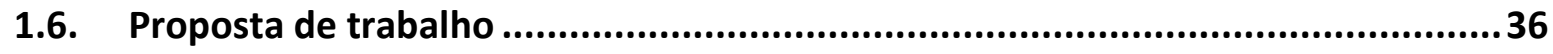

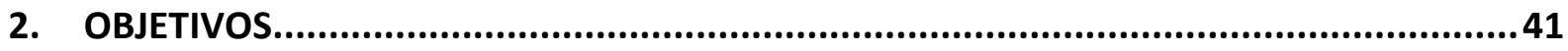

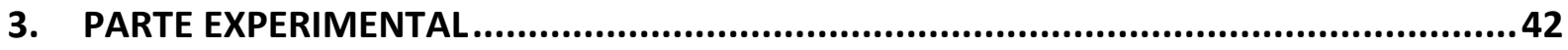

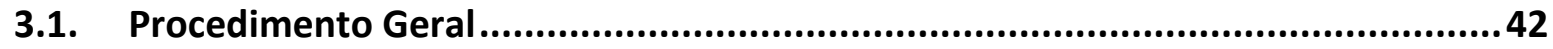

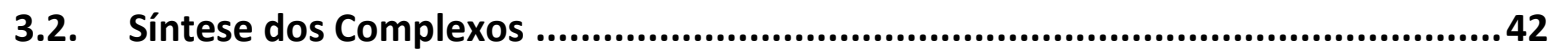

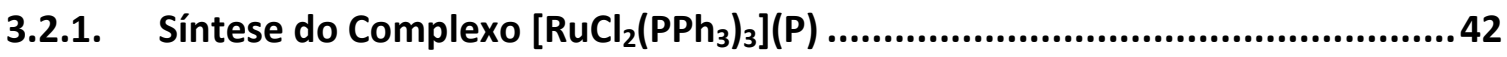

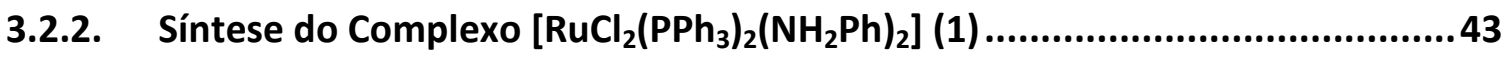

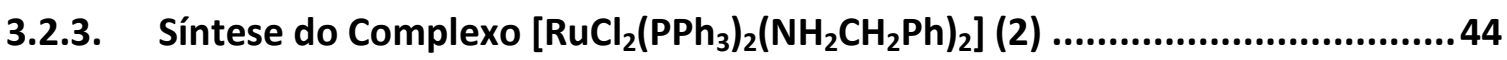

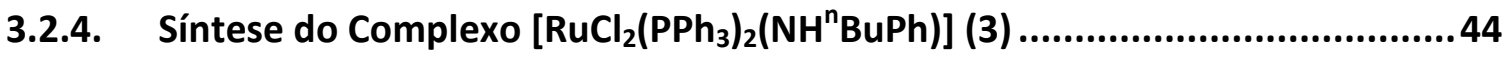

3.3. Procedimento Geral para ROMP de Norborneno, Norbornadieno e

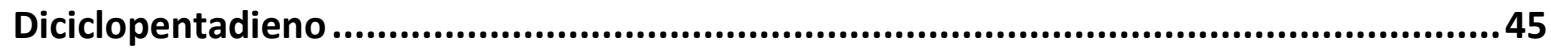

3.4. Procedimento Geral para ROMP de Norborneno na presença dos ligantes $\mathbf{N H}_{2} \mathbf{P h}$,

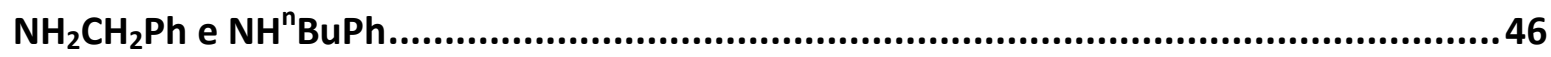

3.5. Procedimento Geral para ROMCP de Norborneno, Norbornadieno e

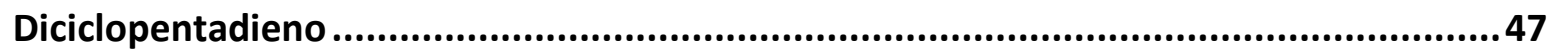

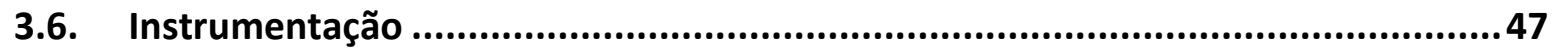

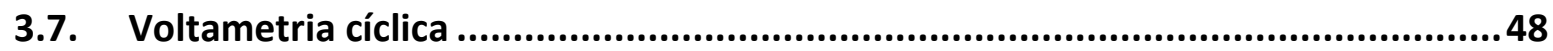

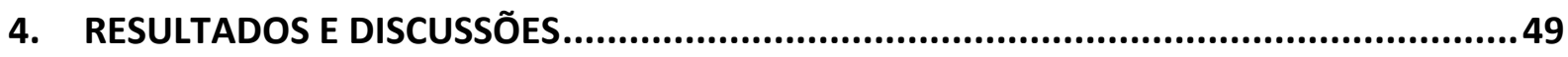




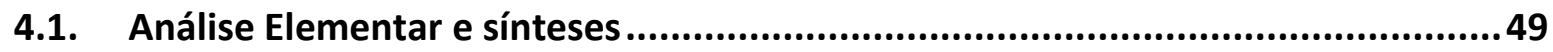

4.2. Análise Espectroscópica na Região do Infra Vermelho .....................................50

4.3. Caracterização por Ressonância Magnética Nuclear de ${ }^{31} \mathrm{P}\left\{{ }^{1} \mathrm{H}\right\} \ldots . . . \ldots \ldots \ldots \ldots . . . . . . . .54$

4.4. Caracterização por Espectroscopia Eletrônica na Região do Uv-Vis ...................61

4.5. Caracterização por Voltametria Cíclica dos complexos....................................67

4.6. Atividade dos complexos $\left[\mathrm{RuCl}_{2}\left(\mathrm{PPh}_{3}\right)_{2}\left(\mathrm{NH}_{2} \mathrm{Ph}\right)_{2}\right],\left[\mathrm{RuCl}_{2}\left(\mathrm{PPh}_{3}\right)_{2}\left(\mathrm{NH}_{2} \mathrm{Bz}\right)_{2}\right]$ e

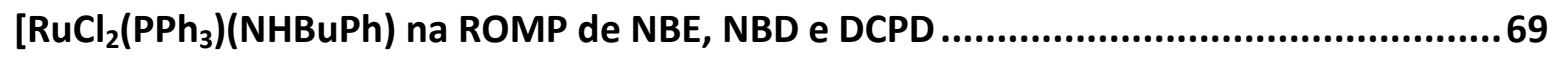

4.6.1. Variação do volume de EDA ..........................................................69

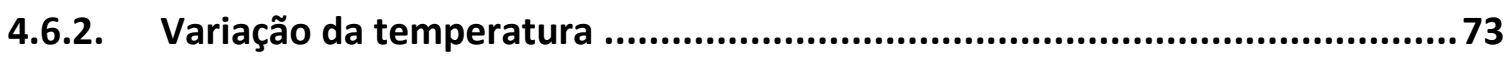

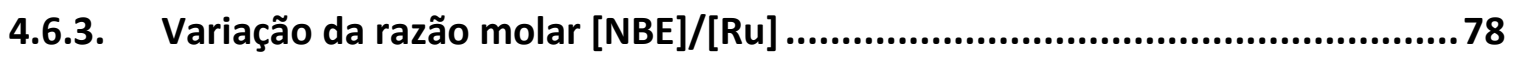

4.7. Atividade dos complexos $\left[\mathrm{RuCl}_{2}\left(\mathrm{PPh}_{3}\right)_{2}\left(\mathrm{NH}_{2} \mathrm{Ph}\right)_{2}\right],\left[\mathrm{RuCl}_{2}\left(\mathrm{PPh}_{3}\right)_{2}\left(\mathrm{NH}_{2} \mathrm{Bz}\right)_{2}\right]$ e $\left[\mathrm{RuCl}_{2}\left(\mathrm{PPh}_{3}\right)\right.$ (NHBuPh) na ROMP de Norborneno na presença dos ligantes $\mathbf{N H}_{2} \mathbf{P h}$,

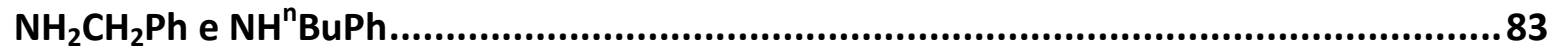

4.8. Atividade dos complexos $\left[\mathrm{RuCl}_{2}\left(\mathrm{PPh}_{3}\right)_{2}\left(\mathrm{NH}_{2} \mathrm{Ph}\right)_{2}\right],\left[\mathrm{RuCl}_{2}\left(\mathrm{PPh}_{3}\right)_{2}\left(\mathrm{NH}_{2} \mathrm{Bz}\right)_{2}\right]$ e $\left[\mathrm{RuCl}_{2}\left(\mathrm{PPh}_{3}\right)\left(\mathrm{NH}^{\mathrm{n}} \mathrm{BuPh}\right)\right.$ na ROMCP de NBE, NBD e DCPD.......................................84

4.9. Atividade dos complexos $\left[\mathrm{RuCl}_{2}\left(\mathrm{PPh}_{3}\right)_{2}\left(\mathrm{NH}_{2} \mathrm{Ph}\right)_{2}\right],\left[\mathrm{RuCl}{ }_{2}\left(\mathrm{PPh}_{3}\right)_{2}\left(\mathrm{NH}_{2} \mathrm{Bz}\right)_{2}\right]$ na $\mathrm{ROMP}$

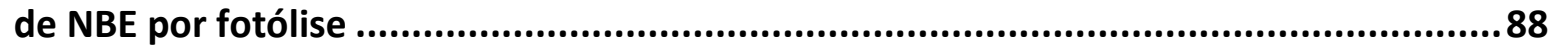

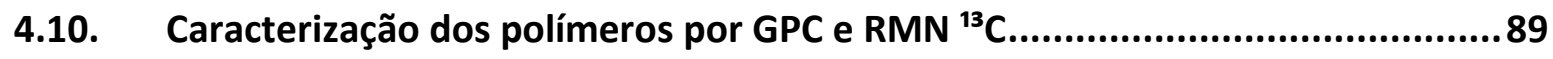

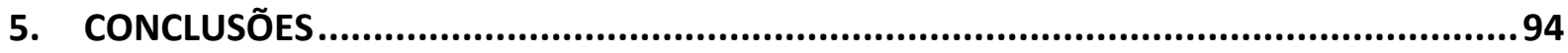

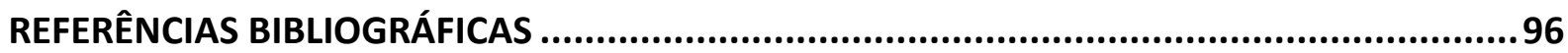

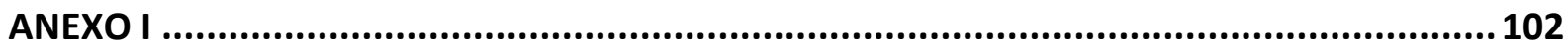

Cromatogramas obtidos por GPC para os complexos 1 , 2 e 3............................... 102 


\section{INTRODUÇÃO}

\subsection{Alguns Aspectos da Metátese de Olefinas}

A palavra metátese é uma combinação das palavras gregas meta (troca) e tithemi (lugar). Enquanto em gramática trata-se da transposição de fonemas ou sílabas de um lugar para outro (ex: casa, saca), em química, refere-se à troca de átomos ou grupos entre duas moléculas ${ }^{1-3}$. Já na química de olefinas, isso descreve a troca de átomos de carbono entre o par das duplas ligações, conforme pode ser visto na Figura 1:

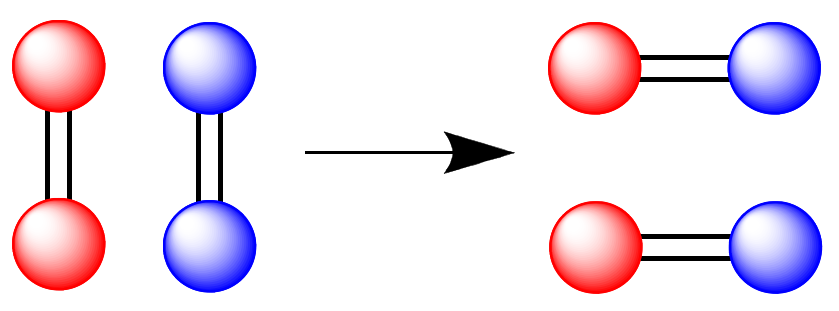

Figura 1. Exemplo geral de metátese.

Há aproximadamente 60 anos foi descoberta acidentalmente a metátese de olefinas ${ }^{2}$. Da década de 50 até meados da década de 80 , as reações de metátese eram feitas a partir de multicomponentes homogêneos e sistemas catalíticos heterogêneos maldefinidos, sendo uma mistura de sais de metais de transição e grupos alquilantes ou depositados em suportes sólidos, tais como $\mathrm{WCl}_{6} / \mathrm{Bu}_{4} \mathrm{Sn}$, WOCl $4 / \mathrm{EtAlCl}_{2}$ e $\mathrm{MoO}_{3} / \mathrm{SiO}_{2}{ }^{2,3}$. 
Sistemas como esses foram utilizados em aplicações comerciais como o Shell Higher Olefin Process, utilizado para síntese de olefinas de cadeias lineares grandes, a partir do eteno.

Esses sistemas foram utilizados também, na síntese de neohexeno (3,3-dimetil-1buteno), intermediário na síntese do Tonalide $^{\circledR}$, perfume sintético do Musk e da Terbinafina ${ }^{\circledR}$, um agente anti-fungo (Figura 2$)^{1-3}$.

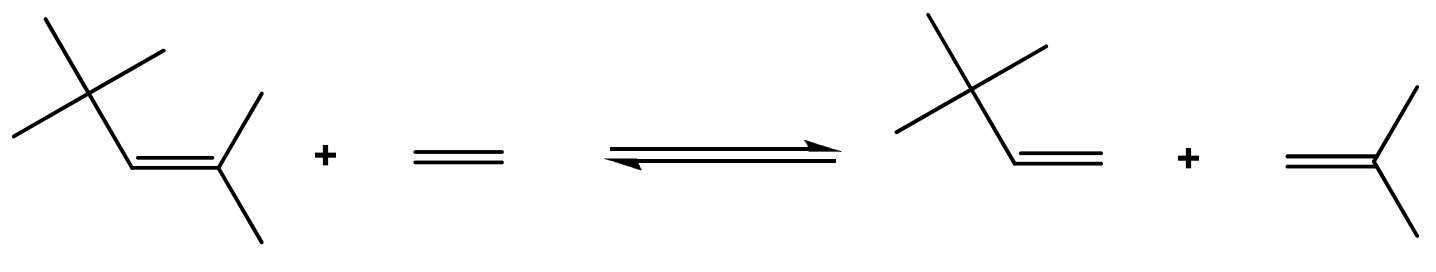

Figura 2. Síntese de neohexeno a partir de 2,2,4-trimetil-2-penteno usando uma mistura catalítica de $\mathrm{WO}_{3} / \mathrm{SiO}_{2}$ e $\mathrm{MgO}(1: 3)$ à $370{ }^{\circ} \mathrm{C}$ e 30 bar através de Metátese Cruzada ( $\mathrm{CM}$ Cross Metathesis).

A Metátese de olefinas é uma reação química fundamental para reações orgânicas. Ela é funcional para fechar e abrir um anel ou polimerizar moléculas olefínicas através do rearranjo das duplas ligações. Existem diferentes tipos de metátese ${ }^{1-5}$. As principas são “Ring Closing Metathesis" (RCM), "Ring Opening Metathesis" (ROM), "Cross-Metathesis" (CM) “Acyclic Diene METathesis" (ADMET) ou “Ring-Opening Metathesis Polymerization” (ROMP), como ilustra a Figura 3.

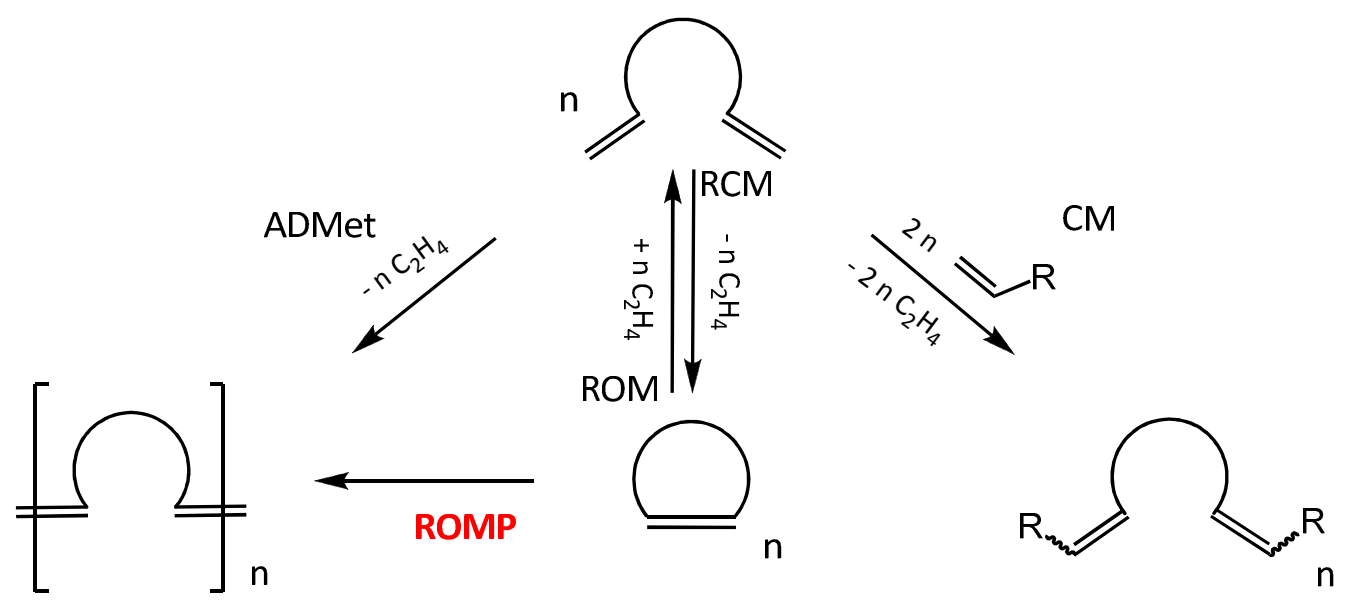

Figura 3. Os principais tipos de metátese de olefinas. 
Os pesquisadores Yves Chauvin (Institut Français Du Pétrole; Rueil-Malmaison, France $)^{6}$, Robert H. Grubbs (CALTECH; Pasadena/CA, USA) ${ }^{7}$ e Richard R. Schrock (MIT; Cambridge/MA, USA) ${ }^{8}$ foram agraciados com o Prêmio Nobel de Química em 2005 por propiciarem o desenvolvimento da metátese em química. Chauvin elucidou o mecanismo de reação, e Grubbs e Schrock contribuíram no desenvolvimento de catalisadores. O mecanismo proposto por Chauvin em 1971, e chamado de mecanismo carbeno/ciclometalobutano ${ }^{9}$, é ilustrado na Figura 4.

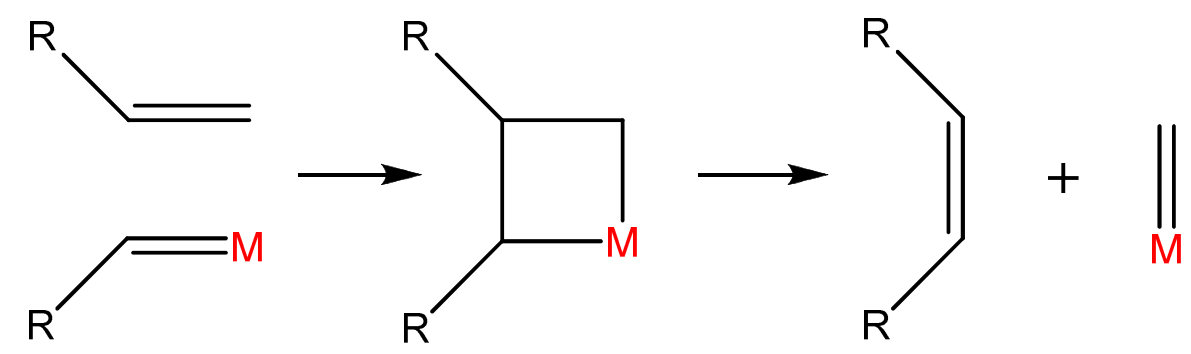

Figura 4. Mecanismo carbeno/ciclometalobutano proposto por Chauvin e Hérisson em $1971^{9}$.

As reações de metátese de olefinas são catalisadas por complexos metálicos que têm carbenos em suas esferas de coordenações, denominados metalo-carbenos. Os sistemas catalíticos mais usados são baseados em compostos facilmente acessíveis de $\mathrm{Mo}, \mathrm{Ru}, \mathrm{Re}$ e W, nos quais as atividades catalíticas dependem das características dos centros metálicos, dos tipos de carbenos e dos demais ligantes coordenados aos metais ${ }^{3-5,10}$.

O mecanismo de reação de metátese é muito. A reação via ROMP (Figura 3), possibilita a obtenção de polímeros com retenção da insaturação olefínica ${ }^{4}$. O processo se inicia pela coordenação da olefina ao complexo metálico contendo um carbeno, a unidade metal-carbeno mimetiza uma das olefinas, assim como acontece no mecanismo proposto por Chauvin, na Figura $4^{9}$. Uma nova ligação metal-carbeno é formada. Caso a olefina não 
fosse cíclica, a reação estaria completa, formando uma nova olefina e um novo complexo metalo-carbeno que estaria pronto para reagir com mais uma olefina. Como a olefina é cíclica, o átomo de carbono da unidade carbeno está ligado a uma unidade monomérica que propicia a propagação da cadeia polimérica na presença de mais monômero, através da mesma seqüência de reações. Isto continua até que todo o monômero seja consumido, uma vez que a unidade metal-carbeno continua presente em uma das extremidades do polímero (Figura 5) ${ }^{4}$.

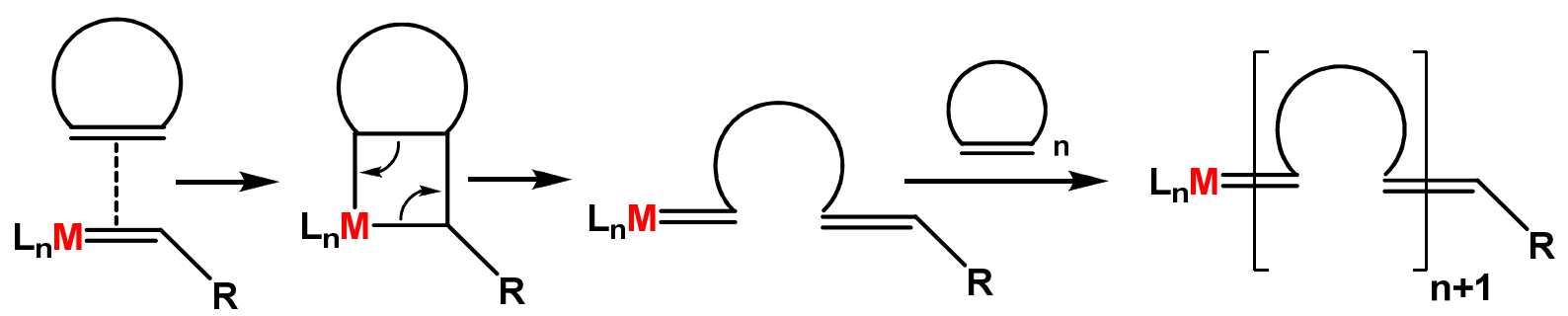

Figura 5. llustração do mecanismo de polimerização de olefinas via ROMP .

\subsection{ROMP - Ring-Opening Metathesis Polymerization}

A ROMP (Ring-Opening Metathesis Polymerization), uma das vertentes da metátese de Olefinas, se apresenta como uma poderosa ferramenta para a síntese de moléculas com grande massa molecular, estereoquímica desejada e funcionalidades para diversas aplicações $^{11}$. A ROMP é utilizada na preparação de polímeros e copolímeros. Por sua característica única de conservar a insaturação no material polimérico formado, ela difere de outros tipos de polimerização de olefinas como: radicalar, aniônica, catiônica ou Ziegler- 
Natta; e essa característica da ROMP proporciona versatilidade, podendo se preparar polímeros com diversas propriedades, baseadas na manutenção da insaturação ao longo da cadeia. Vários metais têm sido utilizados na síntese de catalisadores para serem iniciadores deste tipo de reação, como o titânio, tântalo, molibdênio, tungstênio e rutênio ${ }^{4}$. Com o advento dos catalisadores de molibdênio de Schrock e de rutênio de Grubbs, uma grande variedade de monômeros tem sido abordada, principalmente em sistemas contendo anéis tensionados, como o norborneno e seus derivados, permitindo a síntese de polímeros altamente funcionalizados ${ }^{12}$.

O mecanismo da ROMP consiste em três etapas principais: iniciação, propagação e terminação ${ }^{1-11}$. Na etapa de iniciação (Figura 7), ocorre a coordenação da olefina ao complexo metal-carbeno, que tem a função de mimetizar uma olefina. Os elétrons $d_{\pi}$ do metal, através de uma ligação de retrodoação, populam os orbitais $\pi^{*}$ da olefina. A olefina contendo elétrons em seus orbitais $\pi$ e $\pi^{*}$, tem sua ordem de ligação diminuída, sendo a ligação $\pi$ enfraquece, ativa a olefina e rompe a dupla ligação (Figura 7).

\section{INICIAÇÃO}

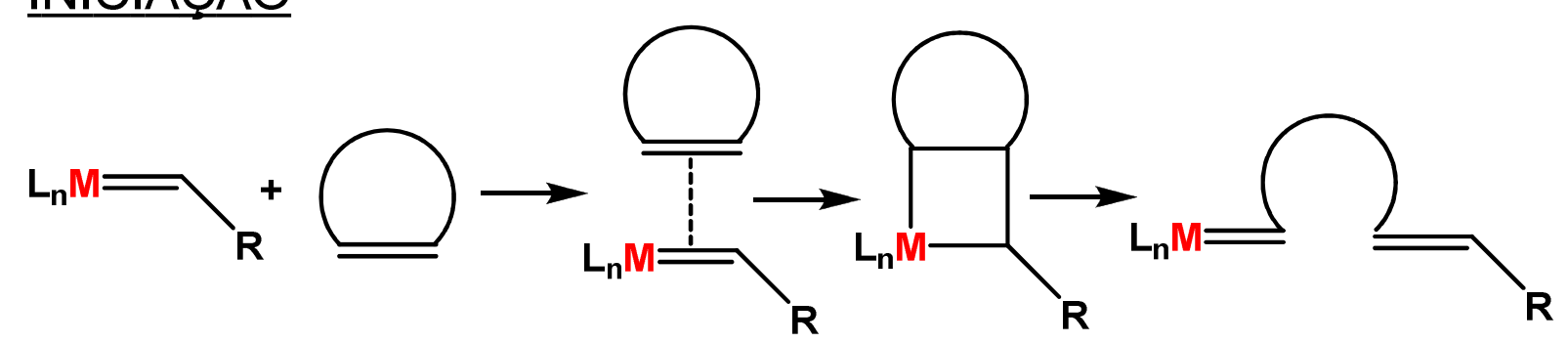

Figura 6. Ilustração do mecanismo de polimerização de olefinas via ROMP. Etapa de iniciação.

Forma-se o intermediário ciclometalobutano, espécie instável formada pelo rompimento da ligação metal-carbeno e a olefina. Neste momento, ocorre uma [2+2] 
cicloadição, formando novamente um complexo contendo a ligação metal carbeno, e formando a primeira unidade polimérica $A$ constante de velocidade associada à formação da primeira unidade polimérica partindo de um iniciador metal-carbeno é chamada $k_{i}$.

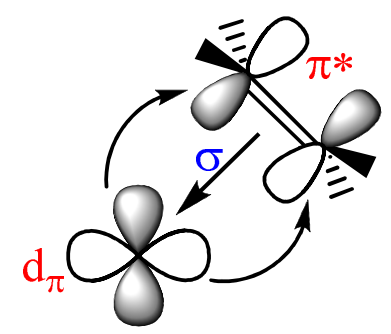

(a)

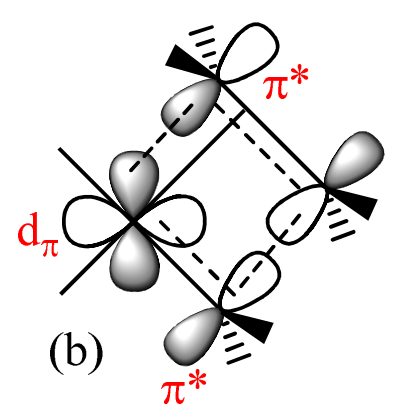

Figura 7. Coordenação da (a) olefina ao centro metálico e (b) formação do ciclometalobutano em termos de orbitais moleculares ${ }^{13,14}$.

Na etapa de propagação (Figura 8), outro monômero pode se coordenar ao metalocarbeno contendo a primeira unidade polimérica, através da mesma seqüência de reações da etapa de iniciação, permitindo o crescimento da cadeia polimérica. Na presença de uma quantidade $n$ de monômero, o processo continua até que todo monômero seja consumido, pois como o catalisador continua ativo com a ligação metal-carbeno presente, se após o término de todo monômero da reação, seja adicionado mais monômero, ele será polimerizado, caracterizando uma polimerização viva ("living polymerization") ${ }^{4}$. Se adicionar um monômero diferente do inicial, são formados copolímeros, ou seja, uma cadeia polimérica com meros diferentes que podem estar organizados em bloco ou aleatoriamente. A constante de velocidade associada à propagação da cadeia polimérica é chamada $k_{p}$. 


\section{PROPAGAC̣ÃO}

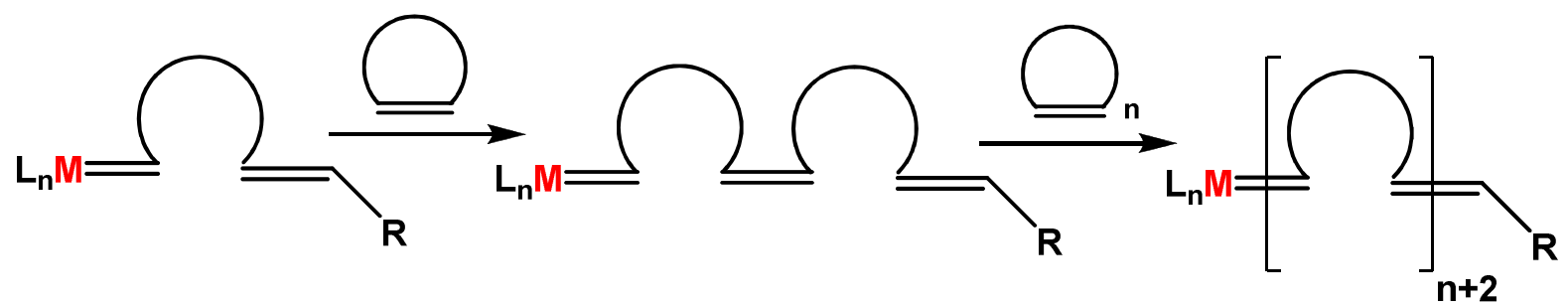

Figura 8. Ilustração do mecanismo de polimerização de olefinas via ROMP. Etapa de propagação.

Na etapa de propagação, em determinadas circunstâncias, pode-se ocorrer reações secundárias: as reações intermoleculares (Figura 9a) e/ou intramoleculares ("back biting")(Figura 9b), bem como a formação de oligômeros.
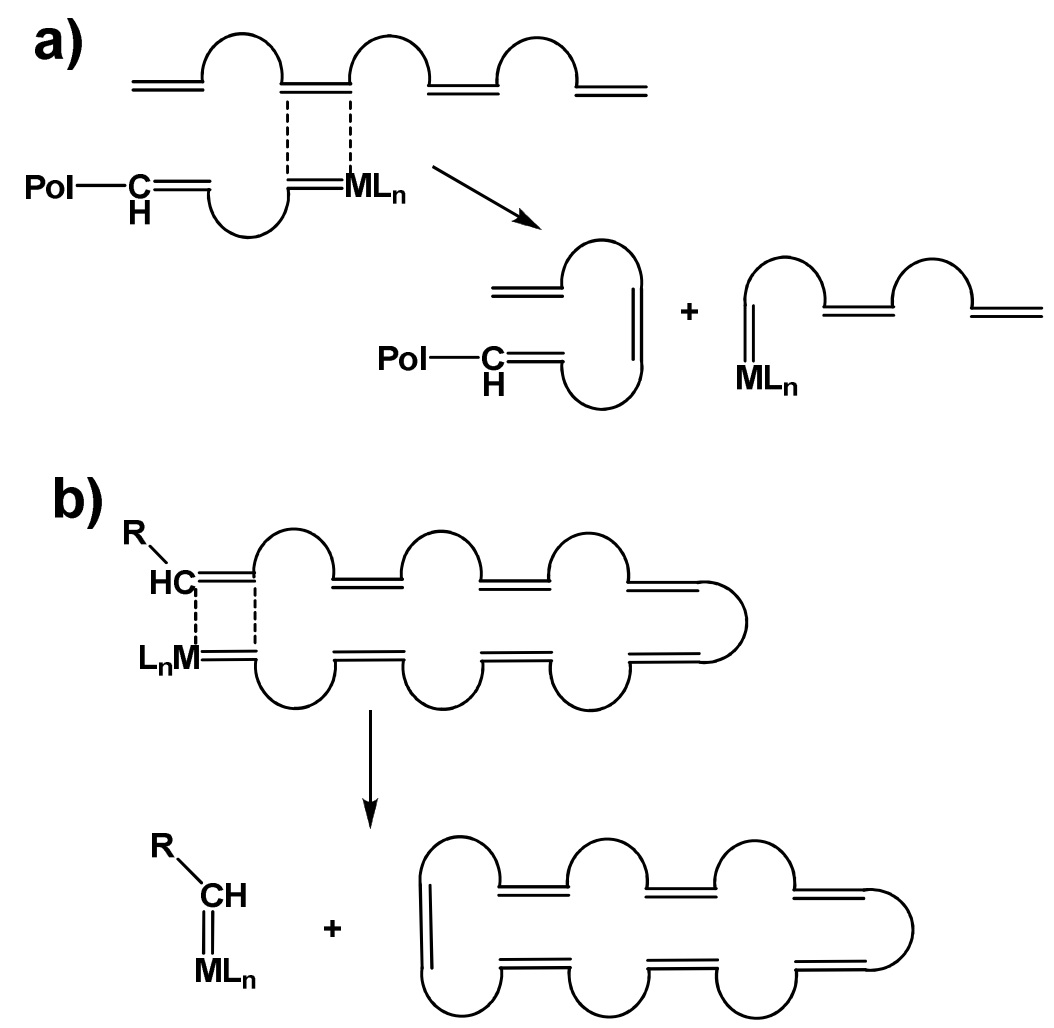

Figura 9. Reações secundárias intermoleculares (a) e intramoleculares (b). 
Na etapa de terminação (Figura 10), é adicionado um agente de transferência de cadeia ou agente de terminação, por exemplo, etil vinil éter, que tem a função de mimetizar uma olefina, e retirar o metal da cadeia polimérica para cessar a polimerização ${ }^{3-5,11}$.

\section{TERMINAC̣ÃO}

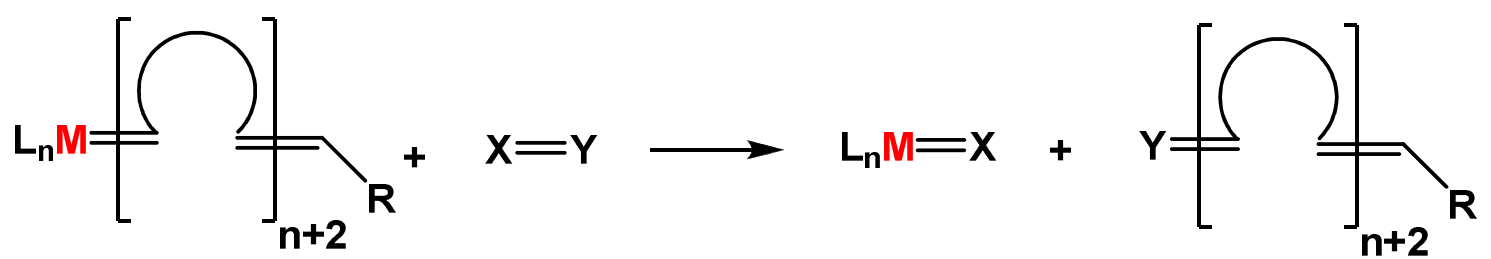

Figura 10. Ilustração do mecanismo de polimerização de olefinas via ROMP. Etapa de terminação.

Para sistemas homogêneos, onde a espécie ativa é formada in situ, existe o período de indução (Figura 11) que antecede a etapa de iniciação da ROMP. Nesse período a espécie ativa metal-carbeno é formada pela descoordenação de ligantes, isomerização, coordenação do grupo carbeno, ativação por luz e/ou calor, entre outras ${ }^{15}$. Devido a essa etapa adicional, as espécies ativas não são formadas todas ao mesmo tempo, propiciando assim que cadeias comecem a ser polimerizadas antes que todas as espécies ativas sejam formadas, o que acarreta em um alto índice de polidispersidade (IPD).

\section{PERÍODO DE INDUCCÃO}

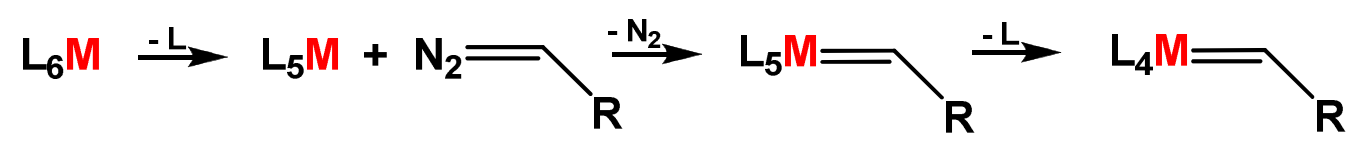

Figura 11. Ilustração do mecanismo de polimerização de olefinas via ROMP. Período de indução. 
Dentre os monômeros estudados na ROMP, pode-se citar o norbornadieno (NBD), diciclopentadieno (DCPD) e 1,5-ciclooctadieno (COD), merecendo destaque o norborneno (NBE). Devido a sua fácil preparação e alta tensão anelar, polimerizando com aproximadamente completa conversão do monômero em polinorborneno com alta massa molecular, sem ocorrer nenhuma ciclização intramolecular secundária ou formação de algum subproduto importante. Polinorbornenos têm sido sintetizados devido às suas excelentes propriedades para aplicações elétricas e também ao seu baixo custo quando comparados aos outros materiais utilizados na microeletrônica. Aumentou-se o interesse na ROMP de norbornenos contendo grupos funcionais, obtendo polímeros com propriedades atrativas e larga aplicação, devido às suas propriedades e resistência química ${ }^{16}$. Na Figura 12 é apresentado um exemplo de polinorborneno funcionalizado.

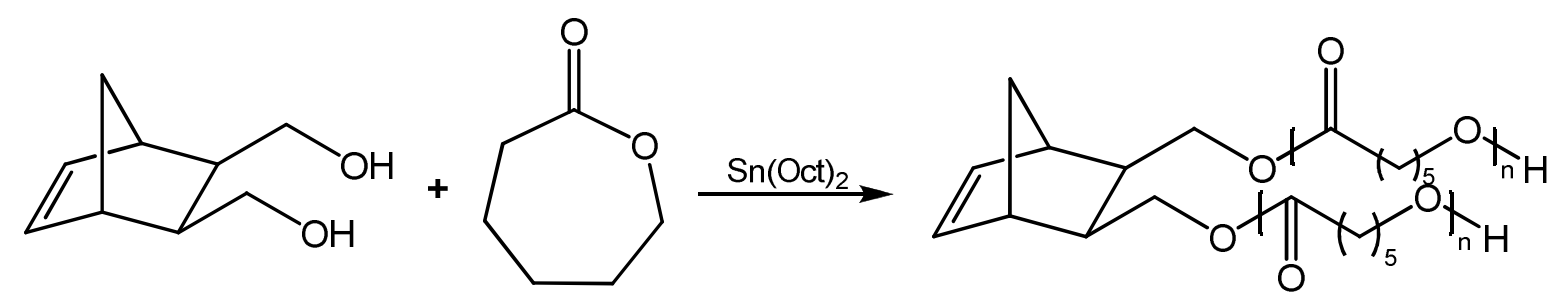
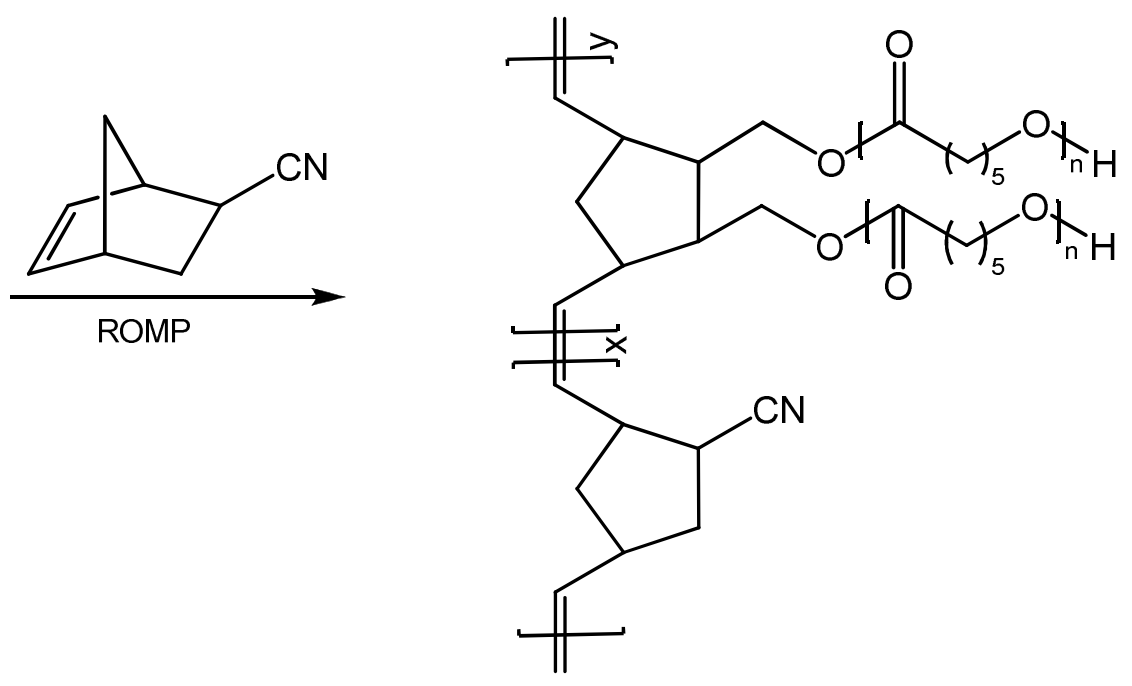

Figura 12. Copolímero de Polinorborneno funcionalizado com $\varepsilon$-caprolactana e norborneno com grupo ciano ${ }^{17}$. 


\subsection{Desenvolvimento de catalisadores para polimerizações via ROMP}

Existem duas categorias de compostos empregados para metátese de olefinas. Uma delas compreende os catalisadores de primeira geração ${ }^{5}$. Esses compostos são aqueles em que a espécie ativa é formada in situ através da reação com um composto diazo, como por exemplo, o etildiazoacetato. É sabido que esses compostos se tornam catalisadores ativos através da formação da ligação carbênica em solução, porém compostos dessa natureza não resultam em boas etapas de iniciação e propagação, dificultando o estudo desses processos ${ }^{4}$

A segunda categoria é a que compreende os catalisadores de segunda geração, que são compostos onde a espécie ativa é formada ex situ, ou seja, o catalisador já possui a ligação metal-carbeno. Sendo assim, permite-se um estudo mais aprofundado do mecanismo das reações, pode-se até monitorar as espécies formadas por Ressonância Magnética Nuclear (RMN) $)^{1,3-5}$.

Na busca por sistemas catalíticos para serem usados na metátese de olefinas, vários complexos tem sido sintetizados, tais como os complexos de Schrock (W e Mo) e Fischer (W), Tebbe (Ti), Basset (W), bem como os catalisadores de Grubbs (Ru). Alguns deles estão exemplificados na Figura 13.
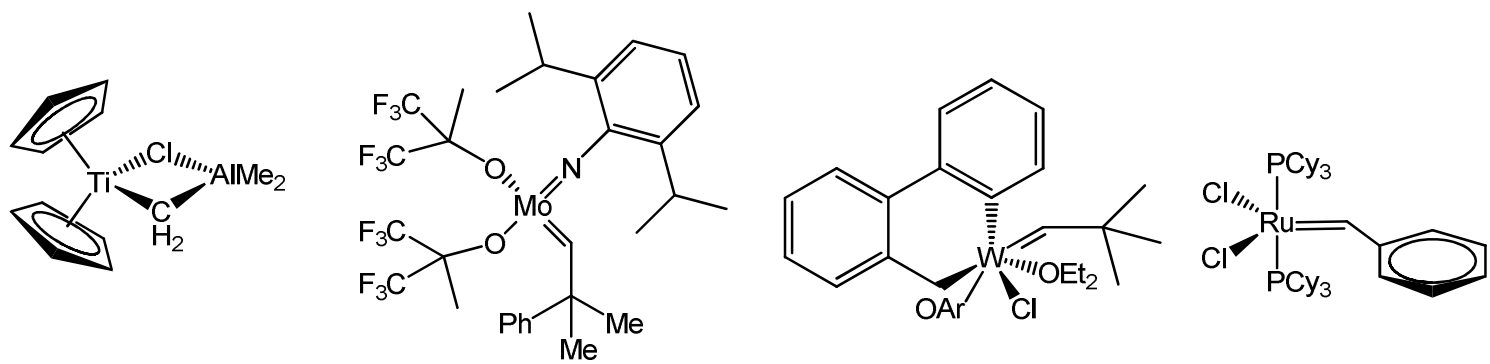

Figura 13. Catalisadores para metátese de olefinas baseados em $\mathrm{Ti}, \mathrm{Mo}, \mathrm{W}$ e $\mathrm{Ru}^{3,4}$. 
Em 1988, o grupo de Grubbs descreveu o desenvolvimento dos primeiros sistemas de catalisadores de rutênio, utilizando o $\mathrm{RuCl}_{3} \cdot \mathrm{xH}_{2} \mathrm{O}$, bem conhecido como iniciador da reação de metátese devido a sua tolerância a oxigênio, água e grupos funcionais, permitindo polimerizações em água e alcoóis e gerando polímeros de alta massa molecular. Apesar disso, os rendimentos são baixos e é limitado para polimerizações de cicloolefinas altamente tensionadas como norborneno $0^{3-5,18}$. Alem de resistência a grupos funcionais, os catalisadores a base de rutênio apresentam maior seletividade frente às olefinas, destacando-se dentre os outros catalisadores com diferentes metais de transição (Tabela 1).

Tabela 1 - Tolerância e reatividade em reações de metátese de catalisadores de metais de transição frente a alguns grupos funcionais em ordem decrescente de reatividade.

\begin{tabular}{cccc} 
Ti/Ta & W & Mo & Ru \\
\hline Ácidos & Ácidos & Ácidos & olefinas \\
Alcoóis & Alcoóis & Alcoóis & Ácidos \\
Aldeídos & Aldeídos & Aldeídos & Alcoóis \\
Cetonas & Cetonas & olefinas & Aldeídos \\
Éster/amidas & olefinas & Cetonas & Cetonas \\
olefinas & Éster/amidas & Éster/amidas & Éster/amidas \\
\hline
\end{tabular}

Diversos estudos, tanto cinéticos quanto mecanísticos foram importantes para se chegar aos catalisadores bem definidos desenvolvidos por Grubbse colaboradores, conhecidos como catalisadores de primeira, segunda e terceira geração de Grubbs. O complexo $\left[\mathrm{RuCl}_{2}\left(\mathrm{PPh}_{3}\right)_{3}\right]$ reagindo com difenilciclopropeno, para gerar a ligação metalcarbeno, apresentava atividade para polimerização de olefinas, porém, somente olefinas ricas em elétrons e bem tensionadas tal como o norborneno ${ }^{19}$. Substituindo $\mathrm{PPh}_{3}$ por $\mathrm{PCy}_{3}$ 
(Primeira Geração de Grubbs, G1), que é uma fosfina com maior ângulo de cone e maior basicidade, foi observado polimerização de olefinas pouco tensionadas e até acíclicas ${ }^{20}$.

No ano de 1998, Grubbs reporta a troca de uma fosfina $\mathrm{PCy}_{3}$ pelo grupamento dialquil imidazol-2-ilideno (um carbeno N-heterocíclico) gerando um catalisador com atividade catalítica superior ao G1, chamado de segunda geração de Grubbs, G2 ${ }^{21}$. Em 2002 foram reportados os catalisadores de terceira geração de Grubbs, $\mathbf{G 3}$, onde ocorre a troca da fosfina $\mathrm{PCy}_{3}$ por piridinas, propiciando características intrínsecas ao novo catalisador. A partir desta data, novos catalisadores baseados em Rull surgiram, como H2, M2 e M31, através dos pesquisadores Grubbs, Hoyeda, entre outros ${ }^{22,23}$. Os catalisadores G1, G2, G3, H2, M2 e M31 estão apresentados na Figura 14.

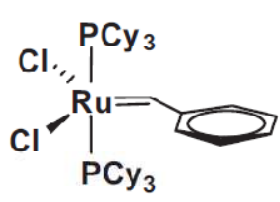

G1<smiles>CC(C)Oc1ccccc1C=C(Cl)C1N(C)CCN1S(C)(=O)=O</smiles>

H2

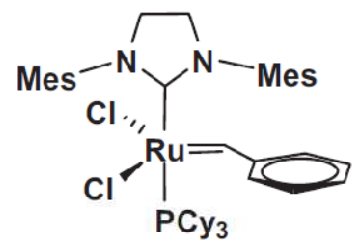

G2

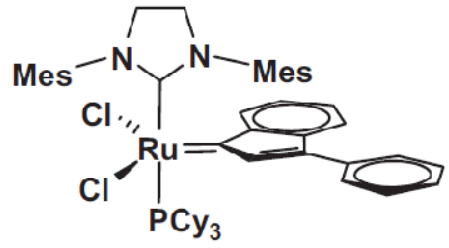

M2

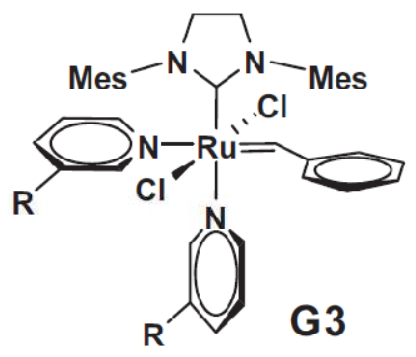

$\mathrm{R}=\mathrm{H}$ or $\mathrm{Br}$

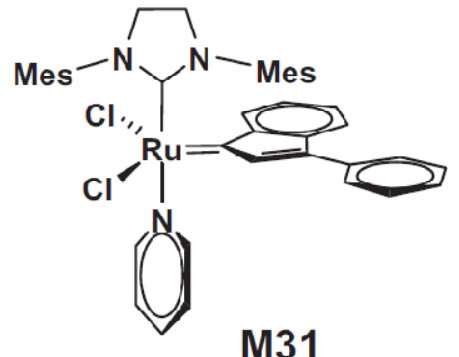

M31

Figura 14. Catalisadores para metátese de olefinas de Grubbs, Grubbs-Hoyeda e modificações ${ }^{22,23}$.

A velocidade de coordenação da olefina ao metalo-carbeno é essencialmente importante e a reação não pode ser dificultada por reações paralelas entre o metal e os 
grupos funcionais do substrato ou espécies presentes no meio ${ }^{1-5}$. Portanto, para se obter maior eficiência em reações, o processo via metátese deve ser catalisado por complexos que não tenham afinidade química com grupos funcionais tais como álcoois, carboxilatos, tióis, amidas, cetonas, aldeídos, etc (Tabela 1). Com ausência de reações paralelas, podem-se obter polímeros com propriedades químicas desejáveis e em grande escala. Assim, a atividade catalítica, as características dos produtos e as condições de reação são determinadas pelo tipo do metal de transição e a combinação com os mais variados tipos de ligantes (óxidos, haletos, fosfinas, alquilas e outros) ${ }^{4,5}$.

Catalisadores formados por metais do grupo da platina, em particular o rutênio ${ }^{24,25}$, têm apresentado reatividade e seletividade superiores aos catalisadores derivados de titânio, tungstênio e molibdênio. São ativos em solventes polares ou próticos, tais como alcoóis, água, fenóis e em ácidos fortes, como por exemplo, ácido tricloroacético ${ }^{26}$. São tolerantes a muitos grupos funcionais orgânicos, ampliando o número de substratos que podem ser usados. São ativos à pressão ambiente e operam em temperaturas abaixo de 100 ${ }^{\circ} \mathrm{C}$, além das reações poderem ser conduzidas em solventes comuns sem prévia purificação ${ }^{27}$.

\subsection{Alguns aspectos sobre ligantes ancilares}

Como já observado, a reação de polimerização via metátese, bem como as propriedades dos polímeros sintetizados, dependem do tipo de metal empregado. Como se trata de complexos, a atividade catalítica deste metal vai depender da natureza dos ligantes 
coordenados ao centro metálico que não são envolvidos diretamente na reação, denominados ligantes ancilares 3 -8,18-23.

Os ligantes ancilares com diferentes características estéricas e eletrônicas podem modificar o processo catalítico, produzindo polímeros com diferentes propriedades, como a massa molecular, o IPD e sua microestrutura ${ }^{1,18,22,23}$.

Por exemplo, os ligantes de fósforos trivalentes (fosfinas, $\mathrm{PR}_{3}$, ou fosfitos, $\mathrm{P}(\mathrm{OR})_{3}$ ) favorecem a atividade do metal (Figura 15), controlando a densidade eletrônica no centro metálico e os efeitos estéricos na esfera de coordenação ${ }^{29-31}$. Isto reflete na formação das ligações com os substratos (olefina), bem como na descoordenação dos produtos (nova olefina ou polímero) ${ }^{32,33}$. Assim, os efeitos (natureza cinética) e influência (natureza termodinâmica) dos ligantes ancilares em catálise homogênea, em geral, são de importância significativa no rendimento e seletividade de reação ${ }^{1,29-32}$.
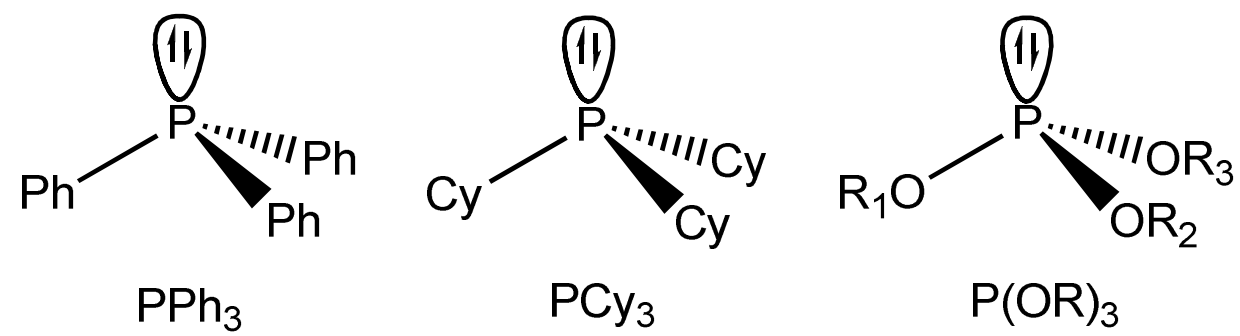

Figura 15. Exemplos de fosfinas e fosfito.

Fósforo trivalente possui orbitais capazes de aceitarem elétrons dos orbitais $d_{\pi}$ dos metais de transição, formando em adição à ligação- $\sigma$ ligante $\rightarrow$ metal, uma ligação- $\pi$ de retro-doação metal $\rightarrow$ ligante (Figura 16). A versatilidade dos compostos de fósforo está associada ao fato destes ligantes serem bons labilizantes no centro metálico e estabilizarem baixos estados de oxidação dos metais ${ }^{29-32}$. Ainda, podem ser volumosos, o que faz com que 
formem complexos que liberem facilmente sítios na esfera de coordenação do centro metálico para a ativação por coordenação dos substratos ${ }^{29-31}$.

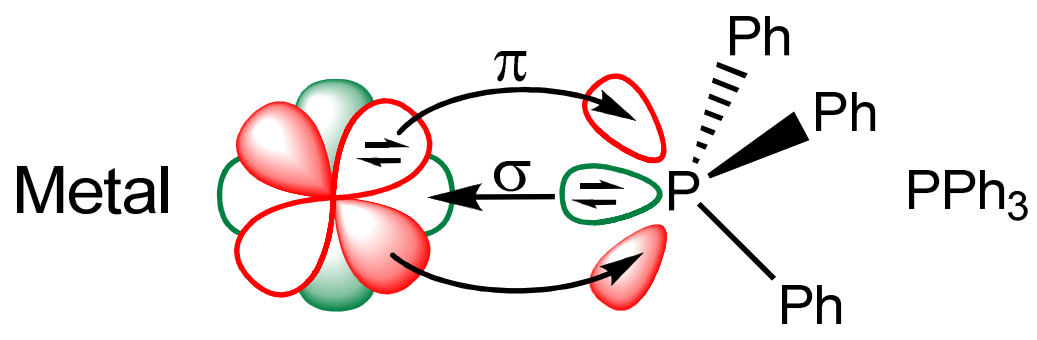

Figura 16. Ligação- $\sigma$ e ligação- $\pi$ entre metal e ligantes fosforados (retrodoação).

Rutênio(II) apresenta configuração eletrônica $d^{6}$, sendo um bom íon metálico para se ligar a ligantes ancilares de fosfinas ou fosfitos ${ }^{29}$. Complexos de Ru"-P"I têm atuado como catalisadores homogêneos em reações de polimerização via metátese $e^{5,19-22,32}$. Neste tipo de complexo, o rutênio apresenta-se com spin baixo, comportando-se como moderado receptor $\sigma$ e bom doador $\pi$ de elétrons ${ }^{33-35}$.

Em estudos sobre a reatividade do complexo de Grubbs $\left[\mathrm{RuX}_{2} \mathrm{P}_{2}(=\mathrm{CHR})\right]$ em $\mathrm{RCM}$ variando-se a fosfina $(\mathrm{P})$ e o haleto $(\mathrm{X})$, observou-se que a atividade catalítica era maior quanto maior o ângulo de cone e maior o caráter doador- $\sigma$ da fosfina, e quanto menor e menos elétron-doador fosse o haleto ${ }^{20}$. Ainda, neste mesmo estudo, observou-se que ocorre descoordenação da fosfina para que ocorra a coordenação da olefina, lembrando um processo do tipo dissociativo ${ }^{20}$. Em outros estudos, foram substituídas uma ou duas fosfinas por carbenos $\mathrm{N}$-heterocíclicos ${ }^{19-24}$ devendo-se observar que nos carbenos $\mathrm{N}$-heterocíclicos os sítios ligantes não são os átomos de nitrogênio.

Observou-se que a combinação dos carbenos $\mathrm{N}$-heterocíclicos e ligantes fosfinas sobre o centro de rutênio melhoram o desempenho do catalisador e também as características dos polímeros sintetizados ${ }^{21-23}$. 
Complexos metálicos com ligantes com características doadoras tais como aminas, despertam também interesse por causa da sua habilidade em labilizar ligantes cis ou trans posicionados em relação aos outros ligantes ${ }^{20}$. Este tipo de complexo tem facilitado diversas transformações estequiométricas e catalíticas de moléculas orgânicas, tais como tautomerizações de acetileno para vinilideno, ou conversões de metal- $\left(\eta^{2}-\mathrm{CH}_{2}=\mathrm{CH}_{2}\right)$ para metal- $(\mathrm{H})\left(\eta^{1}-\mathrm{CH}=\mathrm{CH}_{2}\right)^{16}$. Esses compostos são efetivos precursores para oligomerizações e polimerizações de olefinas, carbonilações de metanol e acetato de metila, e hidrogenações ${ }^{36}$.

Assim como ligantes fosforados, ligantes nitrogenados e outros podem ser empregados como ligantes ancilares, desde que não envenenem o catalisador.

\subsection{A pesquisa sobre Metátese de Olefinas no IQSC}

A pesquisa tem se voltado para a síntese e aplicação de catalisadores em metátese do tipo ROMP, em meio aquoso ou orgânico. Existe o interesse no desenvolvimento de complexos de $\mathrm{Ru}^{\prime \prime}$ e de $\mathrm{Ru}$ III com diversos ligantes ancilares contendo átomos de enxofre", fósforo"' ou nitrogênio"' como elementos de coordenação. Existe a preocupação no desenvolvimento de sistemas que propiciem a reatividade química mediante condições tropicais do Brasil (luz, calor e umidade; e até mesmo a presença de $\mathrm{O}_{2}$ ). $\mathrm{O}$ balanço eletrônico no complexo é explorado como uma ferramenta fundamental, buscando para 
tanto o uso de ligantes relativamente simples de serem adquiridos. Os efeitos estéricos também são explorados ${ }^{37}$.

Estudos recentes alavancaram o desenvolvimento de complexos contendo simultaneamente ligantes de $\mathrm{P}$ e $\mathrm{N}$ trivalentes do tipo $\left[\mathrm{RuCl}_{2}\left(\mathrm{P}^{\mathrm{III}}\right)_{\mathrm{x}}\left(\mathrm{N}^{\mathrm{III}}\right)_{\mathrm{y}}\right]^{38,39}$. Foi observado o efeito das aminas cíclicas e acíclicas como ligantes ancilares na atividade catalítica. Algumas aminas que já foram utilizadas são: piperidina, piridina, 4-picolina, 4-aminopiridina, isonicotinamida, $\mathrm{N}$-(2-hidroxietil)-isonicotinamida, imidazol, 2-metilimidazol, pirazina, difenilamina, dietanolamina, trietanolamina, anilina ou trietilamina ${ }^{39,41}$. O rendimento dos polímeros formados variaram entre $30 \%$ e $100 \%$ à temperatura ambiente ou a $50^{\circ} \mathrm{C}$, com 1 a 5 minutos de reação, em $\mathrm{CHCl}_{3}$, variando o tipo de ligante nitrogenado. Para as aminas cíclicas, pode-se citar como exemplo, o complexo pentacoordenado $\left[\mathrm{RuCl}_{2}\left(\mathrm{PPh}_{3}\right)_{2} \text { (piperidina) }\right]^{38}$. Este complexo polimeriza prontamente norborneno de forma quantitativa à temperatura ambiente, na presença de $5 \mu \mathrm{L}$ de EDA, sendo melhor que o complexo precursor $\left[\mathrm{RuCl}_{2}\left(\mathrm{PPh}_{3}\right)_{3}\right.$. Isso ocorre usando a razão molar $[\mathrm{NBE}] /[\mathrm{Ru}]$ de até $5000 / 1$, resultando em polímero monodisperso $\left(M_{w} / M_{n}=1,05\right)$ e com cadeias longas $\left(M_{n}=\right.$ 2,6 $\left.\times 10^{6}\right)$. Para as aminas acíclicas, pode-se citar, o complexo hexacoordenado $\left[\mathrm{RuCl}_{2}\left(\mathrm{PPh}_{3}\right)_{2}(\text { anilina })_{2}\right]^{41}$ que nas mesmas condições de reação, rende polímeros poucos dispersos $\left(M_{w} / M_{n}=1,62\right)$ e com cadeias longas $\left(M_{n}=9,4 \times 10^{4}\right)$. O centro metálico neste polímero mostra-se ativo na presença de mais monômeros, caracterizando o processo de “living polymerization". Outro exemplo, é o complexo $\left[\mathrm{RuCl}_{2}\left(\mathrm{PPh}_{3}\right)_{2}\left({ }^{\mathrm{sec}} \text { butilamina }\right)_{2}\right]^{41}$, neste caso, a reação é semi-quantitativa (92\%), com baixa distribuição de peso molecular $\left(M_{w} / M_{n}\right.$ $=1,37)$, demonstrando que mesmo um complexo hexacoordenado com ligantes relativamente simples, pode ser ativo em metátese de olefinas. Estas aminas ilustram tipos bem distintos de ligantes em termos de valores de $\mathrm{pK}_{\mathrm{a}}$ e ângulo de cone $(\theta)$ para atuarem 
como ligantes ancilares. Por exemplo, ${ }^{\text {sec }}$ butilamina apresenta $\theta \approx 113^{\circ}$ e $p K_{a}=10,6^{42}$, e anilina apresenta $\theta \approx 111^{\circ}$ e $p K_{a}=4,60^{42}$.(Figura 17)
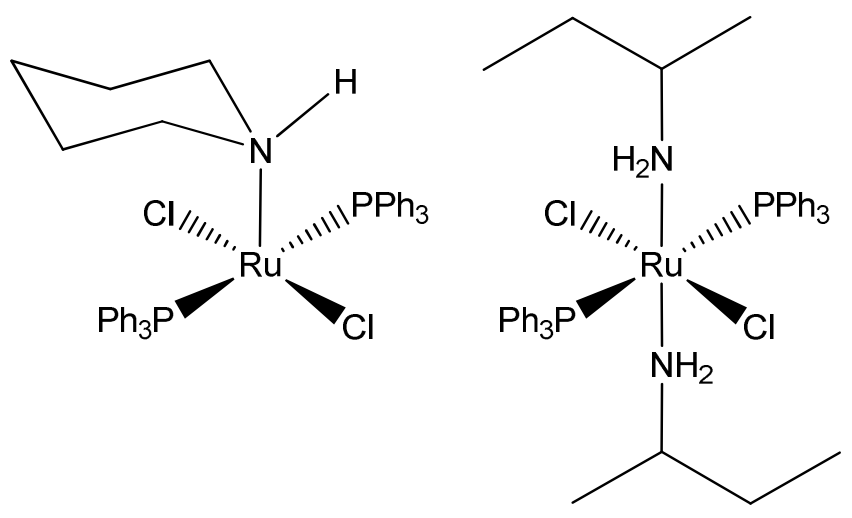

$\left[\mathrm{RuCl}_{2}\left(\mathrm{PPh}_{3}\right)_{2}\right)$ pip $] \quad\left[\mathrm{RuCl}_{2}\left(\mathrm{PPh}_{3}\right)_{2}\left({ }^{\mathrm{sec}} \mathrm{BuN}\right)_{2}\right]$

Figura 17. Complexos sintetizados pelo grupo ${ }^{42}$.

Considerando-se esses resultados ${ }^{38-41}$, conclui-se que as aminas são ativas e promissoras para as reações de ROMP de norborneno e de outras olefinas cíclicas (norbornadieno, norbornenos substituídos e 7-oxanorbornenos substituídos). O emprego de aminas como ligantes ancilares deve-se ao fato de serem mais comuns para serem obtidas em grande variedade no mercado nacional e serem de fácil manuseio.

\subsection{Proposta de trabalho}

Uma das primeiras aplicações industriais de metátese de olefinas que se tem notícia foi desenvolvida pela Phillips Petroleum Co. (EUA), no qual o "Phillips Triolefin Process" produz uma mistura de eteno e 2-buteno com alta pureza a partir do propeno ${ }^{1-5}$. A metátese 
é também muito utilizada na produção, via ROMP, de vários polímeros disponíveis comercialmente tais como o Metton ${ }^{\circledR}$ (polidiciclopentadieno), um plástico usado em antenas de recepção via satélite e o Norsorex $^{\circledR}$ (polinorborneno), uma borracha usada para isolamento acústico e absorção de impacto².

Complexos do tipo $\left[\mathrm{RuCl}_{2}\left(\mathrm{PPh}_{3}\right)_{2}(\text { aminas acíclicas })_{\mathrm{x}}\right]$ e $\left[\mathrm{RuCl}_{2}\left(\mathrm{PPh}_{3}\right)_{2}(\text { aminas cíclicas })_{\mathrm{X}}\right]$ tem sido sintetizados a partir da reação entre $\left[\mathrm{RuCl}_{2}\left(\mathrm{PPh}_{3}\right)_{3}\right]$ e aminas, para serem utilizados na reação de ROMP, onde tem sido concluído a efetiva participação das aminas como ligantes ancilares (Tabela 2$)^{41}$. Um fator de destaque é o ângulo de cone $(\theta)$, bem como deve ser considerado o caráter doador- $\sigma$ avaliado pelo valor de $\mathrm{pK}_{\mathrm{a}}$. A Tabela 2 apresenta resultados referentes às reações de ROMP de norborneno (NBE), onde muitos complexos com aminas apresentaram boa reatividade ${ }^{41}$.

As sínteses dos complexos derivados com dietanolamina, trietanolamina, anilina e ${ }^{s e c}$ butilamina foram bem sucedidas, obtendo-se compostos hexacoordenados. No caso com difenilamina e trietilamina não foi possível isolar os compostos embora tenham sido caracterizados em solução ${ }^{41}$.

Considerando a atividade das aminas acíclicas, esse trabalho tem como proposta fazer a variação dos substituintes no átomo de nitrogênio da anilina, no qual serão analisados conforme suas propriedades eletrônicas e estéricas. Assim, pretende-se estudar complexos de $\mathrm{Ru}^{\text {II }}$ simultaneamente coordenado com $\mathrm{PPh}_{3}$ e aminas acíclicas do tipo $\mathrm{NH}_{2} \mathrm{Ph}$, $\mathrm{NHBuPh}$, e $\mathrm{NH}_{2} \mathrm{CH}_{2} \mathrm{Ph}$, com o intuito de avaliar a atividade catalítica destes complexos como iniciadores de reações de ROMP (Figura 18). 
Tabela 2 - Resultados de ROMP de norborneno (NBE) com $\left[\mathrm{RuCl}_{2}\left(\mathrm{PPh}_{3}\right)_{2} \mathrm{~L}_{\mathrm{x}}\right] ;[\mathrm{Ru}]=1 \mu \mathrm{mol}$, $[\mathrm{NBE}] /[\mathrm{Ru}]=5.000,5 \mu \mathrm{LEDA}$ em $\mathrm{CHCl}_{3}{ }^{41}$.

\begin{tabular}{|c|c|c|c|c|c|c|c|c|}
\hline Ligante ancilar (L) & $\mathrm{pK}_{\mathrm{a}}$ & $\theta$ & $\mathbf{x}$ & Temp. $\left({ }^{\circ} \mathrm{C}\right)$ & $T(\min )$ & Rend (\%) & $M_{n}\left(10^{4}\right)$ & $M_{w} / M_{n}$ \\
\hline $\mathrm{PPh}_{3}$ & 2,73 & $145^{\circ}$ & 1 & 50 & 5 & 63 & 190 & 1,40 \\
\hline imidazol & 6,95 & $82,9^{\circ}$ & 2 & 50 & 5 & 19 & 3.0 & 6,30 \\
\hline $\mathrm{NH}(\mathrm{EtOH})_{2}$ & 8,96 & $125^{\circ}$ & 2 & 50 & 5 & 30 & 89 & 1,57 \\
\hline $\mathrm{N}(\mathrm{EtOH})_{3}$ & 7,76 & $150^{\circ}$ & 2 & 50 & 5 & 36 & 23 & 2,43 \\
\hline 4- $\mathrm{H}_{2} \mathrm{~N}-\mathrm{py}$ & 9,17 & $91,9^{\circ}$ & 2 & 50 & 5 & 63 & 19 & 1,80 \\
\hline py $^{\mathrm{a}}$ & 5,23 & $91.9^{\circ}$ & 2 & 50 & 5 & 67 & 4.2 & 1,32 \\
\hline $\mathrm{NEt}_{3}$ & 10,8 & $150^{\circ}$ & $\mathrm{NI}$ & TA & 5 & 67 & 64 & 2,00 \\
\hline 4- $\mathrm{H}_{3} \mathrm{C}-\mathrm{py}{ }^{\mathrm{a}}$ & 5,98 & $91,9^{\circ}$ & 2 & 50 & 5 & 70 & 4.3 & 1,46 \\
\hline $\mathrm{NH}_{2} \mathrm{Ph}$ & 4,60 & $111^{\circ}$ & 2 & 50 & 5 & 78 & 9.4 & 1,62 \\
\hline 4- $\mathrm{H}_{3} \mathrm{C}-\mathrm{py}{ }^{\mathrm{a}}$ & 5,98 & $91,9^{\circ}$ & 2 & 50 & 120 & 83 & 80 & 1,72 \\
\hline $\mathrm{NH}_{2}{ }^{\mathrm{s}} \mathrm{Bu}$ & 10,6 & $113^{\circ}$ & 2 & TA & 5 & 85 & 73 & 1,46 \\
\hline $\mathrm{NHPh}_{2}$ & 0,78 & $136^{\circ}$ & $\mathrm{NI}$ & 50 & 5 & 90 & 62 & 1,90 \\
\hline $\mathrm{NH}_{2}{ }^{5} \mathrm{Bu}$ & 10,6 & $113^{\circ}$ & 2 & 50 & 5 & 92 & 62 & 1,37 \\
\hline 4- $\mathrm{H}_{2} \mathrm{NC}(\mathrm{O})-\mathrm{py}$ & 3,61 & $91,9^{\circ}$ & 2 & 50 & 5 & 94 & 17 & 1,45 \\
\hline 4- $\mathrm{H}_{2} \mathrm{NC}(\mathrm{O})-\mathrm{py}$ & 3,61 & $91,9^{\circ}$ & 2 & 50 & 120 & 94 & 83 & 1,20 \\
\hline $\mathrm{NEt}_{3}$ & 10,8 & $150^{\circ}$ & $\mathrm{NI}$ & 50 & 5 & 98 & 69 & 1,70 \\
\hline piperidina & 11,2 & $121^{\circ}$ & 1 & TA & $<1$ & 99 & 120 & 1,90 \\
\hline
\end{tabular}

$\mathrm{NI}=$ complexo não foi isolado; ${ }^{\mathrm{a}}[\mathrm{NBE}] /[\mathrm{Ru}]=3000$ 


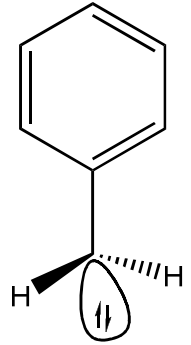

$\mathrm{NH}_{2} \mathrm{Ph}$

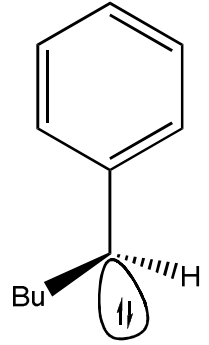

$\mathrm{NH}^{\mathrm{n}} \mathrm{BuPh}$

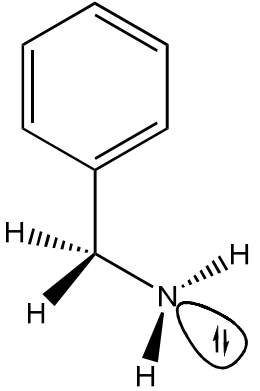

$\mathrm{NH}_{2} \mathrm{CH}_{2} \mathrm{Ph}$

Figura 18. Ligantes ancilares nitrogenados utilizados neste trabalho.

Diferentes combinações eletrônicas, mantendo-se o efeito estérico na mistura de ligantes podem levar a uma sintonia na reatividade do centro de rutênio. Mantendo as propriedades eletrônicas e variando o efeito estérico, pode-se conseguir uma alta seletividade do catalisador, influenciando nas propriedades estruturais cis e trans e no IPD do polímero formado.

Quanto às reações de ROMP, serão realizados estudos em função das concentrações de monômero e complexo, tempo, temperatura e volume de etil diazoacetato (usado como fonte de carbeno), com os monômeros norborneno (NBE), norbornadieno (NBD) e diciclopentadieno (DCPD) com o objetivo de avaliar a reatividade dos complexos frente à tensão anelar das olefinas cíclicas. Serão feitos também estudos de polimerização para se obter co-polímeros entre os monômeros citados. $\mathrm{O}$ efeito dos valores de $\mathrm{pK}_{\mathrm{a}}$ entre as aminas como ligantes ancilares serão analisados na reatividade das reações de ROMP, observandose rendimentos e características dos polímeros isolados. Sendo assim, pretende-se observar a perturbação nas propriedades eletrônicas e estéricas que os grupos substituintes causam no sítio ligante $\mathrm{N}$ dos ligantes nitrogenados. As ligantes nitrogenados que serão utilizads e seus respectivos ângulos de cone e $\mathrm{pK}_{\mathrm{a}}$ são apresentados na Tabela 1. 
Este estudo auxiliará no sentido de melhorar o conhecimento da influência das aminas como ligantes ancilares em reações de metátese.

Tabela 3 - Valores de $\mathrm{pK}_{\mathrm{a}}$ e ângulo de cone para fosfina e ligantes nitrogenados ${ }^{42}$.

\begin{tabular}{lcccc}
\cline { 2 - 5 } & $\mathbf{N H}_{2} \mathbf{P h}$ & $\mathbf{N H}^{\mathrm{n}} \mathbf{B u P h}$ & $\mathbf{N H}_{2} \mathbf{C H}_{2} \mathbf{P h}$ & $\mathbf{P P h}_{3}$ \\
\hline $\mathbf{p K} \mathrm{a}_{\mathrm{a}}$ & 4,6 & 4,95 & 9,33 & 2,73 \\
$\theta$ & 111 & $\approx 150^{\mathrm{a}}$ & 106 & $145^{\circ}$ \\
\hline
\end{tabular}

${ }^{a}$ Estimativa considerando os valores para NHEtPh $\theta=126^{\circ}$; e $\mathrm{NEt}_{2} \mathrm{Ph} \theta=170^{\circ}$ 


\section{OBJETIVOS}

Os objetivos deste projeto são:

a) Sintetizar e caracterizar complexos de $\mathrm{Ru}$ (II) coordenados simultaneamente a $\mathrm{PPh}_{3} \mathrm{e}$ aminas acíclicas do tipo $\mathrm{NH}_{2} \mathrm{Ph}, \mathrm{NH}^{\mathrm{n}} \mathrm{BuPh}$ e $\mathrm{NH}_{2} \mathrm{CH}_{2} \mathrm{Ph}$;

b) Aplicar os complexos sintetizados em reações de polimerização via ROMP e ROMCP de norborneno, norbornadieno e diciclopentadieno.

c) Estabelecer uma correlação entre as características dos polímeros isolados com as características dos complexos. 


\section{PARTE EXPERIMENTAL}

\subsection{Procedimento Geral}

Todas as sínteses dos complexos aconteceram sob atmosfera de argônio. Os possíveis traços de oxigênio do argônio comercial foram eliminados conduzindo-os através de frascos lavadores contendo íons $\mathrm{Cr}^{2+}$, resultado da solução ácida de $\mathrm{Cr}^{3+}$ na presença de amalgama de zinco.

Os solventes (metanol, acetona, clorofórmio e $n$-hexano) foram de grau HPLC da J. T. Baker ou Tedia e usados como adquiridos. O éter etílico, da Mallinckrodt, foi destilado ao abrigo da luz, em seguida misturado a sulfato ferroso amoniacal, filtrado, e tratado com sódio metálico ao abrigo da luz por $24 \mathrm{~h}$. Os reagentes utilizados foram $\mathrm{RuCl}_{3} \cdot \mathrm{xH}_{2} \mathrm{O}$, norborneno (biciclo[2.2.1] hepta-2-eno; NBE), norbornadieno (biciclo[2.2.1]hepta-2,5-dieno; NBD), diciclopentadieno (triciclo[5.2.1.0 $\left.0^{2,6}\right]$ deca-3,8-dieno; DCPD) etildiazoacetato (EDA), trifenilfosfina $\left(\mathrm{PPh}_{3}\right)$, anilina $\left(\mathrm{NH}_{2} \mathrm{Ph}\right)$, benzilamina $\left(\mathrm{NH}_{2} \mathrm{CH}_{2} \mathrm{Ph}\right), \mathrm{N}-{ }^{\mathrm{n}}$ Butilanilina $\left(\mathrm{NH}^{\mathrm{n}} \mathrm{BuPh}\right) \mathrm{da}$ Aldrich. Para os estudos de $\mathrm{RMN}$ de ${ }^{31} \mathrm{P}$ foi utilizado $\mathrm{CDCl}_{3}$ (Tedia) $99 \%$. Temperatura ambiente (TA) foi de $25 \pm 1$ 回.

\subsection{Síntese dos Complexos}

\subsubsection{Síntese do Complexo $\left[\mathrm{RuCl}_{2}\left(\mathrm{PPh}_{3}\right)_{3}\right](\mathrm{P})$}


A síntese do complexo foi desenvolvida seguindo a metodologia utilizada por Wilkinson e Stephenson ${ }^{43,44}$. Dissolveu-se 1,52 mmol de $\mathrm{RuCl}_{3} \cdot \mathrm{xH}_{2} \mathrm{O}(0,47 \mathrm{~g})$ e 9,17 mmol de trifenilfosfina $(2,4 \mathrm{~g})$ em $50 \mathrm{~mL}$ de metanol e deixou-se a mistura em refluxo por 4 horas, formando um precipitado de cor marrom escura. Em seguida o produto foi filtrado a vácuo e lavado com metanol gelado previamente degaseado, sendo então secado a vácuo, obtendo $85 \%$ de rendimento. (Figura 19)

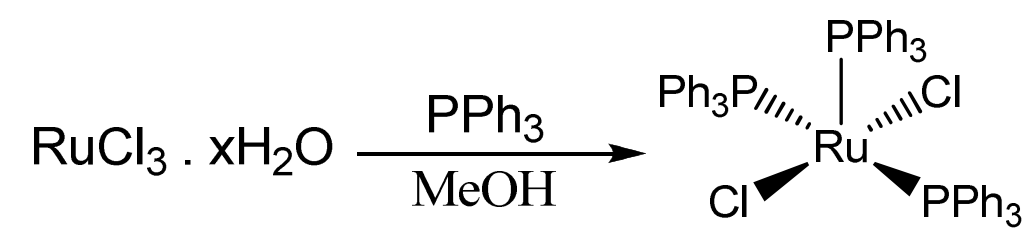

Figura 19. Rota para obtenção do complexo precursor $\left[\mathrm{RuCl}_{2}\left(\mathrm{PPh}_{3}\right)_{3}\right](\mathbf{P})$.

\subsubsection{Síntese do Complexo $\left[\mathrm{RuCl}_{2}\left(\mathrm{PPh}_{3}\right)_{2}\left(\mathrm{NH}_{2} \mathrm{Ph}\right)_{2}\right](1)$}

Em uma solução de $\mathrm{NH}_{2} \mathrm{Ph}(10,4 \mathrm{mmol})$ em acetona $(30 \mathrm{~mL})$ foi adicionado $\left[\mathrm{RuCl}_{2}\left(\mathrm{PPh}_{3}\right)_{3}\right](0,52 \mathrm{mmol})$. A mistura resultante foi agitada a TA por $12 \mathrm{~h}$. O volume da solução é reduzido para $\approx 5 \mathrm{~mL}$ por evaporação do solvente mediante um fluxo maior de argônio. É adicionado $n$-hexano gelado até a precipitação de um complexo vinho. O sólido foi filtrado, lavado com éter etílico e seco a vácuo. O rendimento é de $60 \%$. (Figura 20) ${ }^{41}$

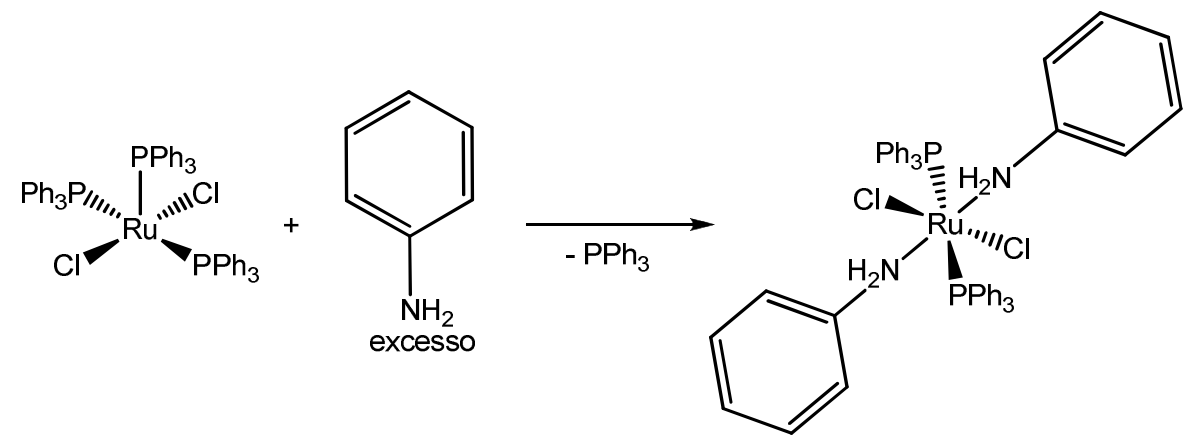

Figura 20. Rota para obtenção do complexo $\left[\mathrm{RuCl}_{2}\left(\mathrm{PPh}_{3}\right)_{2}\left(\mathrm{NH}_{2} \mathrm{Ph}\right)_{2}\right]$ (1). 


\subsubsection{Síntese do Complexo $\left[\mathrm{RuCl}{ }_{2}\left(\mathrm{PPh}_{3}\right)_{2}\left(\mathrm{NH}_{2} \mathrm{CH}_{2} \mathrm{Ph}\right)_{2}\right]$ (2)}

Em uma solução de $\mathrm{NH}_{2} \mathrm{CH}_{2} \mathrm{Ph}(1,37 \mathrm{mmol})$ em acetona $(40 \mathrm{~mL})$ foi adicionado $\left[\mathrm{RuCl}_{2}\left(\mathrm{PPh}_{3}\right)_{3}\right](0,47 \mathrm{mmol})$. A mistura resultante foi agitada a TA por $24 \mathrm{~h}$. O volume da solução é diminuído para $\approx 5 \mathrm{~mL}$ por evaporação do solvente mediante um fluxo maior de argônio. O complexo precipitado verde foi filtrado, lavado com éter etílico e seco sob vácuo. O rendimento é de $44 \%$. Não foram encontradas referências na literatura acerca desse complexo, caracterizando um complexo inédito. (Figura 21)

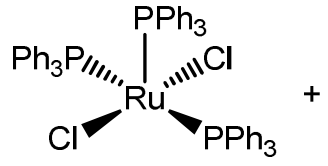<smiles>NCc1ccccc1</smiles>

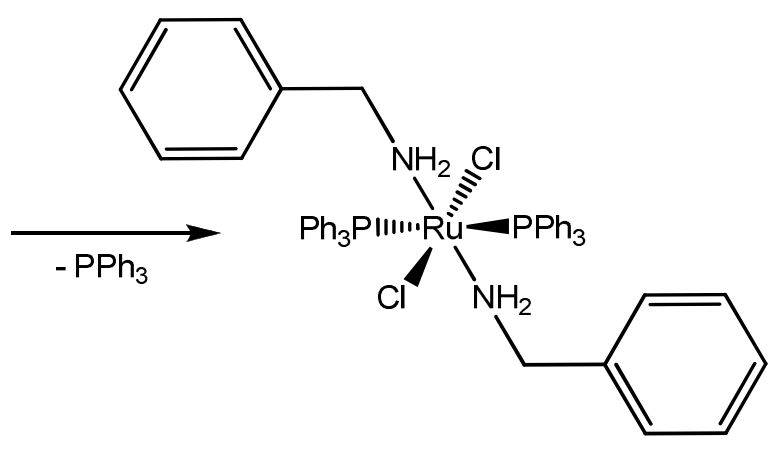

Figura 21. Rota para obtenção do complexo $\left[\mathrm{RuCl}_{2}\left(\mathrm{PPh}_{3}\right)_{2}\left(\mathrm{NH}_{2} \mathrm{CH}_{2} \mathrm{Ph}\right)_{2}\right](2)$.

\subsubsection{Síntese do Complexo $\left[\mathrm{RuCl}_{2}\left(\mathrm{PPh}_{3}\right)_{2}\left(\mathrm{NH}^{\mathrm{n}} \mathrm{BuPh}\right)\right]$ (3)}

Em uma solução de $\mathrm{NH}^{\mathrm{n}} \mathrm{BuPh}(5,2 \mathrm{mmol})$ em acetona: $\mathrm{CHCl}_{3}(25: 2 \mathrm{~mL})$ foi adicionado $\left[\mathrm{RuCl}_{2}\left(\mathrm{PPh}_{3}\right)_{3}\right](0,52 \mathrm{mmol})$. A mistura resultante foi agitada a TA por $24 \mathrm{~h}$. O volume da solução é diminuído para $\approx 5 \mathrm{~mL}$ por evaporação de solvente mediante fluxo maior de argônio. É adicionado éter de petróleo gelado e ocorre a precipitação de um complexo verde escuro. O sólido foi filtrado, lavado com éter etílico e seco sob vácuo. O rendimento é de 
40\%. Assim como para 2, não foram encontradas referências na literatura acerca deste complexo, caracterizando-o como um complexo inédito. (Figura 22)

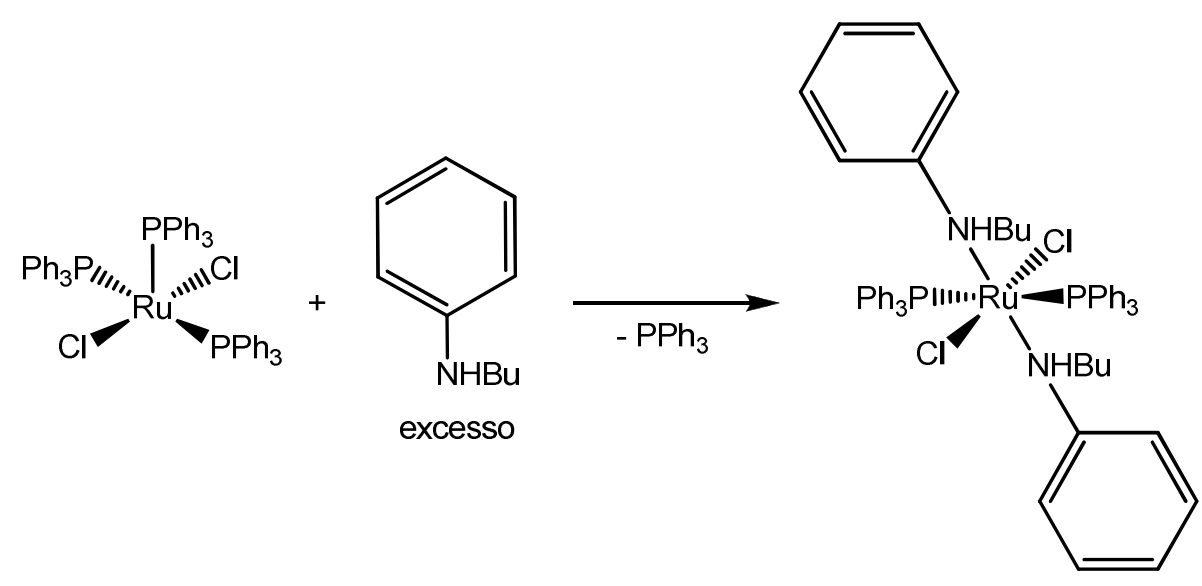

Figura 22. Rota para obtenção do complexo $\left[\mathrm{RuCl}_{2}\left(\mathrm{PPh}_{3}\right)_{2}\left(\mathrm{NH}^{\mathrm{n}} \mathrm{BuPh}\right)\right]$ (3).

\subsection{Procedimento Geral para ROMP de Norborneno, Norbornadieno e Diciclopentadieno}

Todas as polimerizações foram feitas em atmosfera de argônio. Em um experimento usando 1,2 ou 3, $1.0 \mu \mathrm{mol}$ de complexo é dissolvido em $2 \mathrm{~mL}$ de $\mathrm{CHCl}_{3}$ e monômero é adicionado para que a razão molar [monômero]/[Ru] seja a desejada; neste trabalho foram utilizadas razões molares de 1000,3000, 5000 e 10000, após o qual é adicionado $5 \mu \mathrm{L}$ de etildiazoacetato (EDA). A solução é mantida à temperatura ambiente ou a $50 \pm 1{ }^{\circ} \mathrm{C}$ em banho termostatizado pelo tempo desejado. Em seguida $5 \mathrm{~mL}$ de metanol é adicionado a temperatura ambiente, e o polímero precipitado é retirado do recipiente, lavado com metanol e seco em estufa a vácuo à $27 \pm 1^{\circ} \mathrm{C}$ antes de ser pesado. Para os experimentos com 
luz branca, a solução do complexo é deixada pelo tempo desejado na presença de luz em uma bancada fotoquímica. Os monômeros utilizados são apresentados abaixo. (Figura 23)

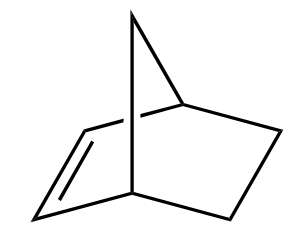

Norborneno (NBE)

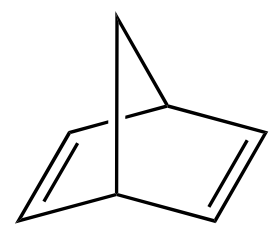

Norbornadieno (NBD)

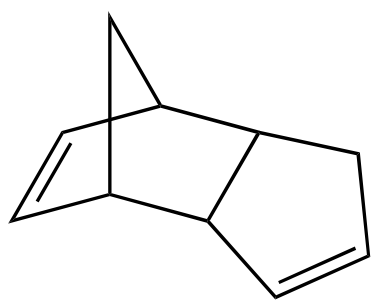

Diciclopentadieno (DCPD)

Figura 23. Monômeros utilizados.

3.4. Procedimento Geral para ROMP de Norborneno na presença dos ligantes $\mathrm{NH}_{2} \mathrm{Ph}$, $\mathrm{NH}_{2} \mathrm{CH}_{2} \mathrm{Ph}$ e $\mathrm{NH}^{\mathrm{n}} \mathrm{BuPh}$

Foram realizados experimentos em presença de 20 excessos $(0,02 \mathrm{mmol})$ de ligantes $\mathrm{PPh}_{3}$ (6,5 mg;) ou amina ( $\left.\mathrm{NH}_{2} \mathrm{Ph}=1,82 \mu \mathrm{L} ; \mathrm{NH}_{2} \mathrm{CH}_{2} \mathrm{Ph}=2,2 \mu \mathrm{L} ; \mathrm{NH}^{\mathrm{n}} \mathrm{BuPh}=3,2 \mu \mathrm{L}\right)$. Os ligantes foram adicionados as soluções dos complexos, seguidas pela adição do monômero na proporção [monômero] $/[$ complexo] $=5000$. Em seguida foi adicionado $5 \mu \mathrm{L}$ de EDA. Apos 30 minutos, o polímero foi precipitado com metanol. O rendimento de reação foi calculado a partir da massa do polímero isolado, o qual foi previamente seco em uma estufa a vácuo a $27 \pm 1^{\circ} \mathrm{C}$. 


\subsection{Procedimento Geral para ROMCP de Norborneno, Norbornadieno e Diciclopentadieno}

Para as reações de copolimerização, os monômeros NBE, NBD e DCPD foram dissolvidos em $\mathrm{CHCl}_{3}(2 \mathrm{~mL})$, e em estabelecidas razões molares de [NBE]:[NBD], [NBE]:[DCPD] e [NBD]:[DCPD] com relação à $1 \mu \mathrm{mol}$ de Ru tal que a relação estabelecida seja [monômero] $]_{\text {total }} /[\mathrm{Ru}]$. Então, $1 \mu \mathrm{mol}$ do complexo foi adicionado, seguido da adição de 5 $\mu \mathrm{L}$ de EDA. A reação acontece em $30,60,120$ e 240 minutos a $50 \pm 1{ }^{\circ} \mathrm{C}$, ao final do tempo determinado, o polímero é precipitado com metanol. O rendimento de reação foi calculado a partir da massa do copolímero isolado, o qual foi previamente seco em uma estufa a vácuo a $27 \pm 1^{\circ} \mathrm{C}$.

\subsection{Instrumentação}

Análises elementares de CHN foram realizadas usando um EA1110 CHNS-O Carlo Erba Instrument. Espectros de infravermelho foram feitos em pastilhas de CsI (1:100) em um Bomem FTIR MB 102. Espectros de $\mathrm{RMN}{ }^{31} \mathrm{P}\left\{{ }^{1} \mathrm{H}\right\}$ foi obtido em $\mathrm{CDCl}_{3}$ a $25,0 \pm 0.1^{\circ} \mathrm{C}$ usando um Bruker $200 \mathrm{MHz}$. O deslocamento químico foi reportado em ppm relativo à freqüência do TMS ou íon $\mathrm{PF}_{6}{ }^{-}$. As análises de cromatografia por permeação em gel (GPC) foram obtidas em um Shimadzu Prominence LC System equipado com uma bomba LC-20AD, um degaseficador DGU-20A5, um módulo de comunicação CBM-20A, um forno CTO-20A e um detector RID-10A, conectado com uma coluna PL gel ( $5 \mu$ MIXED-C: $30 \mathrm{~cm}, \varnothing=7,5 \mathrm{~mm})$. 0 tempo de retenção foi calibrado com o padrão de poliestireno $(570$ a $1.036 .000 \mathrm{~g} / \mathrm{mol}$ ) 
usando $\mathrm{CHCl}_{3}$ grau HPLC como eluente. IPD (Índice de polidispersidade) é $M_{w} / M_{n}$. $M_{w}$ é a massa molecular ponderal média do polímero e $M_{n}$ é a massa molecular numérica média.

\subsection{Voltametria cíclica}

As análises de voltametria cíclica dos complexos foram feitas em um potenciostato PAR Model 264A, utilizando eletrodos de Pt como eletrodo de trabalho e contra-eletrodo, e eletrodo de calomelano saturado como eletrodo de referência. O eletrólito foi TBA (Tetrabutilamônio hexafluorofosfato) em $\mathrm{CH}_{2} \mathrm{Cl}_{2}$ na concentração de $0,1 \mathrm{M}$ e os complexos como analito na concentração de 0,001 M. 


\section{RESULTADOS E DISCUSSÕES}

\subsection{Análise Elementar e sínteses}

A Tabela 4 apresenta os resultados de análise elementar ( $\mathrm{CHN}$ ) para os complexos isolados a partir da reação de $\left[\mathrm{RuCl}_{2}\left(\mathrm{PPh}_{3}\right)_{3}\right.$ e as aminas $\mathrm{NH}_{2} \mathrm{Ph}, \mathrm{NH}_{2} \mathrm{CH}_{2} \mathrm{Ph}$ e $\mathrm{NH}^{\mathrm{n}} \mathrm{BuPh}$. Observa-se que os valores experimentais são consistentes com complexos hexacoordenados nos casos para $\mathrm{NH}_{2} \mathrm{Ph}$ e $\mathrm{NH}_{2} \mathrm{CH}_{2} \mathrm{Ph}$, onde se deu a substituição de uma molécula de trifenilfosfina $\left(\mathrm{PPh}_{3}\right)$ por uma amina alifática no complexo precursor, com adição de mais uma amina posteriormente. No caso com $\mathrm{NH}^{\mathrm{n}} \mathrm{BuPh}$, o complexo resultante é pentacoordenado.

Tabela 4 - Dados da análise elementar para os complexos de Ru" sintetizados.

\section{Análise elementar - Esperado (Obtido)}

\begin{tabular}{c|ccccc}
\cline { 2 - 5 } & Complexos & \%C & \%H & \%N & Cor \\
\hline $\mathbf{1}$ & {$\left[\mathrm{RuCl}_{2}\left(\mathrm{PPh}_{3}\right)_{2}\left(\mathrm{NH}_{2} \mathrm{Ph}\right)_{2}\right]$} & $65,20(64,63)$ & $5,07(5,21)$ & $3,22(3,16)$ & Vinho \\
\hline $\mathbf{2}$ & {$\left[\mathrm{RuCl}_{2}\left(\mathrm{PPh}_{3}\right)_{2}\left(\mathrm{NH}_{2} \mathrm{Bz}\right)_{2}\right]$} & $65,88(63,08)$ & $5,27(5,22)$ & $3,07(3,11)$ & Verde \\
\hline $\mathbf{3}$ & {$\left[\mathrm{RuCl}_{2}\left(\mathrm{PPh}_{3}\right)_{2}(\mathrm{NHBuPh})\right]$} & $65,32(65,71)$ & $5,36(5,41)$ & $1,66(1,79)$ & Verde escuro \\
\hline
\end{tabular}

O grande ângulo de cone $\left(\theta \approx 150^{\circ}\right)$ do ligante $\mathrm{NH}^{\mathrm{n}} \mathrm{BuPh}$ favoreceu a formação do complexo pentacoordenado, mesmo sendo usado um grande excesso de 10 vezes de ligante 
na síntese. Quando os ligantes amina apresentam menores ângulo de cone $\left(\theta \approx 111^{\circ} \mathrm{e} 106^{\circ}\right)$, os complexos resultantes são hexacoordenados.

É interessante ser observado que as cores dos complexos variam em cada caso. Nos complexos hexacoordenados, o complexo é vinho com $\mathrm{NH}_{2} \mathrm{Ph}\left(\mathrm{pK}_{\mathrm{a}}=4,6\right)$ e verde com $\mathrm{NH}_{2} \mathrm{CH}_{2} \mathrm{Ph}\left(\mathrm{pK}_{\mathrm{a}}=9,3\right)$. Isso pode ser relacionado com a diferença de basicidade das aminas, com implicação direta nos campos ligantes em cada caso. Já o complexo pentacoordenado, verde escuro, está relacionado com o número de coordenação frente o campo ligante, mesmo com a amina apresentando a basicidade similar à $\mathrm{NH}_{2} \mathrm{Ph}$.

Ainda é observado que os complexos com $\mathrm{NH}_{2} \mathrm{Ph}$ e $\mathrm{NH}^{\mathrm{n}} \mathrm{BuPh}$ precipitam somente com a adição de solventes bem apolares ( $n$-Hexano e Éter de petróleo), ao contrário do complexo com $\mathrm{NH}_{2} \mathrm{CH}_{2} \mathrm{Ph}$ que já precipita apenas com a redução de volume. Uma extrapolação desse fato estaria relacionada com a densidade de carga nos anéis fenílicos que poderia propiciar maior polarização com o solvente acetona, precisando diminuir a constante dielétrica do meio por adição de outro solvente. Já no caso com $\mathrm{NH}_{2} \mathrm{CH}_{2} \mathrm{Ph}$, a unidade $-\mathrm{CH}_{2}$ - blinda o deslocamento de carga do átomo de $\mathrm{N}$ frente ao anel fenílico, visto que ele é melhor doador $\sigma$.

\subsection{Análise Espectroscópica na Região do Infra Vermelho}

Os espectros obtidos em pastilhas de CsI são apresentados na Figura 24, Figura 25 e Figura 26. 
O espectro do complexo precursor é também apresentado para fins de comparação. A Tabela 5 apresenta as bandas em cada caso com a possível atribuição que é discutida a seguir, seguindo a literatura ${ }^{44-46}$.

Os espectros dos complexos apresentam bandas características de compostos aromáticos na região de $3080-3010 \mathrm{~cm}^{-1}$, que correspondem ao modo vibracional de estiramento axial $v(C-H)$ e vibrações de estiramento $v(C=C)$ na região de $1625-1430 \mathrm{~cm}^{-1}$ com intensidade variável. Essas bandas são atribuídas aos anéis aromáticos do ligante $\mathrm{PPh}_{3} \mathrm{e}$ dos ligantes amina.

O modo vibracional de estiramento $v(\mathrm{P}-\mathrm{C})$ aparece normalmente na região de 1130 $1090 \mathrm{~cm}^{-1}$, sendo observado para os complexos em aproximadamente $1084 \mathrm{~cm}^{-1}$.

Em fosfinas contendo a ligação P-Ph, ocorrem vibrações de deformação angular fora do plano $\delta(C-H)$ na região de $750-680 \mathrm{~cm}^{-1}$.

Assim como no complexo precursor, nos complexos em questão foram observadas duas bandas na região de $743-689 \mathrm{~cm}^{-1}$, correspondendo a essas vibrações. Em compostos contendo ligações P-Ph, ocorrem tipicamente estiramentos na região de $560-480 \mathrm{~cm}^{-1}$, conforme pode ser visto no complexo precursor $\left[\mathrm{RuCl}_{2}\left(\mathrm{PPh}_{3}\right)_{3}\right]$ encontrados na literatura ${ }^{44}$.

Para os três complexos foram observadas três bandas intensas na região de 548 $498 \mathrm{~cm}^{-1}$, correspondendo aos estiramentos da trifenilfosfina. 


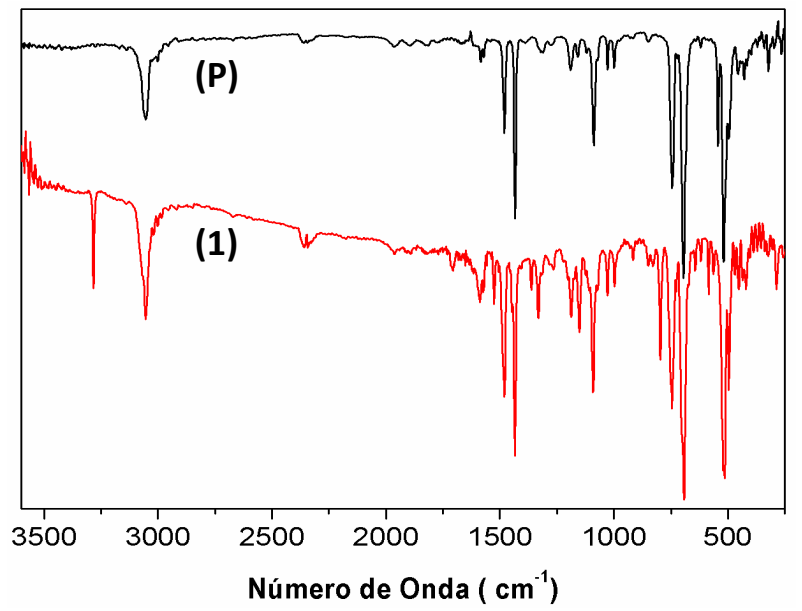

Figura 24. Espectro vibracional na região do infravermelho em pastilha de Csl do complexo precursor $\left[\mathrm{RuCl}_{2}\left(\mathrm{PPh}_{3}\right)_{3}\right](\mathbf{P})$ e do complexo[RuCl$\left.{ }_{2}\left(\mathrm{PPh}_{3}\right)_{2}\left(\mathrm{NH}_{2} \mathrm{Ph}\right)_{2}\right](\mathbf{1})$ em vermelho.

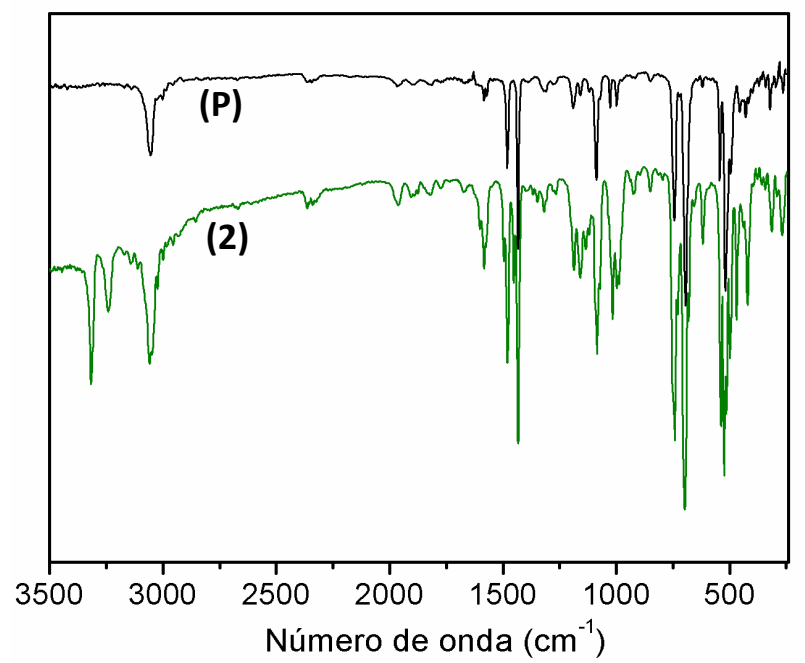

Figura 25. Espectro vibracional na região do infravermelho em pastilha de Csl do complexo precursor $\left[\mathrm{RuCl}_{2}\left(\mathrm{PPh}_{3}\right)_{3}\right](\mathbf{P})$ e do complexo $\left[\mathrm{RuCl}_{2}\left(\mathrm{PPh}_{3}\right)_{2}\left(\mathrm{NH}_{2} \mathrm{Bz}\right)_{2}\right](2)$ em verde.

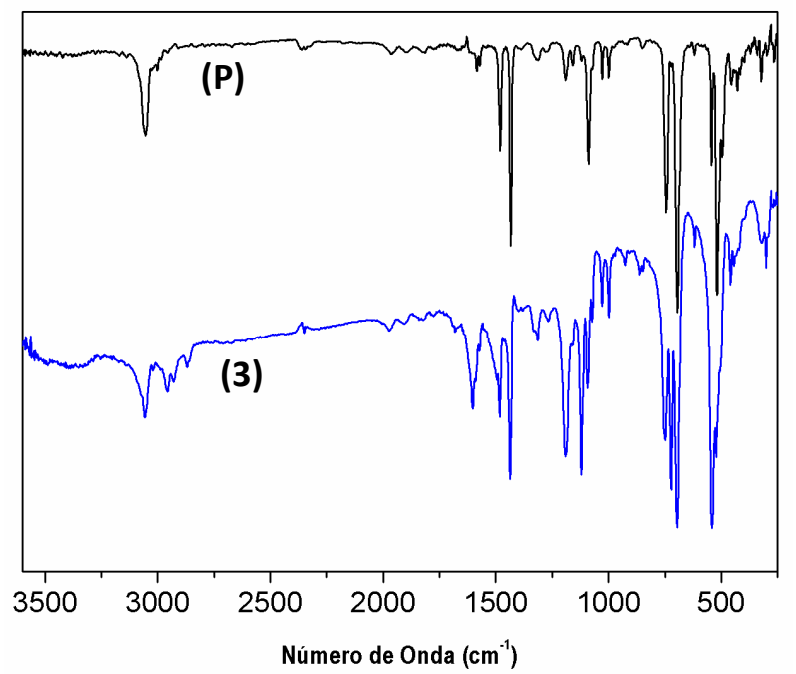

Figura 26. Espectro vibracional na região do infravermelho em pastilha de CsI do complexo precursor $\left[\mathrm{RuCl}_{2}\left(\mathrm{PPh}_{3}\right)_{3}\right]$ (P) e do complexo $\left[\mathrm{RuCl}_{2}\left(\mathrm{PPh}_{3}\right)_{2}\left(\mathrm{NH}^{\mathrm{n}} \mathrm{BuPh}\right)\right](3)$ em azul. 
Tabela 5 - Bandas dos espectros de FTIR dos complexos $\left[\mathrm{RuCl}_{2}\left(\mathrm{PPh}_{3}\right)_{2}\left(\mathrm{~N}_{\text {III }}\right)_{\mathrm{x}}\right]$, para $\mathrm{N}_{\text {III }}=$ $\mathrm{NH}_{2} \mathrm{Ph}, \mathrm{NH}_{2} \mathrm{CH}_{2} \mathrm{Ph}$ e $\mathrm{NH}^{\mathrm{n}} \mathrm{BuPh}$ com $\mathrm{x}=2$ para $\mathrm{NH}_{2} \mathrm{Ph}, \mathrm{NH}_{2} \mathrm{CH}_{2} \mathrm{Ph}$ e $\mathrm{x}=1$ para NH${ }^{\mathrm{n}} \mathrm{BuPh} .{ }^{45,46}$

\section{LIGANTE}

\begin{tabular}{|c|c|c|c|}
\hline Banda $\left(\mathrm{cm}^{-1}\right)$ & $\mathrm{NH}_{2} \mathrm{Ph}$ & $\mathrm{NH}_{2} \mathrm{CH}_{2} \mathrm{Ph}$ & $\mathrm{NH}^{\mathrm{n}} \mathrm{BuPh}$ \\
\hline $\mathrm{v}(\mathrm{N}-\mathrm{H})$ anilina & 3283 & 3313,3247 & -- \\
\hline$v(C-H) s p^{2}$ da $P P h_{3}$ e Ph & 3053 & 3054 & 3055 \\
\hline $\begin{array}{c}v(\mathrm{C}-\mathrm{H}) s p^{2} \text { do }-\mathrm{CH}_{2}-\text { do grupo } \\
\mathrm{NH}_{2} \mathrm{CH}_{2} \mathrm{Ph} \text { e } \mathrm{NH}^{\mathrm{n}} \mathrm{BuPh}\end{array}$ & -- & 2952, 2917 & 2956, 2929 \\
\hline $\begin{array}{c}\mathrm{v}(\mathrm{C}-\mathrm{H}) s p^{3} \text { do }-\mathrm{CH}_{3} \text { do } \\
\text { grupo } \mathrm{NH}^{\mathrm{n}} \mathrm{BuPh}\end{array}$ & -- & - & 2869 \\
\hline $\mathrm{v}(\mathrm{C}=\mathrm{C})$ da $\mathrm{PPh}_{3}$ e $\mathrm{Ph}$ & $1525,1480,1433$ & $1481,1453,1435$ & $1496,1483,1436$ \\
\hline $\mathrm{V}(\mathrm{P}-\mathrm{C}) \mathrm{da} \mathrm{PPh}_{3}$ e $\mathrm{Ph}$ & 1090 & 1091 & 1092 \\
\hline$\delta(C-H)$ da $\mathrm{PPh}_{3}$ e Ph & 745,691 & $746,721,695$ & $748,722,695$ \\
\hline$v(P-P h)$ e $P h$ & $519,512,495$ & $541,526,501$ & $541,522,503$ \\
\hline$v(\mathrm{Ru}-\mathrm{Cl})$ & 287 & 274,316 & 300 \\
\hline
\end{tabular}

Em complexos que contêm a ligação $\mathrm{Ru}-\mathrm{Cl}$ são observadas bandas na região de 270 $350 \mathrm{~cm}^{-1}$ que variam em quantidade dependendo da disposição dos íons $\mathrm{Cl}^{-}$na esfera de coordenação. No complexo precursor $\left[\mathrm{RuCl}_{2}\left(\mathrm{PPh}_{3}\right)_{3}\right]$, aparece uma banda em $320 \mathrm{~cm}^{-1}$, que corresponde aos ligantes cloro trans-posicionados entre si. Nos três complexos, foram observadas bandas na região de $316-274 \mathrm{~cm}^{-1}$ atribuídas ao estiramento $v(\mathrm{Ru}-\mathrm{Cl})$. Nos casos de 1 e 3 é observada uma única banda, enquanto que no complexo 2 são observadas duas bandas. Assim, os complexos $\mathbf{1}$ e $\mathbf{3}$ apresentam os ligantes cloro trans-posicionados, e no complexo 2, cis-posicionados.

No caso do $\left[\mathrm{RuCl}_{2}\left(\mathrm{PPh}_{3}\right)_{3}\left(\mathrm{NH}_{2} \mathrm{Ph}\right)_{2}\right](\mathbf{1})$ é observada uma banda de alta intensidade na região de $3280 \mathrm{~cm}^{-1}$ característica do estiramento $v(\mathrm{~N}-\mathrm{H})$ da anilina, enquanto que o 
complexo precursor não apresenta essa banda características, sendo um indício da coordenação da amina.

Com $\left[\mathrm{RuCl}_{2}\left(\mathrm{PPh}_{3}\right)_{3}\left(\mathrm{NH}_{2} \mathrm{CH}_{2} \mathrm{Ph}\right)_{2}\right](2)$, são observadas duas bandas de alta intensidade na região de $3300 \mathrm{~cm}^{-1}$ característica do estiramento $v(\mathrm{~N}-\mathrm{H})$ da benzilamina, enquanto que o complexo precursor não apresenta essas bandas características, sendo um indício da coordenação da amina.

No caso com $\left[\mathrm{RuCl}_{2}\left(\mathrm{PPh}_{3}\right)_{3}\left(\mathrm{NH}^{\mathrm{n}} \mathrm{BuPh}\right)\right](3)$, não é observada uma banda característica na região de $3200 \mathrm{~cm}^{-1}$ para o estiramento $\nu(\mathrm{N}-\mathrm{H})$ da anilina, possivelmente devido às características dos grupos ligados ao átomo de nitrogênio. Essa banda pode estar sobreposta pela banda de estiramento $v(\mathrm{C}-\mathrm{H})$ dos anéis aromáticos. Porém, são observadas bandas em 2957, 2928 e $2869 \mathrm{~cm}^{-1}$, atribuídas ao estiramento $v(\mathrm{C}-\mathrm{H})$ dos grupos $\mathrm{CH}_{2}$ e $\mathrm{CH}_{3}$ do grupamento ${ }^{\mathrm{n}}$ butil da amina $\mathrm{NH}^{\mathrm{n}} \mathrm{BuPh}$, enquanto que o complexo precursor não apresenta essas banda características, e é também um indício da coordenação da amina.

\subsection{Caracterização por Ressonância Magnética Nuclear de ${ }^{31} \mathrm{P}\left\{{ }^{1} \mathrm{H}\right\}$}

O espectro de $\mathrm{RMN}{ }^{31} \mathrm{P}\left\{{ }^{1} \mathrm{H}\right\}$ em $\mathrm{CDCl}_{3}$ do complexo 1 mostra somente um sinal em 2,05 ppm por até $12 \mathrm{~h}$ a $25^{\circ} \mathrm{C}$ (Figura 27). Deve ser notado que não existe sinal de $\mathrm{PPh}_{3}$ livre (-4,53 ppm). Como os dados de análise elementar indicam massa molecular do complexo com duas moléculas de $\mathrm{PPh}_{3}$, então é sugerido que essas moléculas de $\mathrm{PPh}_{3}$ estejam transposicionadas. Assim, o complexo tem conformação do tipo ttt- $\left[\mathrm{RuCl}_{2}\left(\mathrm{PPh}_{3}\right)_{2}\left(\mathrm{NH}_{2} \mathrm{Ph}\right)_{2}\right]$, em concordância também com o espectro de infra vermelho que sugere que os cloros estão 
trans-posicionados. O espectro de $\mathrm{RMN}{ }^{31} \mathrm{P}\left\{{ }^{1} \mathrm{H}\right\}$ na presença de excesso de $\mathrm{PPh}_{3}$ não apresenta deslocamento ou mudança de sinal por até $12 \mathrm{~h}$, sugerindo que não ocorre descoordenação de $\mathrm{PPh}_{3}$, sendo o complexo inerte.

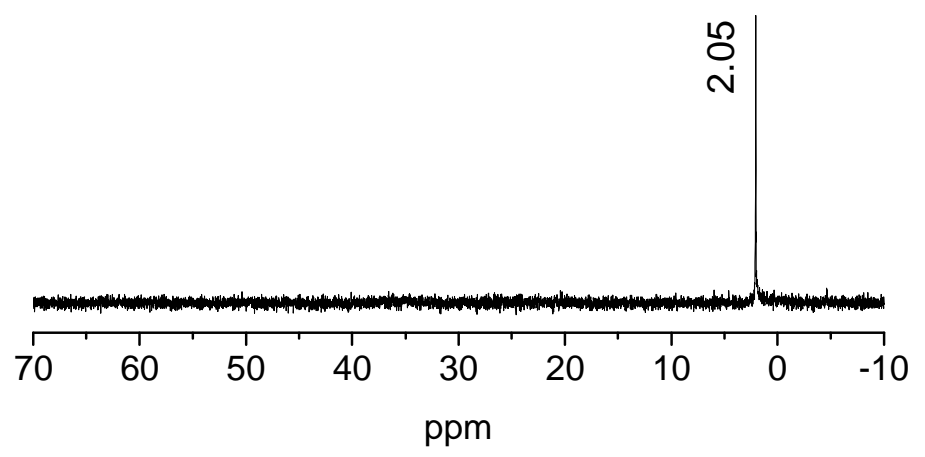

Figura 27. Espectro de $\mathrm{RMN}{ }^{31} \mathrm{P}\left\{{ }^{1} \mathrm{H}\right\}$ em $\mathrm{CDCl}_{3}$ para o complexo $\left[\mathrm{RuCl}_{2}\left(\mathrm{PPh}_{3}\right)_{2}\left(\mathrm{NH}_{2} \mathrm{Ph}\right)_{2}\right](\mathbf{1})$.

Com a finalidade de verificar a estabilidade do complexo 1 em solução, alguns experimentos mediante irradiação com luz branca foram realizados.

Após a irradiação do complexo 1 por $1 \mathrm{~h}$ a TA, o espectro de $\mathrm{RMN}{ }^{31} \mathrm{P}\left\{{ }^{1} \mathrm{H}\right\}$ da solução irradiada(Figura 28) apresentou novos sinais que podem ser associados a novas espécies em solução (Figura 29).

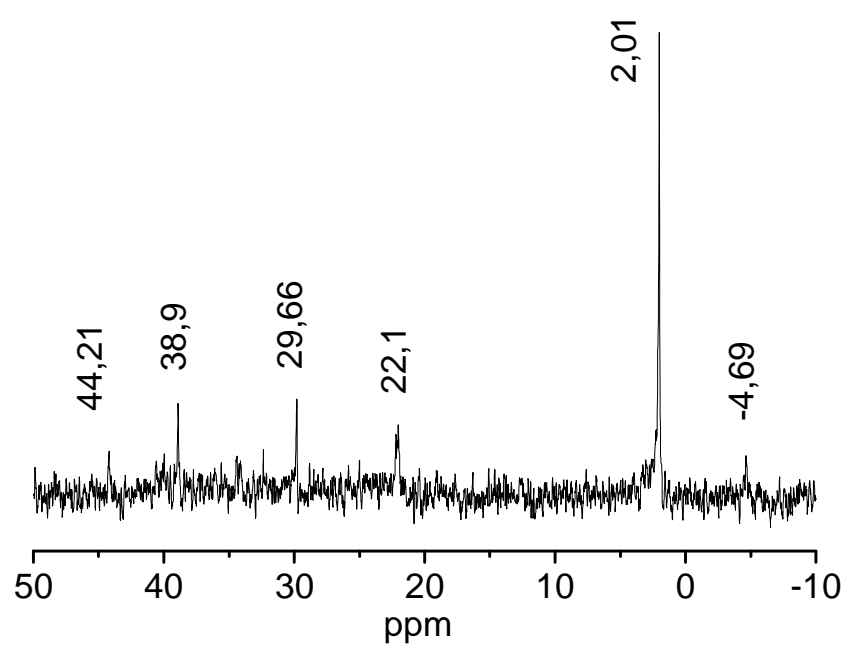

Figura 28. Espectro de $\mathrm{RMN}{ }^{31} \mathrm{P}\left\{{ }^{1} \mathrm{H}\right\}$ em $\mathrm{CDCl}_{3}$ para o complexo $\left[\mathrm{RuCl}_{2}\left(\mathrm{PPh}_{3}\right)_{2}\left(\mathrm{NH}_{2} \mathrm{Ph}\right)_{2}\right](\mathbf{1})$ após irradiação de luz branca por 60 minutos. 
O sinal em 2 ppm é associado ao complexo 1 inicial (espécie I). Os sinais em 38,9 e 44,21 ppm são atribuídos a espécies pentacoordenadas formadas pela saída de uma molécula de $\mathrm{PPh}_{3}$ e de uma molécula de $\mathrm{NH}_{2} \mathrm{Ph}$, respectivamente espécies II e III. Essas espécies apresentariam formas geométricas de pirâmide de base quadrada, que estariam associadas à descoordenação de moléculas de $\mathrm{PPh}_{3}$; nota-se a presença de sinais em -4,69 e 29,7 ppm que correspondem à $\mathrm{PPh}_{3}$ livre e $\mathrm{OPPh}_{3}$ livre, respectivamente, confirmando a descoordenação. O sinal em 22,1 ppm corresponde a espécie pentacoordenada IV, formada pela saída de uma molécula de $\mathrm{NH}_{2} \mathrm{Ph}$ em I e posterior isomerização para a geometria bipirâmide trigonal que é isômero de III.

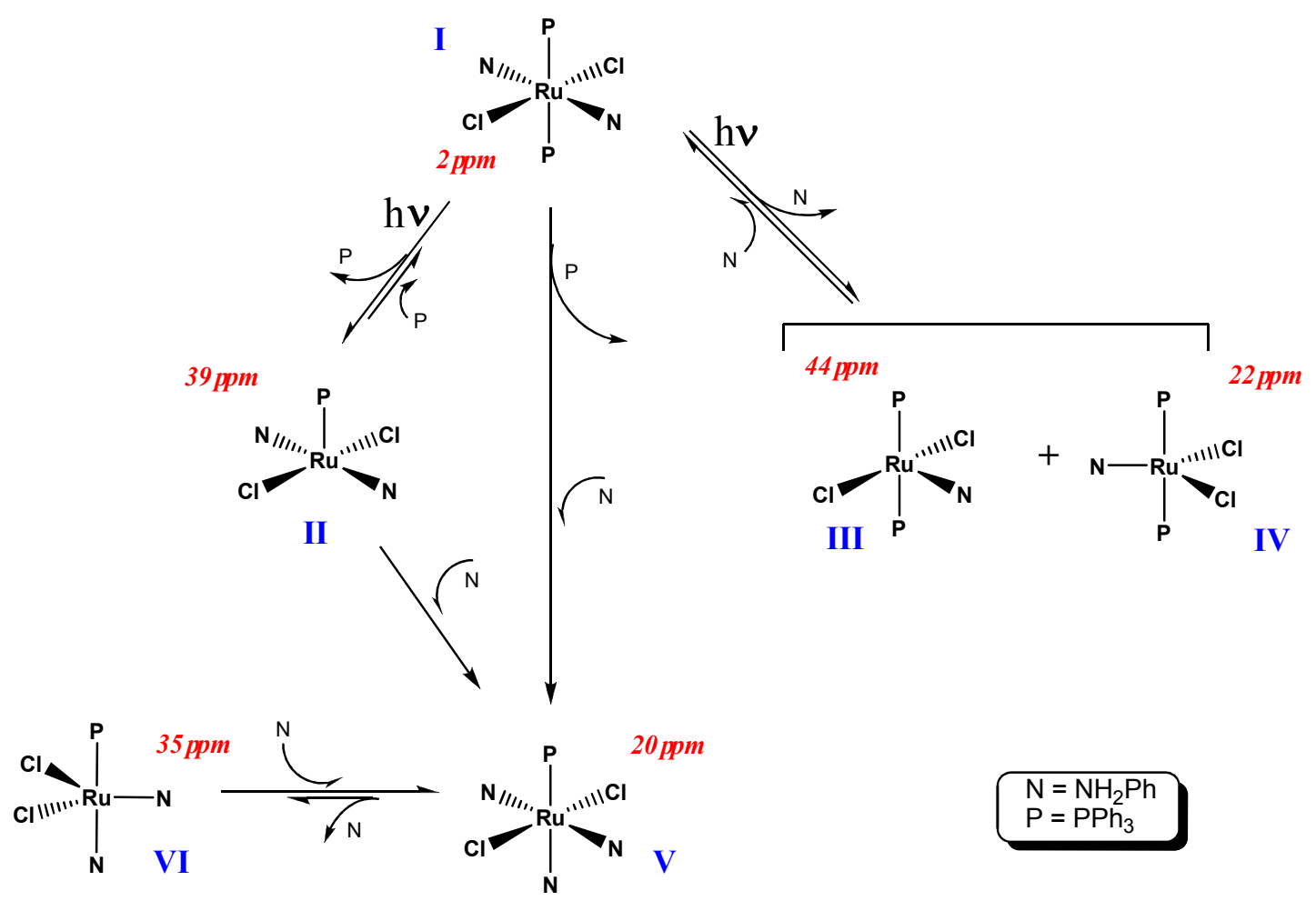

Figura 29. Proposta mecanística para o complexo $\left[\mathrm{RuCl}_{2}\left(\mathrm{PPh}_{3}\right)_{2}\left(\mathrm{NH}_{2} \mathrm{Ph}\right)_{2}\right](\mathbf{1})$ em solução e na presença de ligantes.

Com a irradiação do complexo 1 na presença de excesso de $\mathrm{NH}_{2} \mathrm{Ph}$, observa-se os seguintes sinais no espectro de $\operatorname{RMN}{ }^{31} \mathrm{P}\left\{{ }^{1} \mathrm{H}\right\}$ (Figura 30): (i) desaparecimento dos sinais em 2 
ppm (I), 38 ppm (II) e 44 ppm (III); (ii) surgimento dos sinais em 20 ppm (V) e 34 ppm (VI); e (iii) permanência do sinal em 22 ppm (IV). É esperado que II tenha se convertido em $\mathbf{V}$ pela coordenação de uma molécula de $\mathrm{NH}_{2} \mathrm{Ph}$. A espécie $\mathrm{VI}$ pode ter sido gerada através da descoordenação de uma molécula de $\mathrm{NH}_{2} \mathrm{Ph}$ da espécie $\mathbf{V}$, que se rearranja para uma bipirâmide trigonal e que III retorne para I através coordenação de uma molécula de $\mathrm{NH}_{2} \mathrm{Ph}$.

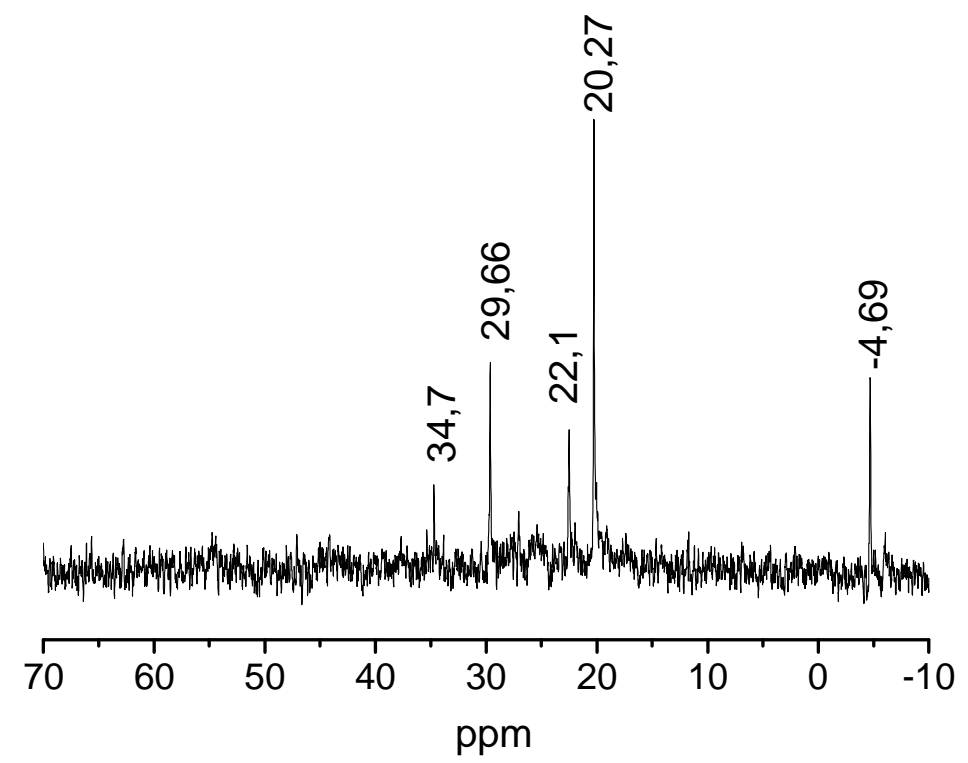

Figura 30. Espectro de $\mathrm{RMN}{ }^{31} \mathrm{P}\left\{{ }^{1} \mathrm{H}\right\}$ em $\mathrm{CDCl}_{3}$ para o complexo $\left[\mathrm{RuCl}_{2}\left(\mathrm{PPh}_{3}\right)_{2}\left(\mathrm{NH}_{2} \mathrm{Ph}\right)_{2}\right](\mathbf{1})$ após irradiação de luz branca por 60 minutos e adição de excesso de $\mathrm{NH}_{2} \mathrm{Ph}$.

Isso pode ser confirmado através da Figura 31, que mostra o espectro de RMN ${ }^{31} \mathrm{P}\left\{{ }^{1} \mathrm{H}\right\}$ para o complexo 1 na presença de excesso de amina $\left(\mathrm{NH}_{2} \mathrm{Ph}\right)$, onde podem ser vistos os mesmos sinais da Figura 31. A evidência da posterior coordenação da amina é a presença do sinal de $\mathrm{PPh}_{3}$ livre (-4,53 ppm) que confirma que ocorreu a descoordenação de $\mathrm{PPh}_{3}$. 


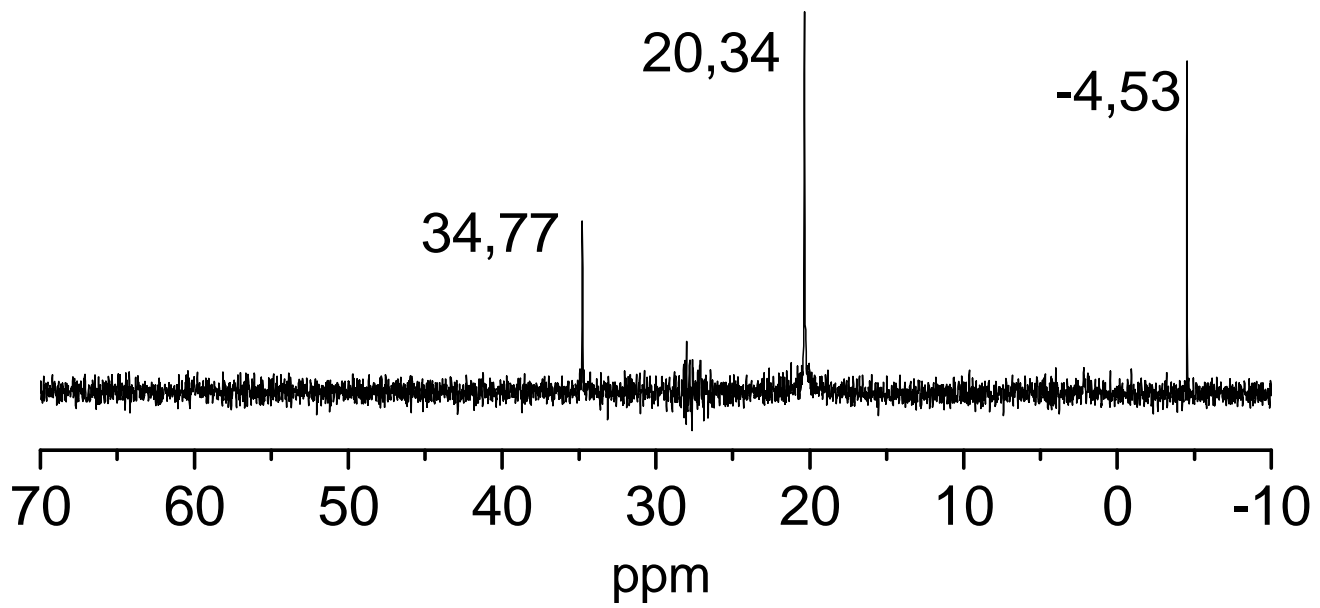

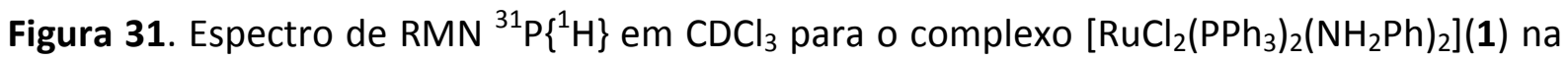
presença de $\mathrm{NH}_{2} \mathrm{Ph}$.

O espectro de $\mathrm{RMN}{ }^{31} \mathrm{P}\left\{{ }^{1} \mathrm{H}\right\}$ do complexo 2 é apresentado na (Figura 32). Para melhor visualização dos sinais o espectro é reapresentado na Figura 33 com uma escala diferente. Observam-se singletos em -4.79 e 29.83 ppm ( $\mathrm{PPh}_{3}$ e $\mathrm{OPPh}_{3}$, respectivamente), dubleto em $50.64 \mathrm{ppm}(J=28,5 \mathrm{~Hz})$, duplo dubleto em 26,14 e 40,61 ppm $(J=7,5 \mathrm{~Hz})$ e singletos em 29,64 e 40,43 ppm.

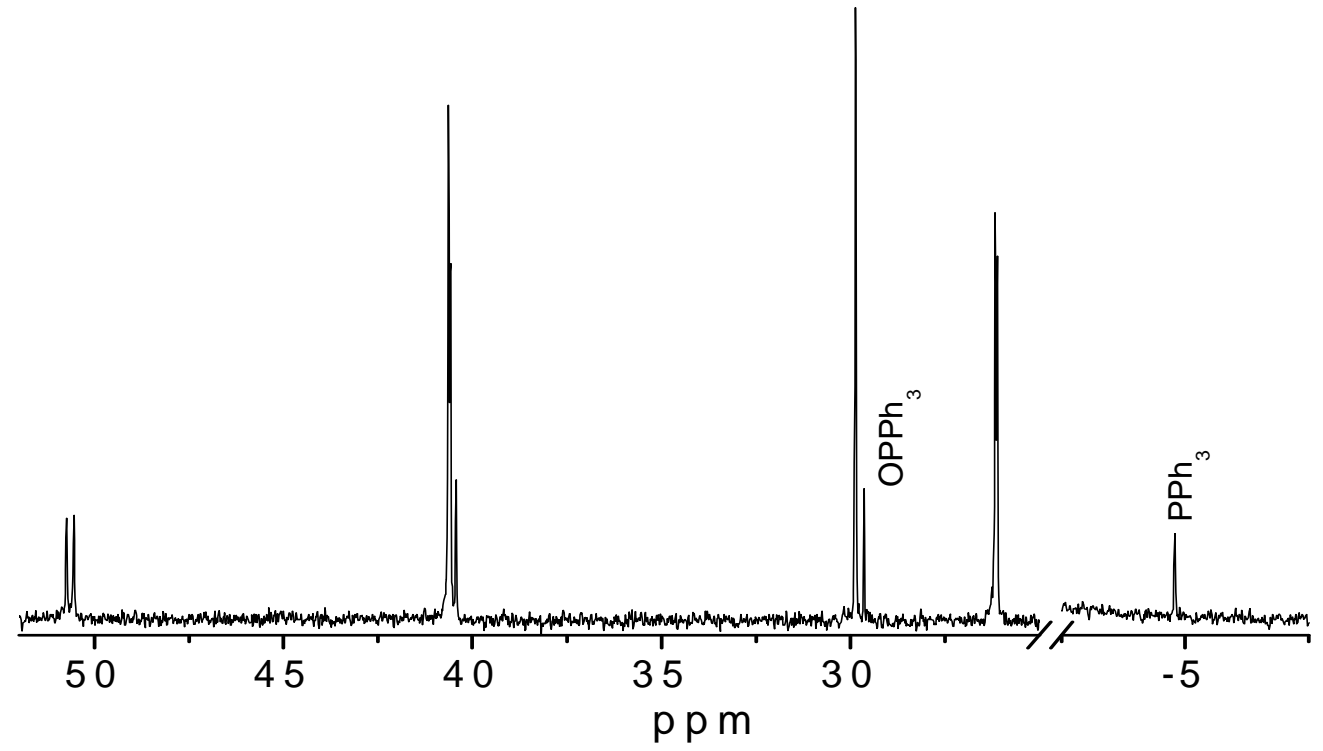

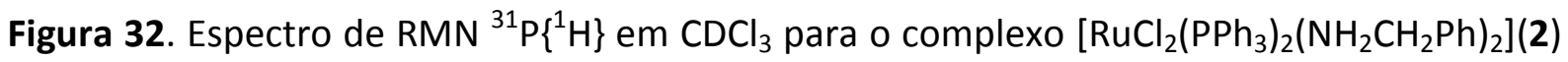
em 6 minutos. 


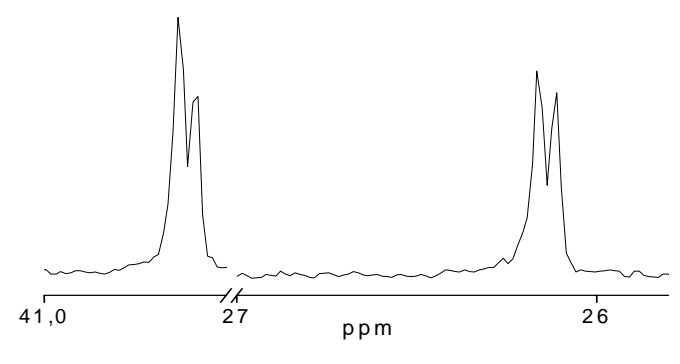

$\bar{c}$

\& $J_{\text {P-P }}=7,5 \mathrm{~Hz}$

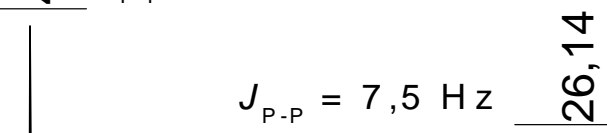

苞 $J_{\text {P-P }}=28,5 \mathrm{~Hz}$

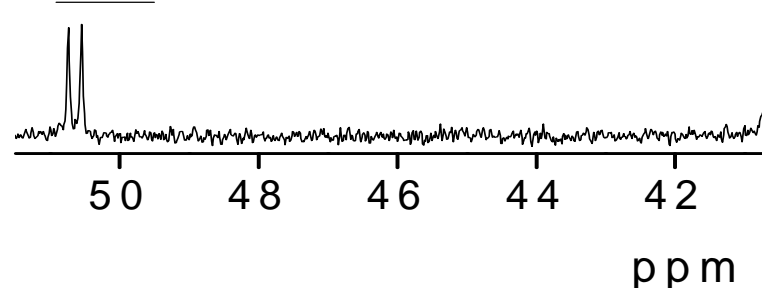

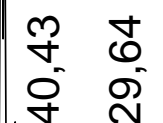
$J_{\text {P-P }}=7,5 \mathrm{~Hz} \stackrel{\mathfrak{Q}}{\underline{N}}$

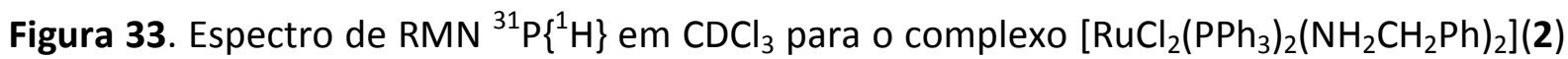
em 6 minutos. Espécies contendo metal.

Com os dados do espectro de $\mathrm{RMN}{ }^{31} \mathrm{P}\left\{{ }^{1} \mathrm{H}\right\}$ pode-se propor um comportamento do complexo 2 em solução (Figura 34).

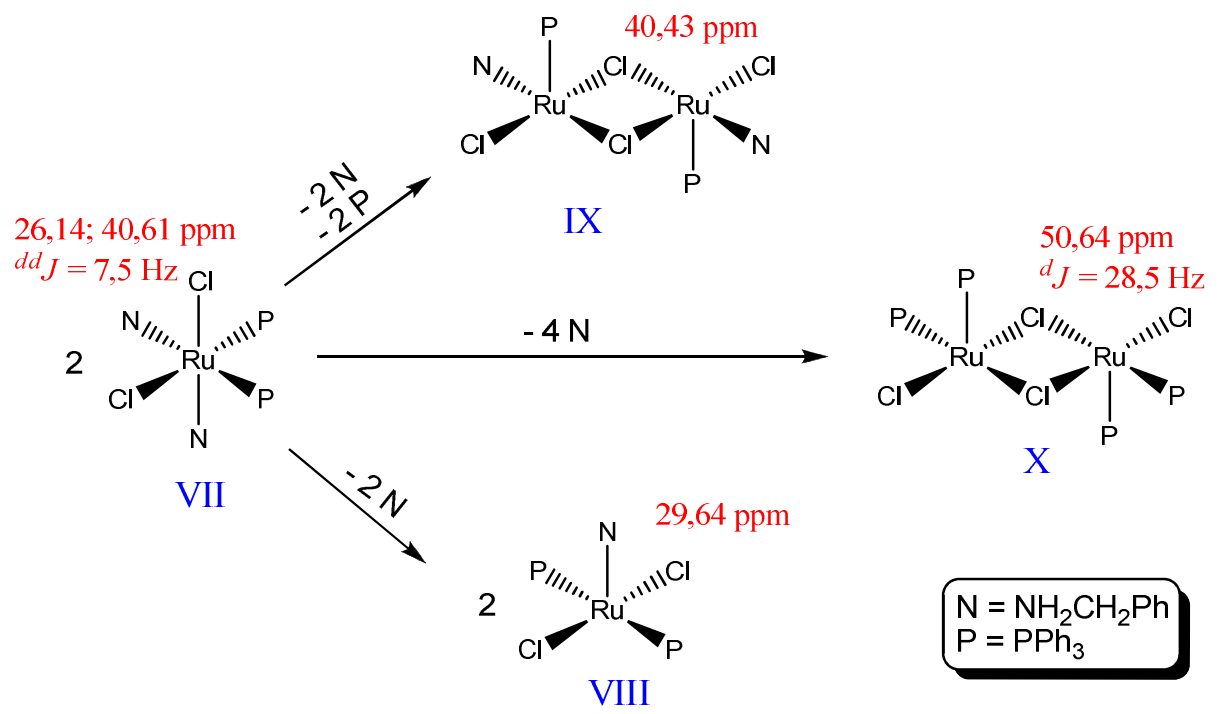

Figura 34. Proposta mecanística para o complexo $\left[\mathrm{RuCl}_{2}\left(\mathrm{PPh}_{3}\right)_{2}\left(\mathrm{NH}_{2} \mathrm{CH}_{2} \mathrm{Ph}\right)_{2}\right](2)$ em solução $^{47,49}$. 
O duplo dubleto centrado em 26,14 e 40,61 ppm $\left({ }^{d d} J=7,5 \mathrm{~Hz}\right)$ é atribuído a espécie inicial VII. O sinal em 29,86 ppm corresponde a espécie VIII com as molécula de $\mathrm{PPh}_{3}$ trans posicionadas, e é formada pela descoordenação de uma molécula de $\mathrm{NH}_{2} \mathrm{CH}_{2} \mathrm{Ph}$ da espécie VII. A espécie IX, com sinal em 40,43 ppm, é formada pela dimerização de duas espécies de VIII após a saída de uma molécula de $\mathrm{PPh}_{3}$, e a espécie $\mathbf{X}\left(50,64\right.$ ppm; $\left.{ }^{d} J=28,5 \mathrm{~Hz}\right)$ é o dímero formado por duas espécies VIII após a descoordenação de outra molécula de $\mathrm{NH}_{2} \mathrm{CH}_{2} \mathrm{Ph}$. Essa interpretação está em acordo com compostos similares descritos na literatura $^{47-49}$.

O espectro de RMN ${ }^{31} \mathrm{P}\left\{{ }^{1} \mathrm{H}\right\}$ de 2 na presença de excesso de $\mathrm{PPh}_{3}$ apresenta o mesmo perfil. Quando 2 é irradiado por 1 hora com luz branca, os mesmos sinais são observados.

Pode ser visto na Figura 35 o espectro de $\operatorname{RMN}{ }^{31} \mathrm{P}\left\{{ }^{1} \mathrm{H}\right\}$ em $\mathrm{CDCl}_{3}$ para o complexo 3 que mostra somente um sinal em $27,85 \mathrm{ppm}$ após 5 minutos a $25^{\circ} \mathrm{C}$, sugerindo que as moléculas de $\mathrm{PPh}_{3}$ estão trans-posicionadas. O espectro de $\mathrm{RMN}{ }^{31} \mathrm{P}\left\{{ }^{1} \mathrm{H}\right\}$ na presença de excesso de $\mathrm{PPh}_{3}$ não apresenta deslocamento ou mudança de sinal.

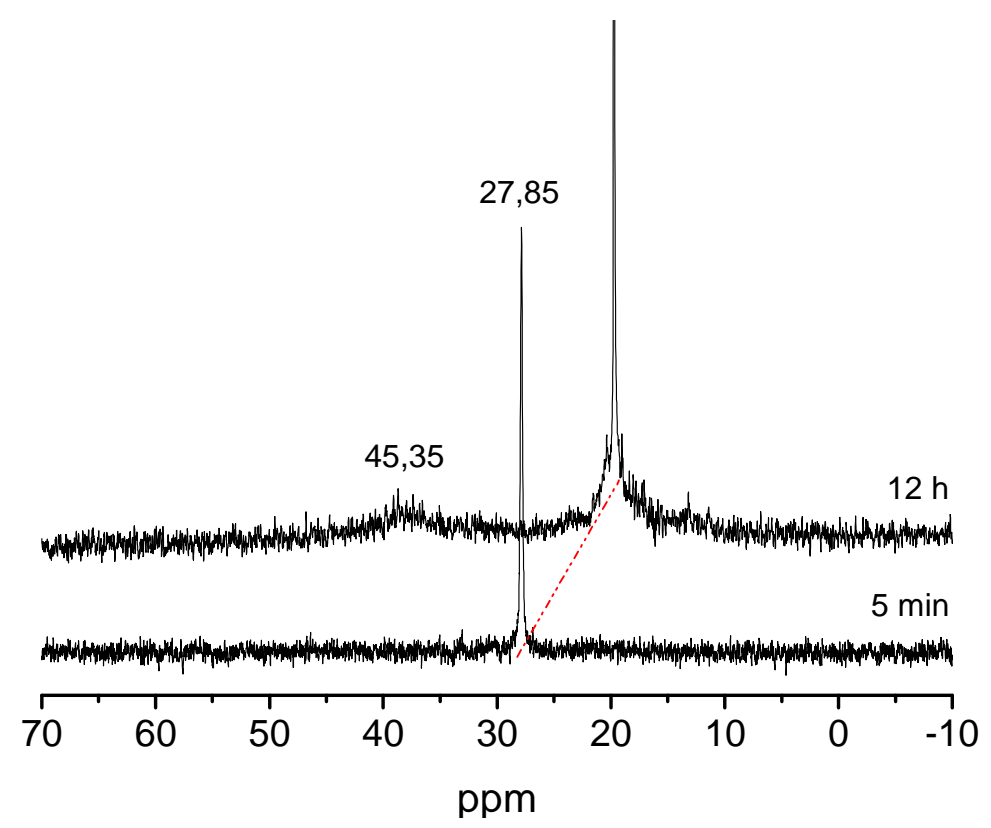

Figura 35. Espectro de $\mathrm{RMN}{ }^{31} \mathrm{P}\left\{{ }^{1} \mathrm{H}\right\}$ em $\mathrm{CDCl}_{3}$ para o complexo $\left[\mathrm{RuCl}_{2}\left(\mathrm{PPh}_{3}\right)_{2}\left(\mathrm{NH}^{\mathrm{n}} \mathrm{BuPh}\right)\right](3)$ em 5 minutos e em 12 horas. 
O espectro de $\mathrm{RMN}^{31} \mathrm{P}\left\{{ }^{1} \mathrm{H}\right\}$ em $\mathrm{CDCl}_{3}$ para o complexo 3 após mostra que o complexo permanece estável, contendo somente uma pequena parcela de outra espécie, que pode ser atribuída ao isômero estrutural na conformação bipirâmide trigonal, como pode ser visto na Figura 36.
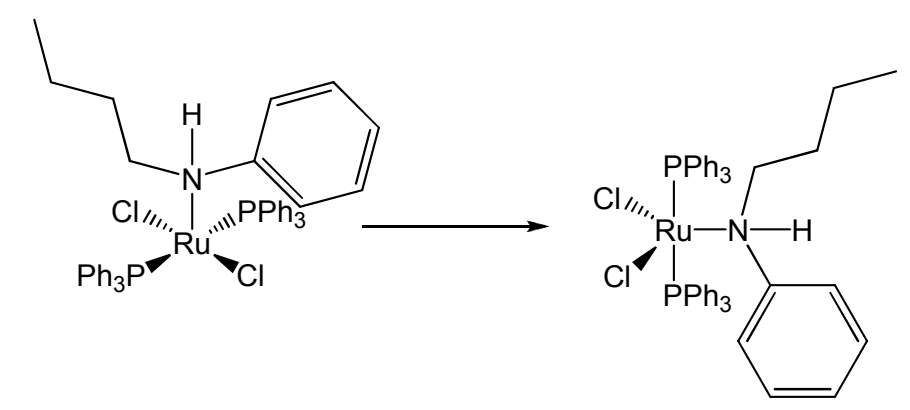

Figura 36. Isomerização para o complexo 3 de pirâmide de base quadrada em bipirâmide trigonal $^{38}$.

\subsection{Caracterização por Espectroscopia Eletrônica na Região do Uv-Vis}

Os experimentos foram realizados para verificar o comportamento dos complexos em solução. As medidas espectrofotométricas foram comparadas com a dos espectros de $R M N{ }^{31} \mathrm{P}\left\{{ }^{1} \mathrm{H}\right\}$. Em todos os casos a temperatura foi mantida constante a $25^{\circ} \mathrm{C}$ ou $50^{\circ} \mathrm{C}$.

Essas informações são importantes para um entendimento melhor das propriedades catalíticas dos complexos quando analisando a reatividade dos mesmos nas reações de ROMP.

Possivelmente mudanças nos espectros eletrônicos em função do tempo podem estar associadas às reorganizações geométricas na esfera de coordenação, reações de substituição ou dissociação de ligantes. 
O complexo 1 mostra ser um complexo estável em solução de $\mathrm{CHCl}_{3}$, como pode ser visto na Figura 37. Essa informação vem de encontro com a informação obtida do espectro de $\operatorname{RMN}{ }^{31} \mathrm{P}\left\{{ }^{1} \mathrm{H}\right\}$ do complexo 1 na mesma condição (Figura 27), onde por 12 horas não observou variação no espectro.

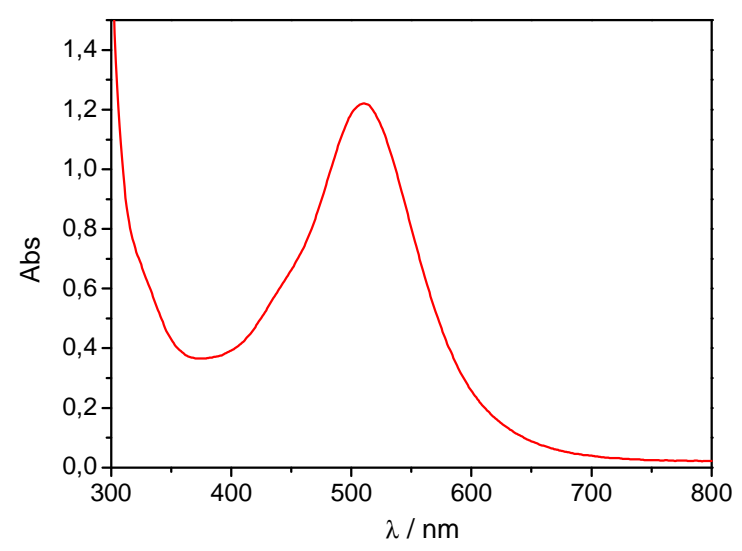

Figura 37. Espectro de UV-vis em $\mathrm{CHCl}_{3}$ para o complexo $\left[\mathrm{RuCl}_{2}\left(\mathrm{PPh}_{3}\right)_{2}\left(\mathrm{NH}_{2} \mathrm{Ph}\right)_{2}\right](\mathbf{1})$. $\mathrm{O}$ complexo não apresenta variação espectral por 12 horas. $\mathrm{Ru}^{\prime \prime}=10^{-4} \mathrm{~mol} . \mathrm{L}^{-1}$ à $25^{\circ} \mathrm{C}$.

Após a irradiação com luz branca por 30 minutos à TA, observou-se variação no espectro eletrônico de 1 (Figura 38). Os dados corroboram com os dados de $\mathrm{RMN}{ }^{31} \mathrm{P}\left\{{ }^{1} \mathrm{H}\right\}$ para o complexo 1 como visto na Figura 28.

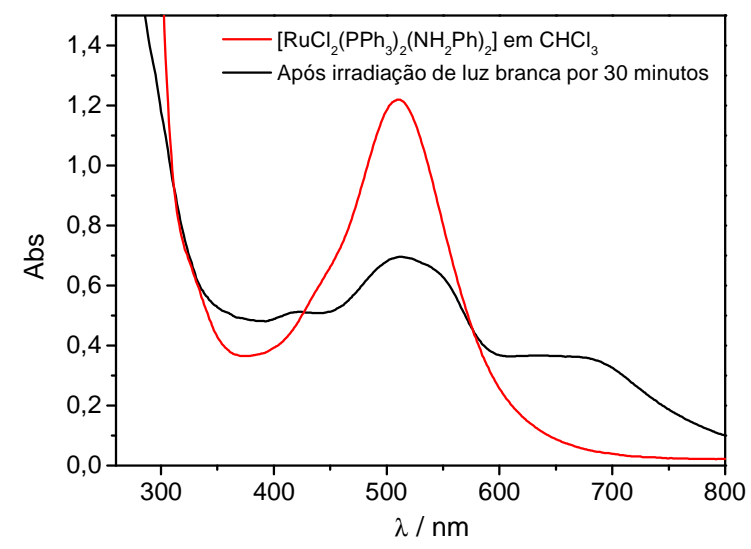

Figura 38. Espectro de UV-vis em $\mathrm{CHCl}_{3}$ para o complexo $\left[\mathrm{RuCl}_{2}\left(\mathrm{PPh}_{3}\right)_{2}\left(\mathrm{NH}_{2} \mathrm{Ph}\right)_{2}\right](\mathbf{1})$ após 30 minutos de irradiação. $\mathrm{Ru}^{\prime \prime}=10^{-4} \mathrm{~mol} . \mathrm{L}^{-1}$ à $25^{\circ} \mathrm{C}$. 
Após a irradiação por 30 minutos foi adicionado um excesso de $\mathrm{NH}_{2} \mathrm{Ph}$ ocorrendo a regeneração da banda em 510 nm (Figura 39). Uma informação importante que se pode tirar desse espectro eletrônico é que a banda em $510 \mathrm{~nm}$ tinha sido suprimida quando a solução sofreu irradiação com luz branca. Entretanto, a absorção entre 600 e 700 nm permanece com deslocamento para o azul.

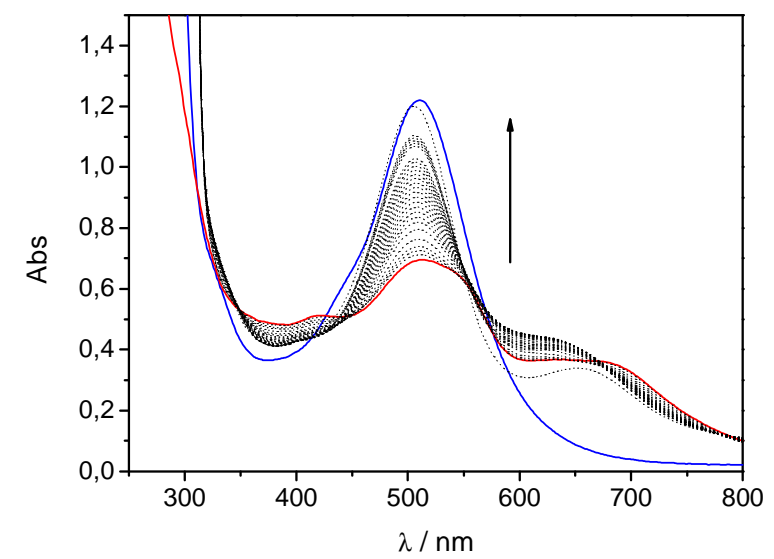

Figura 39. Espectro de UV-vis em $\mathrm{CHCl}_{3}$ para o complexo $\left[\mathrm{RuCl}_{2}\left(\mathrm{PPh}_{3}\right)_{2}\left(\mathrm{NH}_{2} \mathrm{Ph}\right)_{2}\right](\mathbf{1})$ após 30 minutos de irradiação e posterior adição de $\mathrm{NH}_{2} \mathrm{Ph}$. A linha azul é correspondente ao espectro inicial da solução pura; linha vermelha é correspondente ao espectro após irradiação e as linhas pretas pontilhadas são correspondentes a evolução espectral após adição de excesso de $\mathrm{NH}_{2} \mathrm{Ph}$. $\mathrm{Ru}^{\prime \prime}=10^{-4}$ mol. $\mathrm{L}^{-1}$ à $25^{\circ} \mathrm{C}$.

O espectro do complexo 1 na presença de monômero NBD (100 vezes), o qual apresenta duas duplas ligações e pode-se coordenar duplamente ao complexo para formar um novo complexo estável frente as reações de ROMP. O espectro do complexo 1 não apresentou variação por até 60 minutos (Figura 40). Isso demonstrando o caráter estável desse complexo. 


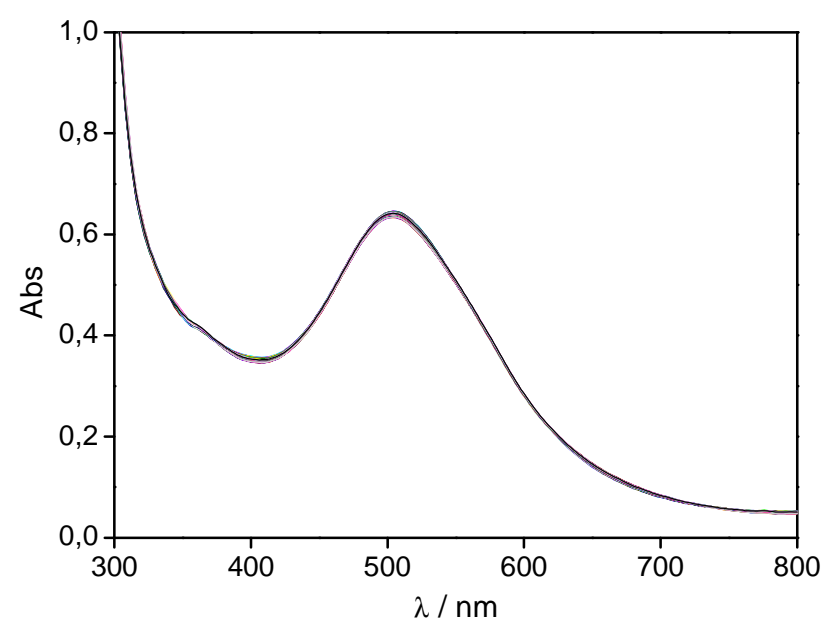

Figura 40. Espectro de UV-vis em $\mathrm{CHCl}_{3}$ para o complexo $\left[\mathrm{RuCl}_{2}\left(\mathrm{PPh}_{3}\right)_{2}\left(\mathrm{NH}_{2} \mathrm{Ph}\right)_{2}\right](\mathbf{1})$ na presença de NBD por 60 minutos. $\mathrm{Ru}^{\prime \prime}=10^{-4} \mathrm{~mol}^{-L^{-1}}$ à $25^{\circ} \mathrm{C}$.

O complexo 2 apresenta variação espectral no uv-vis como por de ser visto na Figura $41 \mathrm{a}$, a $25^{\circ} \mathrm{C}$, e também na Figura $41 \mathrm{~b}$, a $50^{\circ} \mathrm{C}$. Concluiu-se que a temperatura favorece a dinâmica do complexo em solução, caracterizando que o complexo é lábil. Isso pode resultar em uma maior eficiência catalítica frente às reações de ROMP.
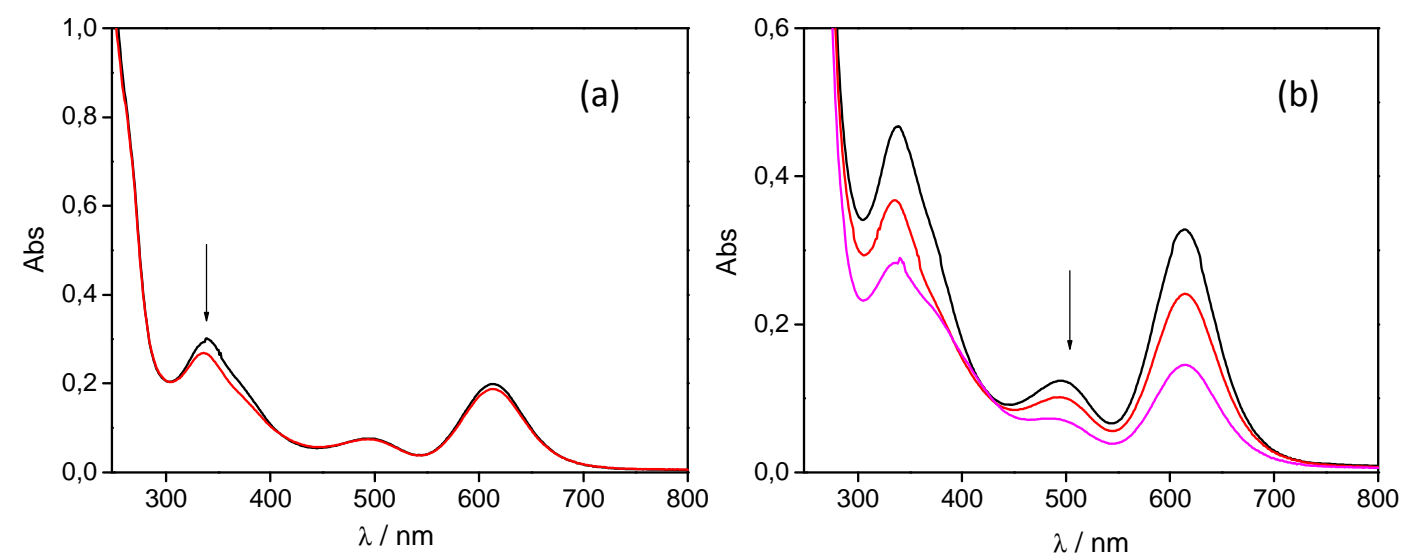

Figura 41. Espectro de UV-vis em $\mathrm{CHCl}_{3}$ para o complexo $\left[\mathrm{RuCl}_{2}\left(\mathrm{PPh}_{3}\right)_{2}\left(\mathrm{NH}_{2} \mathrm{CH}_{2} \mathrm{Ph}\right)_{2}\right](2)$ a $25^{\circ} \mathrm{C}$ (a) e $50^{\circ} \mathrm{C}$ (b) após 60 minutos. Ru" $=10^{-4} \mathrm{~mol}^{\prime-1}$.

Experimentos com irradiação de luz branca para o complexo 2, levou a mudanças espectrais similares as que ocorrem em função da temperatura (Figura 42a). Assim a 
irradiação também favorece a dinâmica do complexo em solução, o que pode repercutir nos experimentos de ROMP.

No experimento na presença de EDA, o espectro eletrônico de 2 (Figura 42b) mostrou rápida mundança, podendo assim influenciar nas etapas de iniciação e propagação da ROMP.
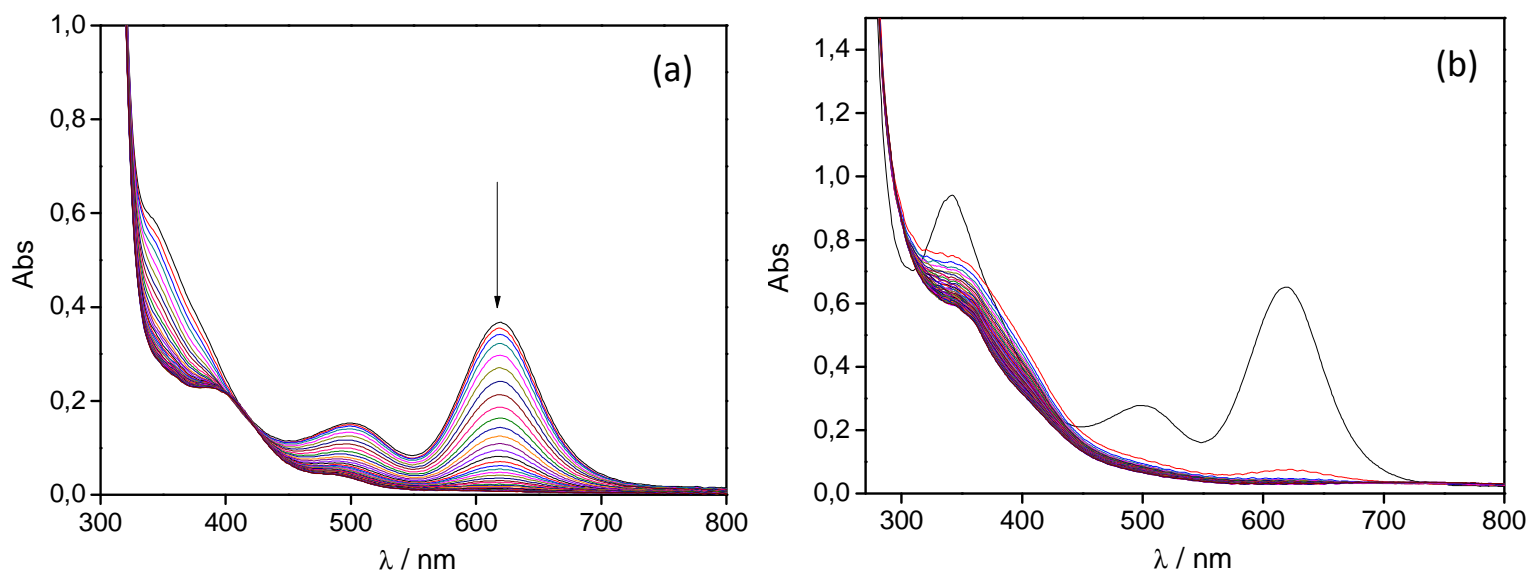

Figura 42. Espectro de UV-vis em $\mathrm{CHCl}_{3}$ para o complexo $\left[\mathrm{RuCl}_{2}\left(\mathrm{PPh}_{3}\right)_{2}\left(\mathrm{NH}_{2} \mathrm{CH}_{2} \mathrm{Ph}\right)_{2}\right](2)$ a $25^{\circ} \mathrm{C}$ por 60 minutos na presença de luz branca (a) e na presença de $\operatorname{EDA}(\mathrm{b}) . \mathrm{Ru}^{\prime \prime}=10^{-4} \mathrm{~mol}^{-\mathrm{L}^{-1}}$.

Os espectros vistos nas Figuras Figura 43a e Figura 43b, representam mudança no complexo 2 na presença de $\mathrm{PPh}_{3}$ a $25^{\circ} \mathrm{C}$ e $50^{\circ} \mathrm{C}$ respectivamente. Pode-se ver que a presença de $\mathrm{PPh}_{3}$ não inibe a evolução espectral da solução pura, isso é ainda mais evidente a $50^{\circ} \mathrm{C}$. A interpretação é que ocorra de descoordenação uma molécula de benzilamina, já que o excesso de $\mathrm{PPh}_{3}$ não suprimiu a descoordenação. 

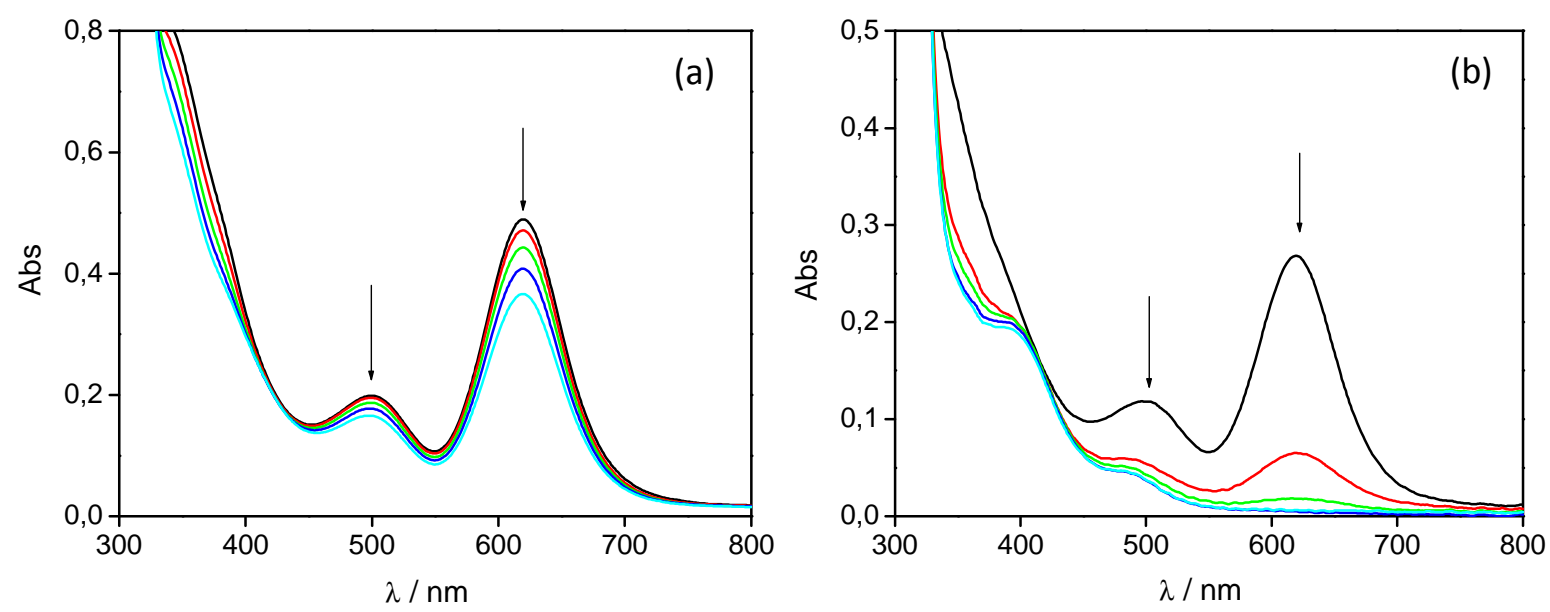

Figura 43. Espectro de UV-vis em $\mathrm{CHCl}_{3}$ para o complexo $\left[\mathrm{RuCl}_{2}\left(\mathrm{PPh}_{3}\right)_{2}\left(\mathrm{NH}_{2} \mathrm{CH}_{2} \mathrm{Ph}\right)_{2}\right](2)$ por 60 minutos na presença de 20 vezes de excesso de $\mathrm{PPh}_{3}$ a $25^{\circ} \mathrm{C}$ (a) e a $50^{\circ} \mathrm{C}(\mathrm{b}) \cdot \mathrm{Ru}^{\prime \prime}=10^{-4}$ mol. $\mathrm{L}^{-1}$.

Para as análises utilizando excesso de $\mathrm{NH}_{2} \mathrm{CH}_{2} \mathrm{Ph}$, foi adicionado à solução um excesso de 20 vezes de ligante amina. Foram feitos os experimentos a $25^{\circ} \mathrm{C}$ e $50^{\circ} \mathrm{C}$ e foi observado que não ocorre alteração espectral. Assim, corroborando com os dados das Figuras Figura 43a e 43b, onde foi proposto que o ligante amina é descoordenado antes da descoordenação de $\mathrm{PPh}_{3}$ (Figura 44).
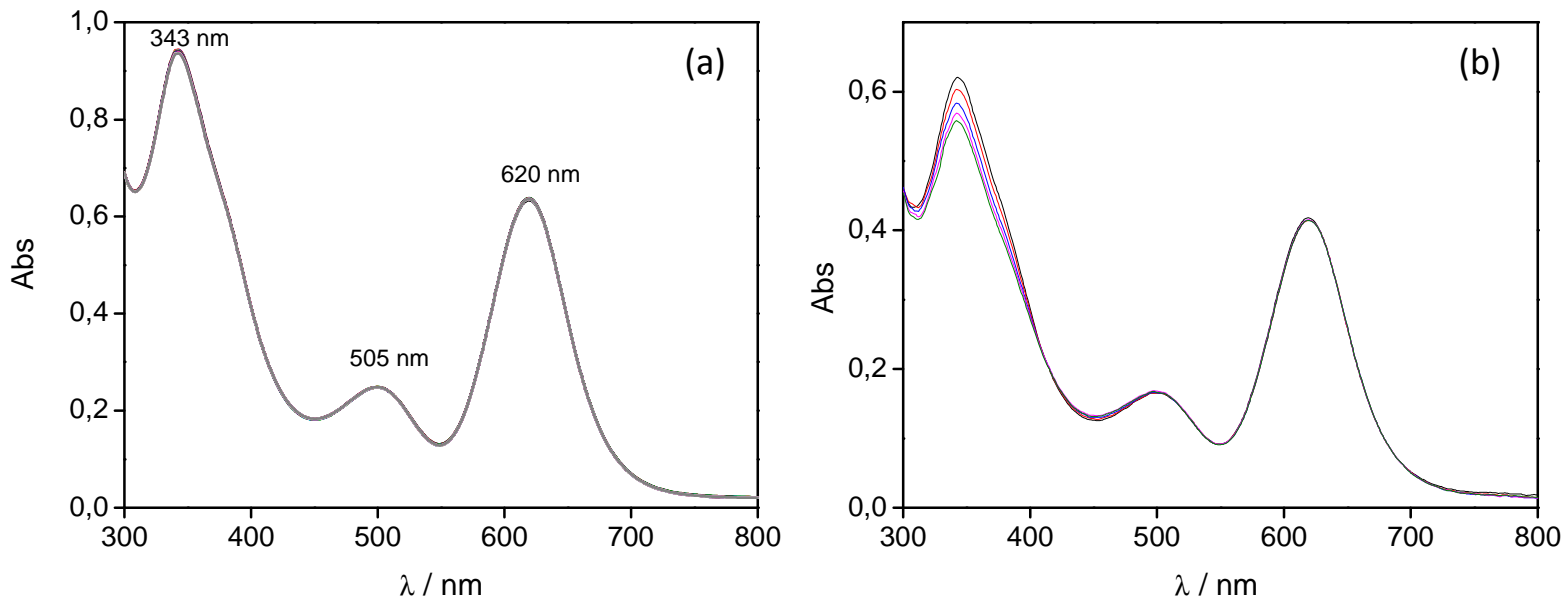

Figura 44. Espectro de UV-vis em $\mathrm{CHCl}_{3}$ para o complexo $\left[\mathrm{RuCl} 2\left(\mathrm{PPh}_{3}\right)_{2}\left(\mathrm{NH}_{2} \mathrm{CH}_{2} \mathrm{Ph}\right)_{2}\right](2)$ por 60 minutos na presença de 20 vezes de excesso de $\mathrm{NH}_{2} \mathrm{CH}_{2} \mathrm{Ph}$ a $25^{\circ} \mathrm{C}$ (a) e a $50^{\circ} \mathrm{C}$ (b). $\mathrm{Ru}^{\prime \prime}=$ $10^{-4}$ mol. $L^{-1}$. 
O espectro eletrônico do complexo 3 é apresentado, e ele não apresenta variação em relação ao tempo (Figura 45), dessa forma não ocorre descoordenação de ligantes ou reorganização de moléculas.

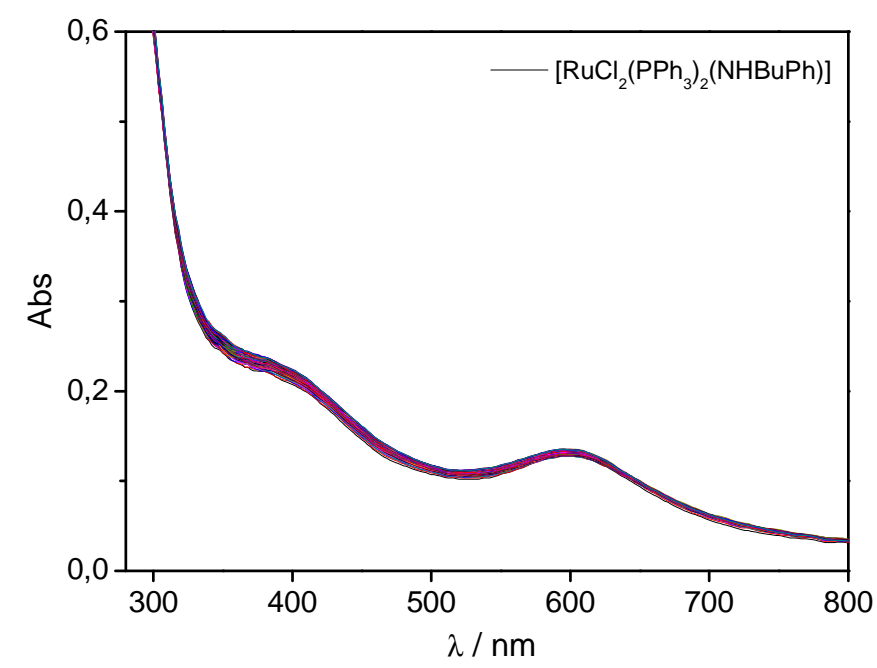

Figura 45. Espectro de UV-vis em $\mathrm{CHCl}_{3}$ para o complexo $\left[\mathrm{RuCl}_{2}\left(\mathrm{PPh}_{3}\right)_{2}\left(\mathrm{NH}^{\mathrm{n}} \mathrm{BuPh}\right)\right](3)$ por 60 minutos a $25^{\circ} \mathrm{C} \cdot \mathrm{Ru} \mathrm{u}^{\prime \prime}=10^{-4} \mathrm{~mol} \cdot \mathrm{L}^{-1}$.

\subsection{Caracterização por Voltametria Cíclica dos complexos}

O voltamograma para o complexo 1 é mostrado na Figura 46. O complexo apresenta um par redox irreversível com pico anódico em $+0,7254 \mathrm{~V}$ e pico catódico em $+0,5754 \mathrm{~V}$. Não é visto nenhum outro processo redox na amostra. 


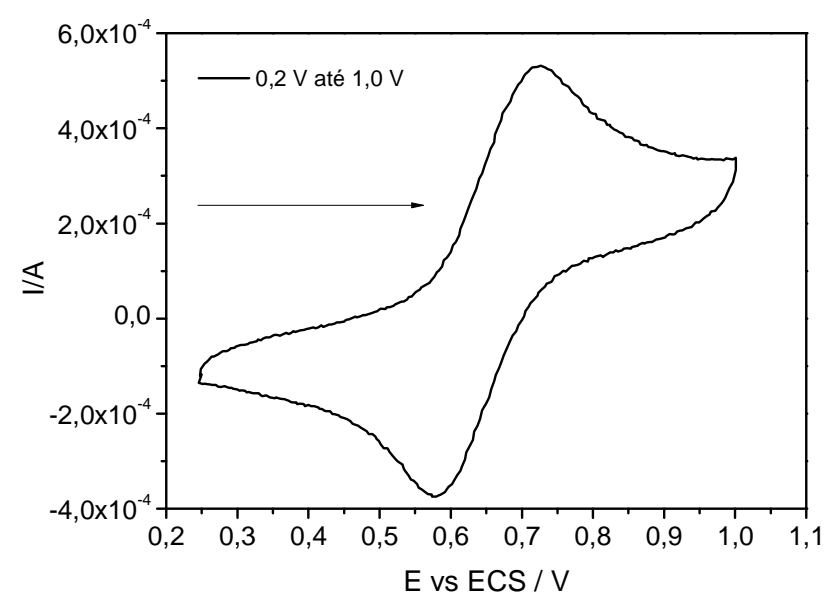

Figura 46. Voltamograma para o complexo $\left[\mathrm{RuCl}_{2}\left(\mathrm{PPh}_{3}\right)_{2}\left(\mathrm{NH}_{2} \mathrm{Ph}\right)_{2}\right](1)$ em $\mathrm{CHCl}_{2}$ a TA. Velocidade de varredura: $200 \mathrm{mV} / \mathrm{s}$.

Para o complexo 2, é observado dois picos anódicos $(+0,71 \mathrm{Ve}+0,85 \mathrm{~V})$ e dois picos catódicos ( + 0,31 V e 0,60 V), como mostra a Figura 47. Uma dos picos pode ser proveniente da descoordenação de uma molécula de benzilamina, onde o complexo apresentaria valores de potencial maiores $(+0,85 \mathrm{~V})$, tendo em vista a descoordenação de uma amina básica ( $\mathrm{pK}_{\mathrm{a}}$ : 9,33). Isso diminui a densidade eletrônica centrada no Ru". A estabilidade do complexo 1 frente ao complexo 2, pode ser vista também pelos espectros de $\mathrm{RMN}{ }^{31} \mathrm{P}\left\{{ }^{1} \mathrm{H}\right\}$ e nos espectros de UV-vis.

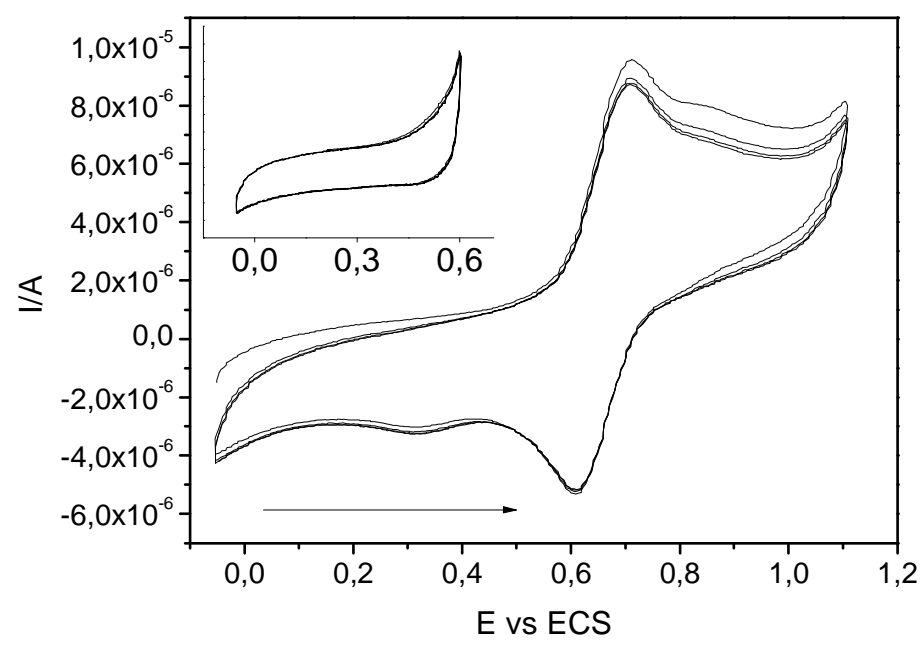

Figura 47. Voltamograma para o complexo $\left[\mathrm{RuCl}_{2}\left(\mathrm{PPh}_{3}\right)_{2}\left(\mathrm{NH}_{2} \mathrm{CH}_{2} \mathrm{Ph}\right)_{2}\right](2)$ em $\mathrm{CHCl}_{2}$ a TA. Velocidade de varredura: $200 \mathrm{mV} / \mathrm{s}$. 
O processo catódico em + 0,3 V está associado a processos anódicos uma vez que não é observado quando o ciclo é entre 0,0 V e + 0,6 V.

No caso para o complexo 3 é observado um pico anódico em $+0,90$ V sendo atribuído a oxidação da espécie inicial que diminui a cada ciclo. Outros picos anódicos e catódicos abaixo de $0,75 \vee$ não estão bem definidos (Figura 48). Os estudos por voltametria estão em continuidade.

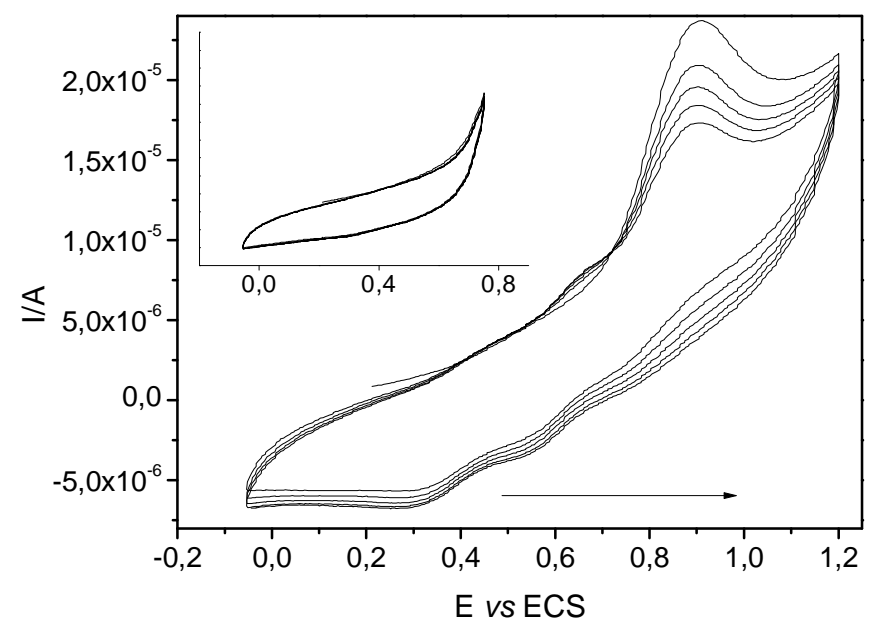

Figura 48. Voltamograma para o complexo $\left[\mathrm{RuCl}_{2}\left(\mathrm{PPh}_{3}\right)_{2}\left(\mathrm{NH}^{\mathrm{n}} \mathrm{BuPh}\right)\right](3)$ em $\mathrm{CHCl}_{2}$ a TA. Velocidade de varredura: $200 \mathrm{mV} / \mathrm{s}$.

4.6. Atividade dos complexos $\left[\mathrm{RuCl}_{2}\left(\mathrm{PPh}_{3}\right)_{2}\left(\mathrm{NH}_{2} \mathrm{Ph}\right)_{2}\right], \quad\left[\mathrm{RuCl}_{2}\left(\mathrm{PPh}_{3}\right)_{2}\left(\mathrm{NH}_{2} \mathrm{Bz}\right)_{2}\right]$ e $\left[\mathrm{RuCl}_{2}\left(\mathrm{PPh}_{3}\right)(\mathrm{NHBuPh})\right.$ na ROMP de NBE, NBD e DCPD

\subsubsection{Variação do volume de EDA}


Considerando a estabilidade do complexo 1 em solução segundo os espectros eletrônicos e de $\mathrm{RMN}{ }^{31} \mathrm{P}\left\{{ }^{1} \mathrm{H}\right\}$, verificou-se inicialmente o comportamento desse complexo quando na presença de EDA. Os espectros em função do tempo (20 minutos) mostram que ocorre reação com $t_{1 / 2}=162 \mathrm{~s}$ (Figura 50 ), logo esse complexo pode ser ativo em ROMP.

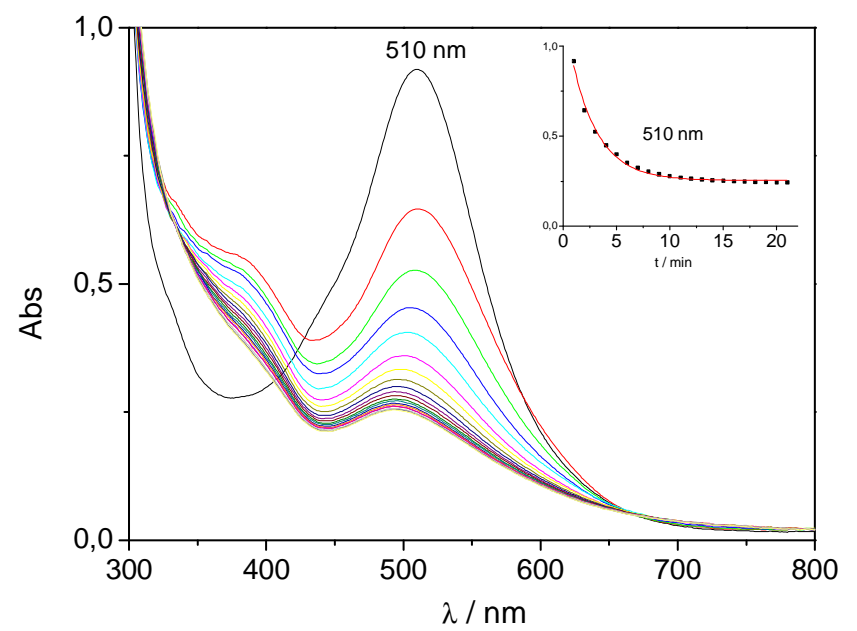

Figura 49. Evolução espectral por 20 minutos na região do UV-vis do complexo $\left[\mathrm{RuCl}_{2}\left(\mathrm{PPh}_{3}\right)_{2}\left(\mathrm{NH}_{2} \mathrm{Ph}\right)_{2}\right]$ em $\mathrm{CHCl}_{3}[\mathrm{Ru}]=1,0 \times 10^{-4} \mathrm{~mol} . \mathrm{L}^{-1}, \mathrm{~T} . \mathrm{A}$.

Foram realizados experimentos variando o volume de EDA em solução do complexo $\left[\mathrm{RuCl}_{2}\left(\mathrm{PPh}_{3}\right)_{2}\left(\mathrm{NH}_{2} \mathrm{Ph}\right)_{2}\right](\mathbf{1})$, a melhor condição será aplicada aos complexos subseqüentes. Os volumes de EDA utilizados nos experimentos de polimerização foram $3 \mu \mathrm{L}, 5 \mu \mathrm{L}, 7 \mu \mathrm{L}$ e 10 $\mu \mathrm{L}$, à $25^{\circ} \mathrm{C}$ com norborneno em reações por 5 minutos.. Os dados são apresentados na Tabela 6.

Tabela 6 - Dependência do rendimento, $M_{w}$ e IPD em relação ao volume de EDA, para a ROMP de NBE com $\left[\mathrm{RuCl}_{2}\left(\mathrm{PPh}_{3}\right)_{2}\left(\mathrm{NH}_{2} \mathrm{Ph}\right)_{2}\right] ;[\mathrm{NBE}] /[\mathrm{Ru}]=5000 ;[\mathrm{Ru}]=1 \mu \mathrm{mol}$ em $2 \mathrm{~mL}$ de $\mathrm{CHCl}_{3}$ à $25^{\circ} \mathrm{C}$ por 5 minutos.

\begin{tabular}{cccc} 
EDA $(\boldsymbol{\mu L})$ & Rendimento $(\mathbf{\%})$ & $\mathbf{M}_{\mathbf{w}}\left(\mathbf{1 0 ^ { 4 }}\right)$ & IPD \\
\hline $\mathbf{3}$ & 21 & 9,5 & $\mathbf{2 , 3 6}$ \\
\hline $\mathbf{5}$ & 42 & 4,4 & 2,08 \\
\hline $\mathbf{7}$ & 22 & 6,5 & 2,16 \\
\hline $\mathbf{1 0}$ & 24 & 7,0 & 2,47
\end{tabular}


Deve ser observado que a massa molécula ponderal média $\left(M_{w}\right)$ foi na ordem de $10^{4}$ em todos os casos, com valores de IPD entre 2,0 e 2,5. Assim como os valores de rendimento não são bons comparados à outros complexos do tipo $\left[\mathrm{RuCl}_{2}\left(\mathrm{PPh}_{3}\right)_{3}(\mathrm{amina})\right]^{\text {ref }}$, os valores de IPD também não são bons. Isso implica em modificar as condições de reação em diferentes tempos e temperaturas, para observar possíveis melhoras nos resultados.

É observado um acréscimo no rendimento de $3 \mu \mathrm{L}$ para $5 \mu \mathrm{L}$, seguido de um decréscimo de $5 \mu \mathrm{L}$ para $7 \mu \mathrm{L}$, até estabilização em $10 \mu \mathrm{L}$.

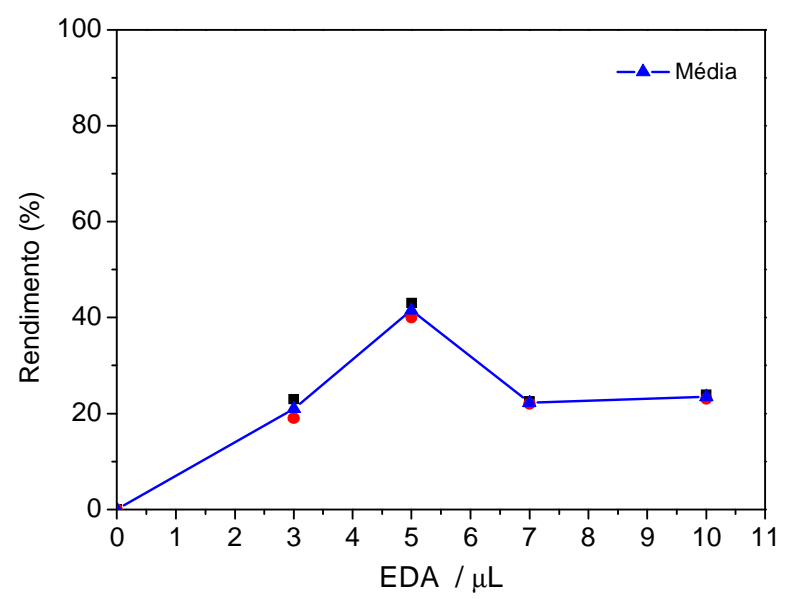

Figura 50. Dependência do rendimento em relação ao volume de EDA, para a ROMP de NBE com $\left[\mathrm{RuCl}_{2}\left(\mathrm{PPh}_{3}\right)_{2}\left(\mathrm{NH}_{2} \mathrm{Ph}\right)_{2}\right] ;[\mathrm{NBE}] /[\mathrm{Ru}]=5000 ;[\mathrm{Ru}]=1 \mu \mathrm{mol}$ em $2 \mathrm{~mL}$ de $\mathrm{CHCl}_{3}$ à $25^{\circ} \mathrm{C}$ por 5 minutos.

Uma possível explicação para o fato da curva de rendimento em função da variação de volume de EDA não ser uma reta contínua, pode ser devido a ocorrência de reações concomitantes com ao aumento da concentração de EDA. Como ilustrado na Figura 51. 
<smiles>CCOC=NC=[N+]=[N-]</smiles>

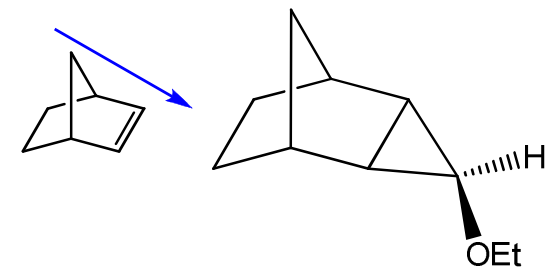

Figura 51. Reações concorrentes provenientes da formação da espécie carbeno em solução.

Pode ocorrer reação de ciclopropanação, entre o carbeno e o monômero norborneno ou a formação de ilidas de fósforo ${ }^{50}$. Ainda, pode ocorrer competição entre o excesso de EDA e monômero pela coordenação no centro metálico, tal como pode ser ilustrado na Figura 52.
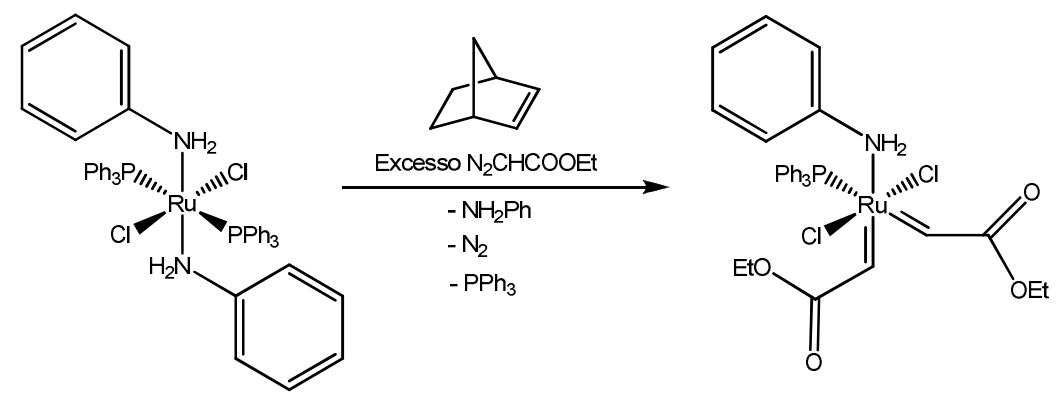

Figura 52. Competição entre olefina e EDA pelo centro metálico na presença de excesso de EDA.

Desses estudos, serão utilizados $5 \mu \mathrm{L}$ de EDA. Outros trabalhos feitos em nosso grupo de pesquisa com complexos semelhantes, tal como para $\left[\mathrm{RuCl}_{2}\left(\mathrm{PPh}_{3}\right)_{2}\right.$ (piperidina) $]$ e $\left[\mathrm{RuCl}_{2}\left(\mathrm{PPh}_{3}\right)_{2}(\text { sec-butilamina })_{2}\right]$, onde a melhor condição de polimerização é a utilização de 5 $\mu \mathrm{L}$ de $\mathrm{EDA}^{41}$. 


\subsubsection{Variação da temperatura}

Experimentos de ROMP de NBE com os três complexos foram realizados a $25^{\circ} \mathrm{C}$ e $50^{\circ} \mathrm{C}$ (Tabela 7). Os resultados são também apresentados na Figura 53 na forma de gráfico. Os experimentos com $\mathbf{1}$ e $\mathbf{2}$ a 5 minutos mostram aumento do rendimento com o aumento da temperatura de $25^{\circ} \mathrm{C}$ para $50^{\circ} \mathrm{C}$. Observou-se um aumento de $M_{w}$ de $4,4 \times 10^{4} \mathrm{~g} / \mathrm{mol}$ para $1,7 \times 10^{5} \mathrm{~g} / \mathrm{mol}$ para 1 , que está associado ao aumento do rendimento dado um maior consumo de monômero, no entanto o valor de IPD aumento muito. Para 2, o valor de IPD teve melhora expressiva de 3,02 para 1,67 com o aumento da temperatura, com aumento significativo no rendimento, isto é, triplicou. Já o valor de $M_{w}$ não varia expressivamente, indicando que, diferentemente do complexo 1, o aumento da temperatura favorece a formação de um número maior de espécies ativas, o que melhora o rendimento e o IPD, mas não necessariamente melhora o valor de $M_{w}$.

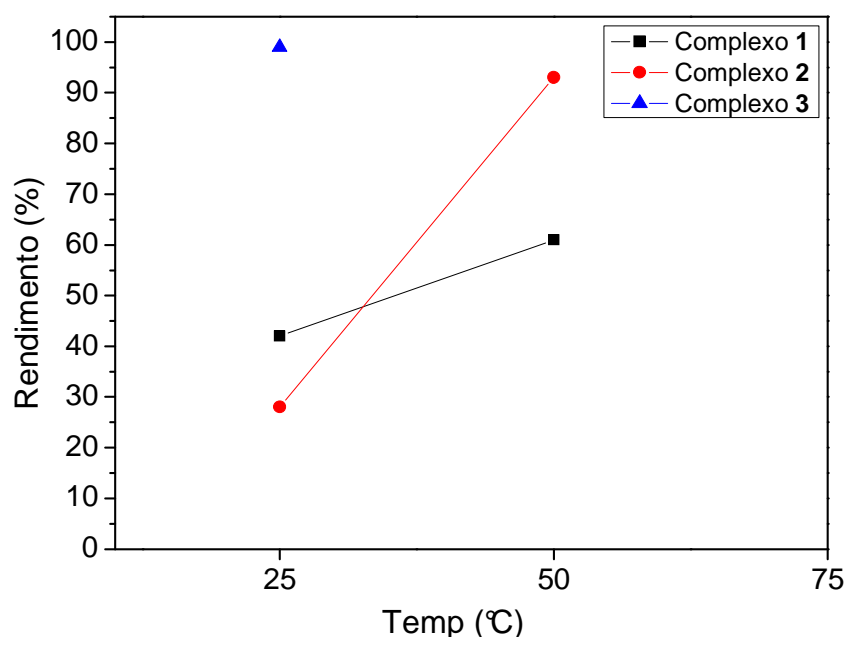

Figura 53. Dependência do rendimento em relação à temperatura, para a ROMP de NBE com 1, 2 e 3; $[\mathrm{NBE}] /[\mathrm{Ru}]=5000 ;[\mathrm{Ru}]=1 \mu \mathrm{mol}$ em $2 \mathrm{~mL}$ de $\mathrm{CHCl}_{3}$ à $25^{\circ} \mathrm{C}$ e $50^{\circ} \mathrm{C}$ por 5 minutos. 
O complexo 3 já apresenta rendimentos quantitativos a $25^{\circ} \mathrm{C}$ com satisfatórios valores de IPD e $M_{w}$ para um complexo em que sua espécie ativa é formada in situ (Tabela 7). No caso do IPD, o valor está abaixo de 2 unidades e $M_{w}$ está na ordem de $10^{5}$.

Tabela 7 - Dependência do rendimento, $\mathrm{M}_{\mathrm{w}}$ e IPD em relação à temperatura, para a ROMP de NBE com 1, 2 e 3; $[\mathrm{NBE}] /[\mathrm{Ru}]=5000 ;[\mathrm{Ru}]=1 \mu \mathrm{mol}$ em $2 \mathrm{~mL}$ de $\mathrm{CHCl}_{3}$ à $25^{\circ} \mathrm{C}$ e $50^{\circ} \mathrm{C}$ por 5 minutos.

\begin{tabular}{|c|c|c|c|c|}
\hline Temp $\left({ }^{\circ} \mathrm{C}\right)$ & Complexo & Rendimento (\%) & $M_{w}\left(10^{4}\right)$ & IPD \\
\hline & 1 & 42 & 4,4 & 2,08 \\
\hline \multirow[t]{3}{*}{25} & 2 & 28 & 10 & 3,02 \\
\hline & 3 & 99 & 10 & 1,85 \\
\hline & 1 & 61 & 17 & 2,87 \\
\hline \multirow[t]{2}{*}{50} & 2 & 93 & 14 & 1,67 \\
\hline & 3 & - & - & - \\
\hline
\end{tabular}

Após a constatação de que o aumento da temperatura não favoreceu a ROMP de NBE com 1. Realizou-se experimento por 30 minutos a $50^{\circ} \mathrm{C}$. O rendimento passou de $61 \%$ para $99 \%$, com redução do valor de IPD de 2,87 para 1,87 . O valor de $M_{w}\left(9,2 \times 10^{4} \mathrm{~g} / \mathrm{mol}\right)$ permaneceu na mesma ordem de grandeza do $\mathrm{M}_{\mathrm{w}}$ obtido na polimerização a $25^{\circ} \mathrm{C}$ por 5 minutos. Pode-se dizer que o aumento do tempo proporcionou uma melhora na etapa de propagação do complexo 1, o qual pode ser visto no aumento de rendimento e na melhora do IPD. Em relação aos complexo 2 e 3, não se fez necessário experimentos com maiores tempos de reação.

Para a ROMP de norbornadieno com 1 e 2, foram testadas reações nas temperaturas de $25^{\circ} \mathrm{C}$ e $50^{\circ} \mathrm{C}$ por 30 minutos (Figura 54). Com o complexo 1, o monômero NBD não foi 
polimerizado a temperatura de $25^{\circ} \mathrm{C}$ por 30 minutos, sendo necessário o aumento da temperatura para $50^{\circ} \mathrm{C}$, o que ainda resultou em baixo rendimento. Em relação ao complexo 2, na temperatura de $25^{\circ} \mathrm{C}$ por 30 minutos, obteve-se rendimento de $5 \%$ e $25 \%$ a $50^{\circ} \mathrm{C}$. Para o complexo 3 , foi observado $44 \%$ de rendimento à $25^{\circ} \mathrm{C}$ e um aumento para $90 \%$ para $50^{\circ} \mathrm{C}$ à 30 minutos, sendo muito favorável o aumento da temperatura.

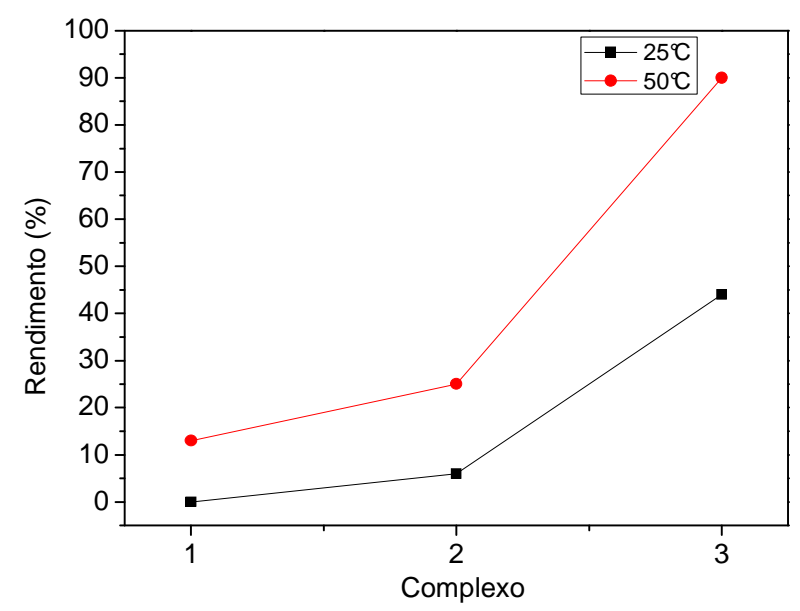

Figura 54. Dependência do rendimento em relação à temperatura, para a ROMP de NBD com 1, 2 e 3; $[\mathrm{NBD}] /[\mathrm{Ru}]=5000 ;[\mathrm{Ru}]=1 \mu \mathrm{mol}$ em $2 \mathrm{~mL}$ de $\mathrm{CHCl}_{3}$ à $25^{\circ} \mathrm{C}$ e $50^{\circ} \mathrm{C}$ por 30 minutos.

Experimentos por 60, 120 e 240 minutos foram realizados na ROMP de NBD utilizando 1 e 2. E foi constatado que o aumento do tempo de polimerização não proporciona um aumento no rendimento, mantendo a mesma faixa de rendimento; em torno de 5-6 \% para 1 e $25 \%$ para 2 (Figura 55). 


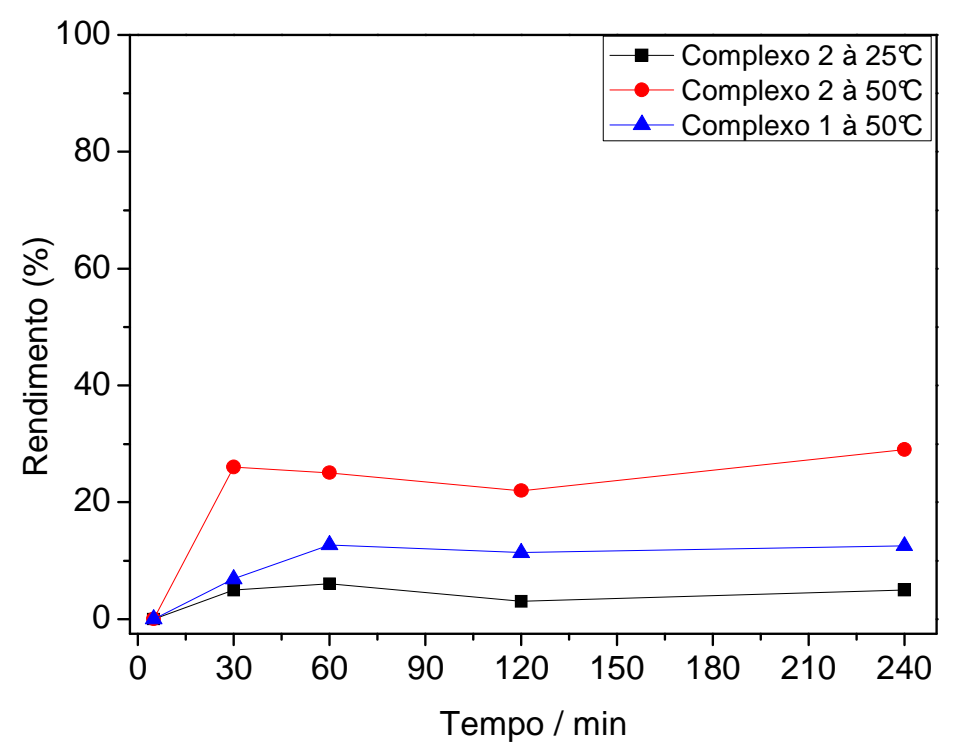

Figura 55. Dependência do rendimento em relação ao tempo, para a ROMP de NBD com 1 e 2; $[\mathrm{NBD}] /[\mathrm{Ru}]=5000 ;[\mathrm{Ru}]=1 \mu \mathrm{mol}$ em $2 \mathrm{~mL}$ de $\mathrm{CHCl}_{3}$ à $25^{\circ} \mathrm{C}$ e $50^{\circ} \mathrm{C}$.

Experimentos de polimerização de $\mathrm{NBD}$ a $50^{\circ} \mathrm{C}$ por 5 minutos com o complexo 3apresentou o valor de 78\%. Isso pode demonstrar que o fator mais importante nesse caso é a temperatura.

A diferença de reatividade entre os complexos 1, 2 e 3 pode estar associada a diferença no número de coordenação de 6 para 1 e 2, diferentemente de 3 que tem o número de coordenação 5, podendo influenciar no período de indução, ou seja, na formação da espécie ativa metal-carbeno. No caso com 3, o período de indução pode ser favorecido pelo sítio de coordenação vazio, pronto para reação com EDA sem a necessidade de descoordenação de ligantes.

Ainda pode existir a possibilidade de dupla coordenação do monômero NBD ao complexo, formando um complexo estável, o que claramente, desativaria o catalisador. Essa constatação foi encontrada para complexos similares e são vistos para monômeros como

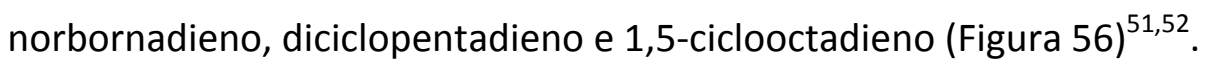




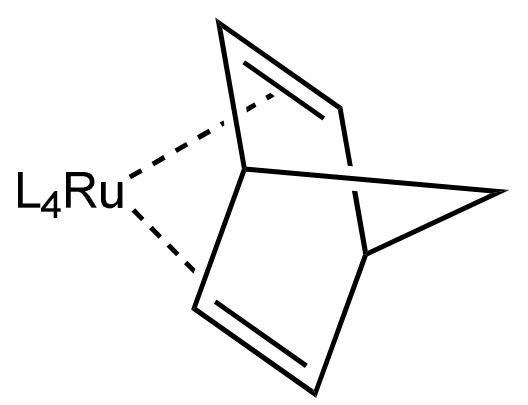

Figura 56. Ilustração de dupla coordenação que pode ocorrer em complexos de rutênio.

Para as polimerizações com DCPD, 1 e $\mathbf{2}$ não foram ativos. Já o complexo $\mathbf{3}$ apresenta atividade à $50^{\circ} \mathrm{C}$ por 60 minutos, com $26 \%$ de rendimento. Na tentativa de aumentar o rendimento dessa polimerização, reações por 120 minutos não propiciaram variação significativa no valor de rendimento, apresentando $21 \%$ de rendimento (Tabela 8 ).

Tabela 8 - Dependência do rendimento em relação ao tempo e a temperatura, para a ROMP de DCPD com 3; [DCPD]/[Ru] = 5000; [Ru] = $1 \mu \mathrm{mol}$ em $2 \mathrm{~mL}$ de $\mathrm{CHCl}_{3}$ à $50^{\circ} \mathrm{C}$ por 60 e 120 minutos.

\begin{tabular}{cccc}
\hline Monômero & Temp. $\left({ }^{\circ} \mathrm{C}\right)$ & Tempo(min) & Rend. (\%) \\
\hline DCPD & 50 & 60 & 26 \\
\hline DCPD & 50 & 120 & 21 \\
\hline
\end{tabular}

Devido à formação de entrecruzamento ${ }^{53}$ nos polímeros formados com NBD e DCPD (Figura 57), não foi possível solubilizá-los em $\mathrm{CHCl}_{3}$ para se realizar as medidas de cromatografia por permeação em gel. 


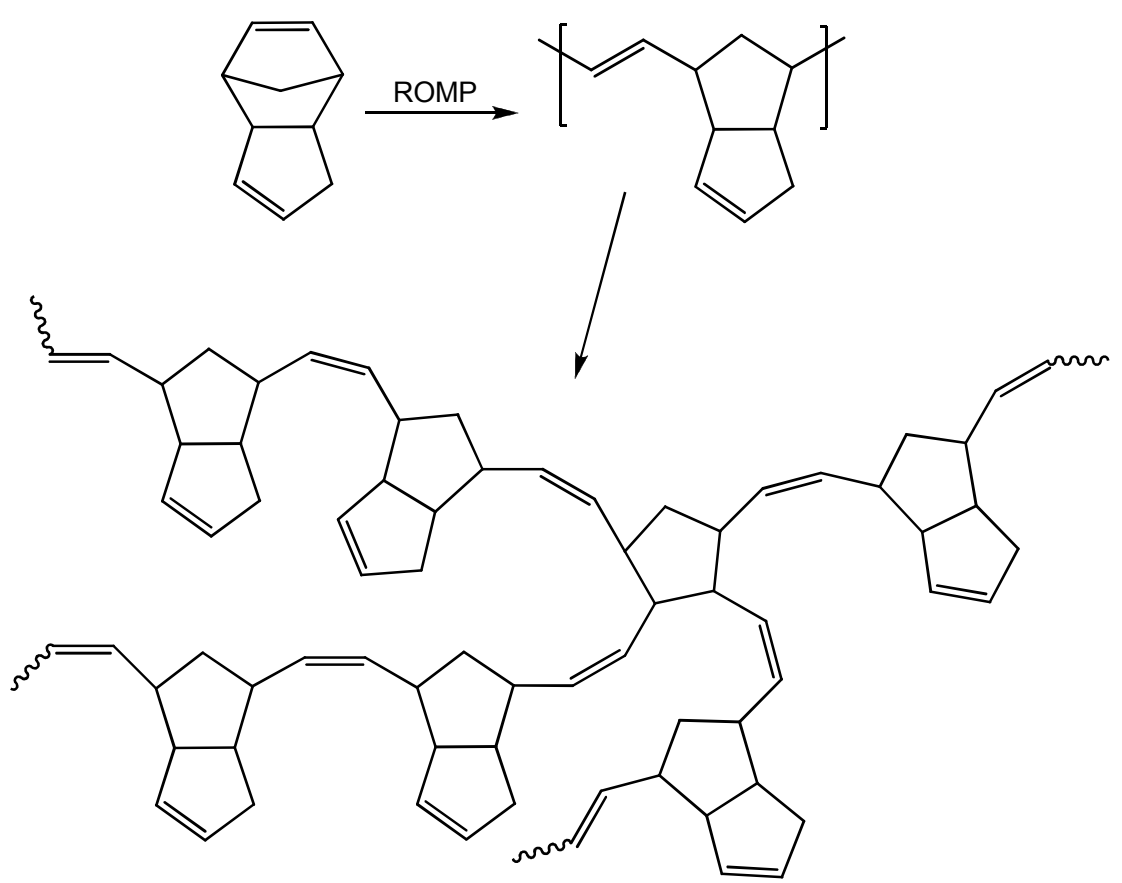

Figura 57. Formação de entrecruzamento na ROMP de diciclopentadieno ${ }^{53}$.

\subsubsection{Variação da razão molar [NBE]/[Ru]}

Foi testada a atividade catalítica dos complexos 1, 2 e 3 em função das razões molares [NBE]/[Ru], sendo iguais a 1000, 3000, 5000 e 10000.

Os resultados obtidos estão apresentados na Figura 58. No caso com 1, seja a $25^{\circ} \mathrm{C}$ oi $50^{\circ} \mathrm{C}$ observa-se um aumento de rendimento de 1000 para 5000. Com razão molar de 10000 não ocorre variação à $50^{\circ} \mathrm{C}$, com decréscimo à $25^{\circ} \mathrm{C}$.

É sabido da literatura que baixas razões molares desfavorecem a ROMP por razões entrópicas, o que pode justificar o aumento de rendimento à medida que aumenta a razão molar. Com razões molares muito altas, existe o fato da alta viscosidade do meio que 
dificulta a interação do complexo com EDA e com o monômero, justificando os resultados com 10000 unidades de monômero por. Isso é consistente com o resultado a $50^{\circ} \mathrm{C}$.

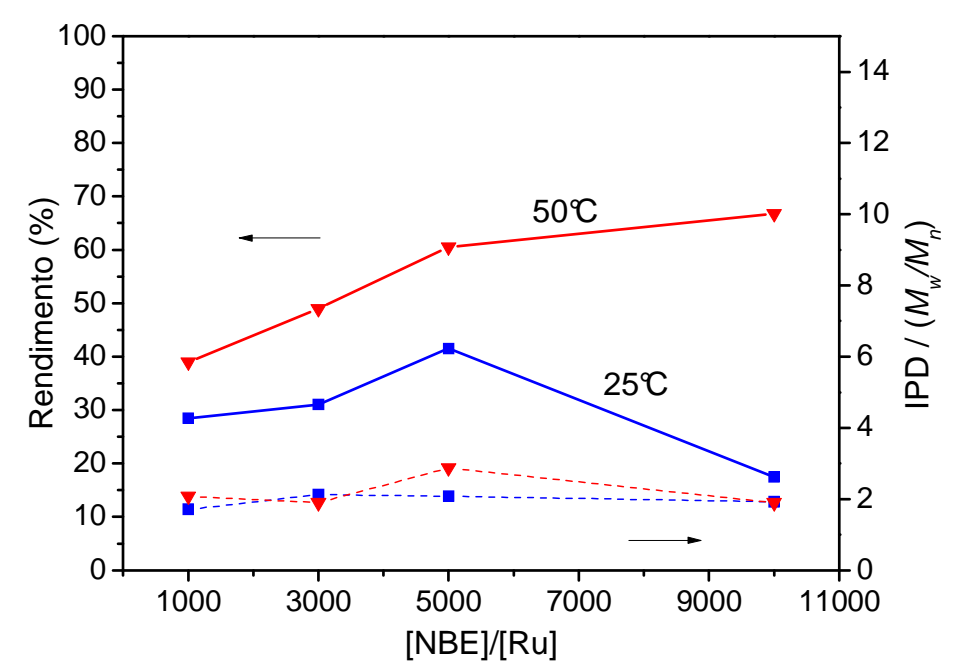

Figura 58. Dependência do rendimento em relação à temperatura, para a ROMP de NBE com $1 \mathrm{em} 2 \mathrm{~mL}$ de $\mathrm{CHCl}_{3}$ por 5 minutos.

Estudos de variação da razão molar para a ROMP a $50^{\circ} \mathrm{C}$ por 30 minutos mostraram resultados de rendimento quantitativos de rendimento, mesmo com razão molar de 10000 (Figura 59). Os estudos de GPC para os polímeros obtidos em função da razão molar estão apresentados na Tabela 9. Onde pode ser visto que o valor de IPD fica na faixa de 2 e o valor de $M_{w}$ variando entre $10^{4}$ e $10^{5} \mathrm{~g} / \mathrm{mol}$.

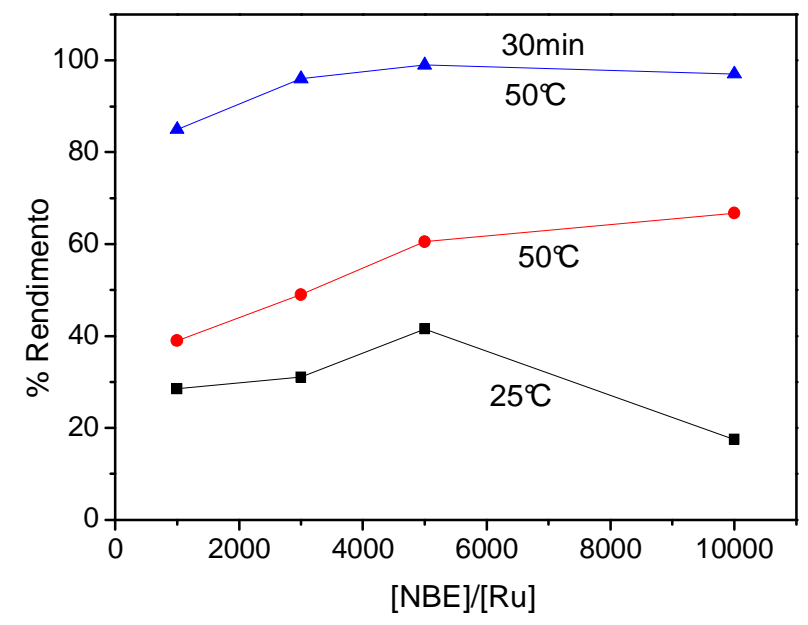

Figura 59. Dependência do rendimento em relação ao tempo e a temperatura, para a ROMP de NBE com 1 em $2 \mathrm{~mL}$ de $\mathrm{CHCl}_{3}$. 
Tabela 9 - Dependência do rendimento, $M_{w}$ e IPD em relação à temperatura, tempo e razão molar para a ROMP de NBE com 1 em $2 \mathrm{~mL}$ de $\mathrm{CHCl}_{3}$.

\begin{tabular}{|c|c|c|c|c|c|}
\hline $\operatorname{Temp}\left({ }^{\circ} \mathrm{C}\right)$ & Tempo & [NBE]/Ru & Rend (\%) & $M_{w}\left(10^{4}\right)$ & IPD \\
\hline \multirow{4}{*}{25} & \multirow{4}{*}{5} & 1000 & 29 & 0,4 & 1,71 \\
\hline & & 3000 & 31 & 5,0 & 2,12 \\
\hline & & 5000 & 42 & 4,4 & 2,08 \\
\hline & & 10000 & 18 & 4,0 & 1,92 \\
\hline \multirow{4}{*}{50} & \multirow{4}{*}{5} & 1000 & 39 & 23 & 2,08 \\
\hline & & 3000 & 49 & 3,6 & 1,9 \\
\hline & & 5000 & 61 & 17,3 & 2,87 \\
\hline & & 10000 & 67 & 34,2 & 1,9 \\
\hline \multirow{4}{*}{50} & \multirow{4}{*}{30} & 1000 & 85 & 5,2 & 3,13 \\
\hline & & 3000 & 96 & 6,4 & 3,5 \\
\hline & & 5000 & 99 & 9,2 & 1,87 \\
\hline & & 10000 & 97 & 88 & 1,73 \\
\hline
\end{tabular}

Na Figura 60 é observada a dependência do rendimento em função das razões molares de $[\mathrm{NBE}] /[\mathrm{Ru}]$ e do tempo para os estudos com o complexo 2. O gráfico de rendimento mostra um perfil de aumento de rendimento de 1000 para 3000 . De 3000 para 5000 o rendimento permanece constante, com pequeno decréscimo de 5000 para 10000. Polimerização a $50^{\circ} \mathrm{C}$ por 5 minutos fornece $100 \%$ de rendimento, evidenciando que não é necessário o uso de um maior tempo de polimerização. Assim, o aumento de rendimento dentro da margem de erro de polimerização, não justifica um aumento no tempo de polimerização em 6 vezes.

Os dados de GPC para as polimerizações com 2 são apresentados na Tabela 10 e pode ser visto que como aumento da razão molar há uma diminuição do valor de IPD. Isso 
pode ser devido ao fato do complexo apresentar uma etapa de propagação descontrolada, por ter uma amina fortemente básica a sua esfera de coordenação. Isso propicia uma ativação mais rápida da olefina. Porém, com o aumento do tempo de reação é possível perceber o controle do IPD, pois todas as cadeias poliméricas tiveram condições de reação (tempo) de se igualarem em tamanho. Isso corrobora com o comportamento do complexo observado nos espectros eletrônicos e de $\mathrm{RMN}{ }^{31} \mathrm{P}\left\{{ }^{1} \mathrm{H}\right\}$.

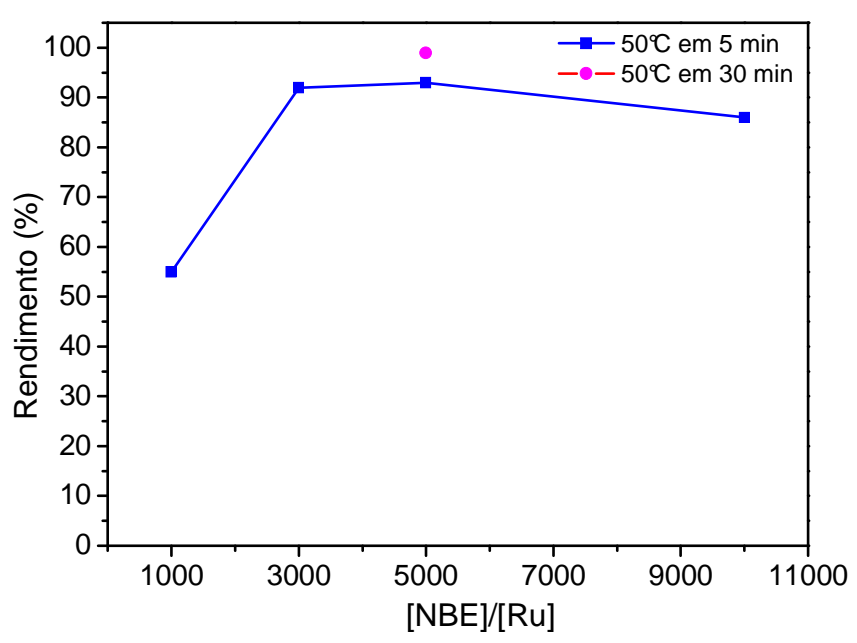

Figura 60. Dependência do rendimento em relação ao tempo e a temperatura, para a ROMP de NBE com 2 em $2 \mathrm{~mL}$ de $\mathrm{CHCl}_{3}$.

Tabela 10 - Dependência do rendimento, $M_{w}$ e IPD em relação à temperatura, tempo e razão molar para a ROMP de NBE com 2 em $2 \mathrm{~mL}$ de $\mathrm{CHCl}_{3}$.

\begin{tabular}{|c|c|c|c|c|c|}
\hline $\operatorname{Temp}\left({ }^{\circ} \mathrm{C}\right)$ & Tempo & [NBE]/Ru & Rend (\%) & $M_{w}\left(10^{4}\right)$ & IPD \\
\hline \multirow{4}{*}{50} & \multirow{4}{*}{30} & 1000 & 55 & 21 & 3,04 \\
\hline & & 3000 & 92 & 8,3 & 3,28 \\
\hline & & 50000 & 93 & 1,4 & 1,67 \\
\hline & & 10000 & 86 & 11 & 1,86 \\
\hline
\end{tabular}

O perfil de rendimento para a variação da razão molar com complexo 3 é apresentado na Figura 61. Devido a boa atividade catalítica de 3, as polimerizações de NBE 
foram feitas a $25^{\circ} \mathrm{C}$ em 5 minutos, e assim já apresentando resultados satisfatórios. A curva para o rendimento com 3 não apresenta grande variação em função da variação da razão molar, uma vez que o complexo apresenta boa atividade catalítica para NBE e não apresenta sensibilidade expressiva para baixas ou altas razões molares.

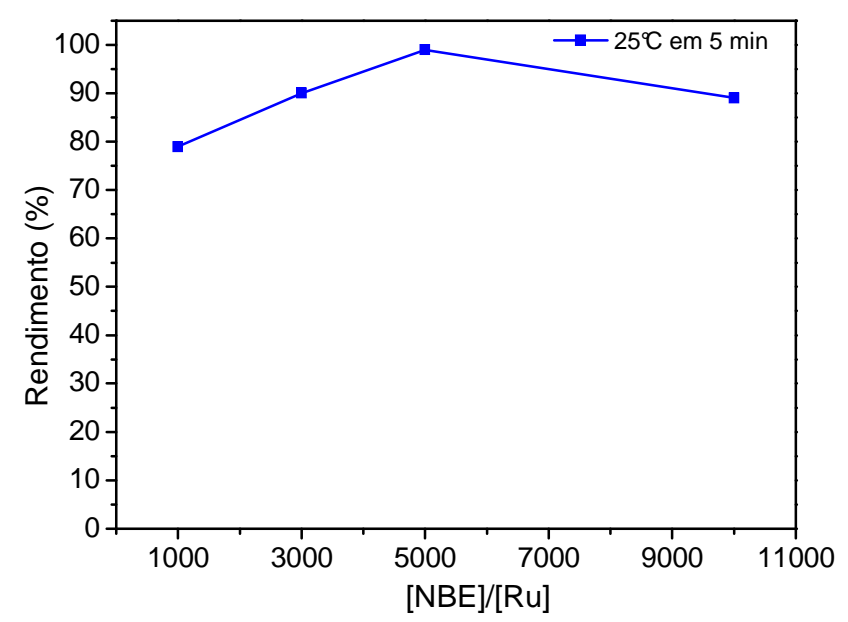

Figura 61. Dependência do rendimento em relação ao tempo e a temperatura, para a ROMP de NBE com 3 em $2 \mathrm{~mL}$ de $\mathrm{CHCl}_{3}$.

Na Tabela 11 é apresentado os dados de GPC para a ROMP a $25^{\circ} \mathrm{C}$ em 5 minutos para os estudos com o complexo 3. É observado que o IPD melhora com o aumento da razão molar, passando de 2,27 na razão molar de 1000 para 1,85 em 5000. O valor de $\mathrm{M}_{\mathrm{w}}$ varia de ordem de grandeza de $10^{4}$ a $10^{5} \mathrm{~g} / \mathrm{mol}$. É interessante observa o valor de 1,96 em 10000, porém é uma valor maior do que aquele com 5000. Para verificar se esse decréscimo é causado pelo aumento da viscosidade, foi feito uma polimerização na razão molar de 10000 em $4 \mathrm{~mL}$ de solvente, para diminuir o efeito da alta viscosidade. Dessa forma, embora seja observado que o rendimento decresceu de $87 \%$ para $78 \%$, os valores de $M_{w}$ e IPD melhoraram consideravelmente. 
Tabela 11 - Dependência do rendimento, $M_{w}$ e IPD em relação à temperatura, tempo e razão molar para a ROMP de NBE com 3 em $2 \mathrm{~mL}$ de $\mathrm{CHCl}_{3}$ em 5 minutos.

\begin{tabular}{|c|c|c|c|c|c|}
\hline $\operatorname{Temp}\left({ }^{\circ} \mathrm{C}\right)$ & Tempo & [NBE]/Ru & Rend (\%) & $M_{w}\left(10^{4}\right)$ & IPD \\
\hline \multirow{5}{*}{50} & \multirow{5}{*}{5} & 1000 & 79 & 2,3 & 2,27 \\
\hline & & 3000 & 90 & 14 & 2,04 \\
\hline & & 50000 & 99 & 10 & 1,85 \\
\hline & & 10000 & 87 & 6,2 & 1,96 \\
\hline & & $10000^{a}$ & 78 & 60 & 1,60 \\
\hline
\end{tabular}

${ }^{a} 4 \mathrm{~mL}$ de solvente

4.7. Atividade dos complexos $\left[\mathrm{RuCl}_{2}\left(\mathrm{PPh}_{3}\right)_{2}\left(\mathrm{NH}_{2} \mathrm{Ph}\right)_{2}\right], \quad\left[\mathrm{RuCl}_{2}\left(\mathrm{PPh}_{3}\right)_{2}\left(\mathrm{NH}_{2} \mathrm{Bz}\right)_{2}\right]$ e $\left[\mathrm{RuCl}_{2}\left(\mathrm{PPh}_{3}\right)\right.$ (NHBuPh) na ROMP de Norborneno na presença dos ligantes $\mathrm{NH}_{2} \mathrm{Ph}$, $\mathrm{NH}_{2} \mathrm{CH}_{2} \mathrm{Ph}$ e $\mathrm{NH}^{\mathrm{n}} \mathrm{BuPh}$

Foram feitos experimentos de ROMP de NBE com 1, 2 e 3 na presença de ligantes ancilares $\mathrm{PPh}_{3}, \mathrm{NH}_{2} \mathrm{Ph}, \mathrm{NH}_{2} \mathrm{CH}_{2} \mathrm{Ph}$ e $\mathrm{NH}^{\mathrm{n}} \mathrm{BuPh}$ para verificar sua influência nas atividades. $\mathrm{O}$ excesso de ligante no meio reacional pode sugerir se os ligantes comuns são descoordenados para que a reação ocorra. Issopode ser corroborado pelas observação nos espectros de $\mathrm{RMN}{ }^{31} \mathrm{P}\left\{{ }^{1} \mathrm{H}\right\}$ e nos espectros eletrônicos. Esses estudos foram a $25^{\circ} \mathrm{C}$ por 5 minutos.

Foi visto que para o complexo 1 o excesso de amina ou fosfina desfavoreceu a ROMP. O rendimento diminuiu de $42 \%$ para $0,6 \%$ na presença de $\mathrm{PPh}_{3}$ e 1,5\% na presença de $\mathrm{NH}_{2} \mathrm{Ph}$. 
Para o complexo 2 foi observado o mesmo comportamento, com quedas bruscas de rendimento, tanto para as polimerizações com $\mathrm{PPh}_{3}$ como para $\mathrm{NH}_{2} \mathrm{CH}_{2} \mathrm{Ph}$, de $28 \%$ para $1,7 \%$ e $1 \%$, respectivamente.

No estudo com o complexo 3, observou-se também diminuição nos rendimentos. Obteve-se redução de $90 \%$ para $7 \%$ e $5 \%$ na presença de $\mathrm{PPh}_{3}$ e amina, respectivamente.

Assim constata-se que no caso dos complexos hexacoordenados, $\mathbf{1}$ e $\mathbf{2}$ se fazem necessário a saída de ligantes amina e fosfina. No caso de $\mathbf{3}$, que é pentacoordenado, podese dizer que o excesso de fosfina inibe a reação pode impedimento da descoordenação de $\mathrm{PPh}_{3}$. Já a reação na presença de amina, deve ocorrer a coordenação com o ligante e bloqueando o prosseguimento da reação

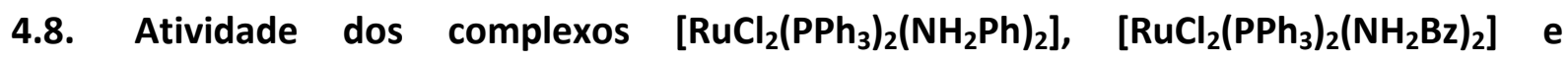 $\left[\mathrm{RuCl}_{2}\left(\mathrm{PPh}_{3}\right)\left(\mathrm{NH}^{\mathrm{n}} \mathrm{BuPh}\right)\right.$ na ROMCP de NBE, NBD e DCPD}

Para as copolimerizações via ROMP foram utilizados os monômeros NBE, NBD e DCPD. A intenção é observar a atividade catalítica dos catalisadores frente à presença de mais de um monômero no meio reacional, observar como eles se comportam frente a diferentes razões molares dos diferentes monômeros. Para isso, variou-se a razão molar de dois monômeros, de tal maneira que fosse possível observar a variação no comportamento do catalisador frente às diferentes razões molares.

As polimerizações foram feitas a $50^{\circ} \mathrm{C}$ por 30 minutos para as polimerizações com NBE e NBD em diferentes frações, como pode ser visto na Figura 62 e Figura 63. 
Foram feitos estudos fixando a razão molar $[\mathrm{NBE}] /[\mathrm{Ru}]$ em 5000 e variando a razão molar $[\mathrm{NBD}] /[\mathrm{Ru}]$ em 500, 1500, 2500 e 5000, perfazendo um total de monômero por metal de $5500,6500,7500$ e 10000.

Os complexos 1 e $\mathbf{2}$ não foram ativos para copolimerizações via ROMP. O complexo $\mathbf{3}$ foi ativo na copolimerização de NBE/NBD.

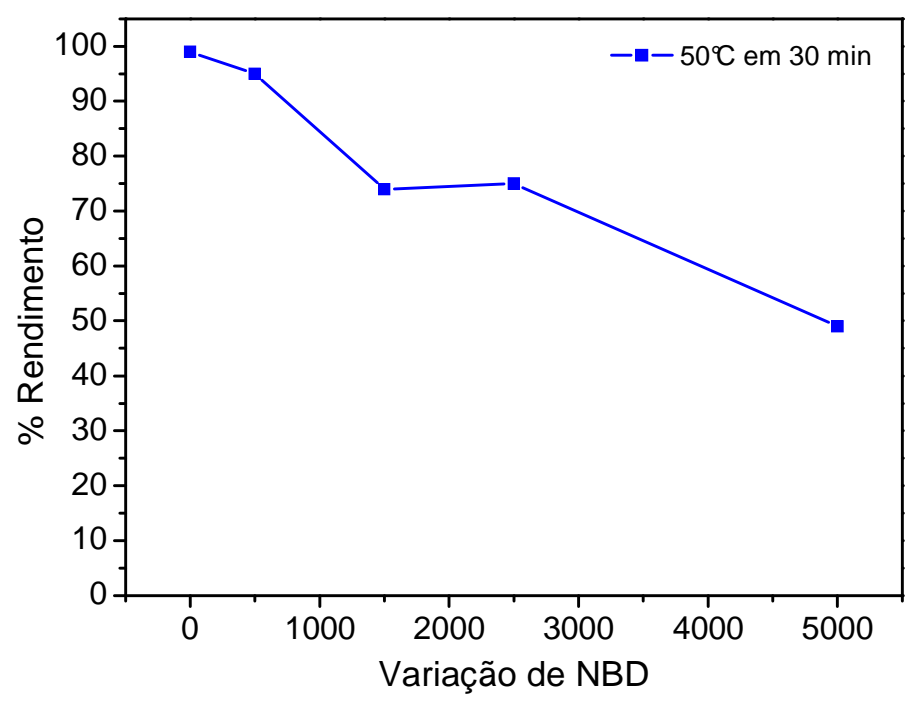

Figura 62. Dependência do rendimento em relação ao aumento da razão molar de NBD para a ROMCP de NBE/NBD com $3 \mathrm{em} 2 \mathrm{~mL}$ de $\mathrm{CHCl}_{3}$ a $50^{\circ} \mathrm{C}$ por 30 minutos.

Foram feitos também, estudos fixando a razão molar [NBD]/[Ru] em 5000 e variando a razão molar $[\mathrm{NBE}] /[\mathrm{Ru}]$ em 500, 1000, 1500, 2000 e 5000, somando-se no total $[$ monômero total $] /[\mathrm{Ru}]=5500,6000,6500,7000$ e 10000, nas mesmas condições, os resultados estão apresentados na Figura 63.

Observa-se o decréscimo no rendimento em função do aumento da razão molar de NBE. A homopolimerização de NBD na razão molar 5000 resulta em rendimento de $90 \%$. Com a presença de uma razão molar de NBE de 500, o rendimento é de apenas $35 \%$, com o aumento da razão molar de NBE até 5000 , os valores tendem a um patamar de $45-55 \%$, dentro do erro de $10 \%$. 


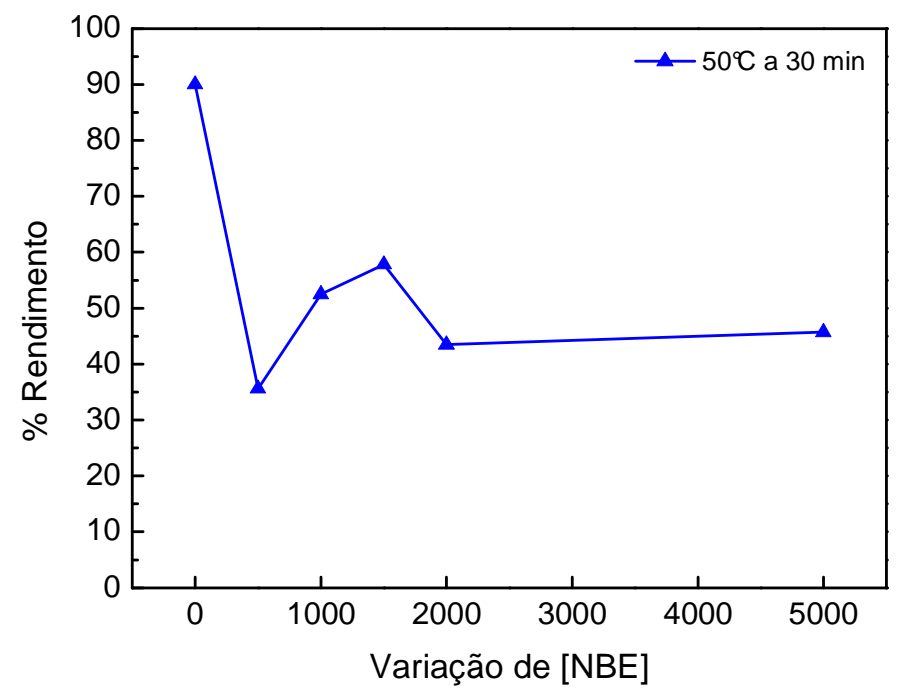

Figura 63. Dependência do rendimento em relação ao aumento da razão molar de NBE para a ROMCP de NBD/NBE com 3 em $2 \mathrm{~mL}$ de $\mathrm{CHCl}_{3}$ a $50^{\circ} \mathrm{C}$ por 30 minutos.

No caso com os complexos 1 e 2, não foram obtidos polímeros misturando 2500 unidades de NBE e 2500 unidades de NBD por mol de complexo de Ru, a $50^{\circ} \mathrm{C}$ por 30 minutos.

No caso com o complexo 3, misturas de 5000 unidades de NBE com 500, 1500, 2500 e 5000 unidades de $\mathrm{NBD}$ por $\mathrm{mol}$ de $\mathrm{Ru}$ a $50^{\circ} \mathrm{C}$ por 30 minutos, resultaram em materiais poliméricos (Figura 62). O rendimento decresce à medida que aumenta a quantidade de NBD. Como 3 propicia rendimentos quantitativos tanto com NBE como com NBD, esse decréscimo no rendimento da ROMCP é um indício de que ocorre copolimerização. Dessa forma, o complexo 3 é sensível a formação de meros $M_{1} M_{2}$ e $M_{2} M_{1}$.

Comparando o perfil gráfico nas Figuras Figura 62 e Figura 63, observa-se que nos dois casos ocorre diminuição nos rendimentos em relação às homopolimerizações. Entretanto, quando a quantidade de NBD é fixa e aumenta-se a quantidade de NBE (Figura Figura 63). O complexo apresenta um comportamento de reatividade constante ao 
aumentar a [NBE]. Ao contrário, quando a quantidade de NBE é fixa e aumenta-se a [NBD], os rendimentos diminuem progressivamente. Pode-se sugerir que a formação de meros $R u=N B E-N B D$ seja melhor que Ru=NBD-NBE, isto é, o excesso de NBD pode levar a inserção de NBE com maior facilidade. Medidas por $\mathrm{RMN}{ }^{13} \mathrm{C}$ e ${ }^{1} \mathrm{H}$ serão realizadas para a compreensão do estudo.

As copolimerizações com DCPD foram feitas com NBE e NBD com razões molares iguais a $50 \%$ de NBE - $50 \%$ de DCPD e $50 \%$ de NBD - 50\% de DCPD. Nos dois casos a soma de monômero é de 5000 unidades por mol de Ru. No caso com 1 e 2, não observou-se formação de produtos. No caso com 3, os rendimentos foram de $30 \%$ e $35 \%$. Os resultados são apresentados na Tabela 12.

Tabela 12 - Rendimentos da copolimerização de DCPD com NBE e NBD com 3 a $50^{\circ} \mathrm{C}$ por 60 minutos.

\begin{tabular}{cccc}
\hline [monômero + DCPD]/Ru & Temperatura $\left({ }^{\circ} \mathrm{C}\right)$ & Tempo (min) & Rend (\%) \\
\hline NBE & 50 & 60 & 35 \\
\hline NBD & 50 & 60 & 31 \\
\hline
\end{tabular}

A reatividade de 3 com DCPD, seja na formação de homo (Tabela 8) ou copolímero (Tabela 12), é um tanto quanto interessante. DCPD é um monômero muito difícil de ser polimerizado devido à capacidade de dupla coordenação. Assim o complexo 3 mostra-se promissor frente à família de complexos do tipo $\left[\mathrm{RuCl}_{2}\left(\mathrm{PPh}_{3}\right)_{2}(\text { amina })_{\mathrm{x}}\right]$. Isso poderia estar principalmente associado ao impedimento estérico. Ainda, a baixa basicidade é superada por esse fenômeno. 


\subsection{Atividade dos complexos $\left[\mathrm{RuCl}_{2}\left(\mathrm{PPh}_{3}\right)_{2}\left(\mathrm{NH}_{2} \mathrm{Ph}\right)_{2}\right],\left[\mathrm{RuCl}_{2}\left(\mathrm{PPh}_{3}\right)_{2}\left(\mathrm{NH}_{2} \mathrm{Bz}\right)_{2}\right]$ na $\mathrm{ROMP}$ de NBE por fotólise}

As soluções dos complexos 1 e $\mathbf{2}$ foram irradiadas em função do tempo, sendo amostras retiradas e postas para reagirem com NBE por 5 min a $25^{\circ} \mathrm{C}$. Para comparação, soluções similares foram deixadas no escuro e nos mesmos intervalos de tempo, amostras foram tomadas para ROMP. Os resultados de rendimento são apresentados na Figura 64 . Observa-se que quanto maior for o tempo de irradiação dos complexos, melhor será o rendimento nas reações nos dois casos, ao contrário das soluções mantidas no escuro. No caso do complexo $\mathbf{2}$ que apresentou menor rendimento do que $\mathbf{1}$ antes da solução ser irradiada, apresenta os mesmos resultados após irradiação. Os rendimentos são equiparados aos obtidos a $50{ }^{\circ} \mathrm{C}$. Assim, a irradiação proporcionou a labilização dos ligantes nos complexos, favorecendo o desenvolvimento da ROMP.

As soluções mantidas no escuro apresentam menores rendimentos porque o envelhecimento das soluções não favorece a formação das espécies ativas, implicando que não são eficientes para ROMP. Pode-se dizer que, na presença de luz, as espécies que serão ativas para ROMP são formadas continuamente, vencendo-se o período de indução.

Foram realizadas polimerizações a $50^{\circ} \mathrm{C}$ após as soluções terem sido irradiadas por luz para verificar se esses efeitos benéficos poderiam ser somados. Entretanto, foi observado que o aumento de temperatura durante a polimerização não afetou os rendimentos (53\% para 1; $57 \%$ para 2 ). Isso se deve, provavelmente ao fato de que a irradiação com luz branca já labiliza os ligantes, formando novas espécies que ativam a reação e o aumento de temperatura não proporciona o surgimento de outras espécies ou 
mesmo o aumento da concentração de espécies já ativas em solução. Ainda, as etapas de iniciação e propagação também não são favorecidas. Isso pode ser esperado, uma vez que a ROMP é favorecida em temperaturas baixas. Dessa forma, a irradiação propicia uma diminuição no período de indução, sem a necessidade de aumentar a temperatura, não interferindo na reação de polimerização.

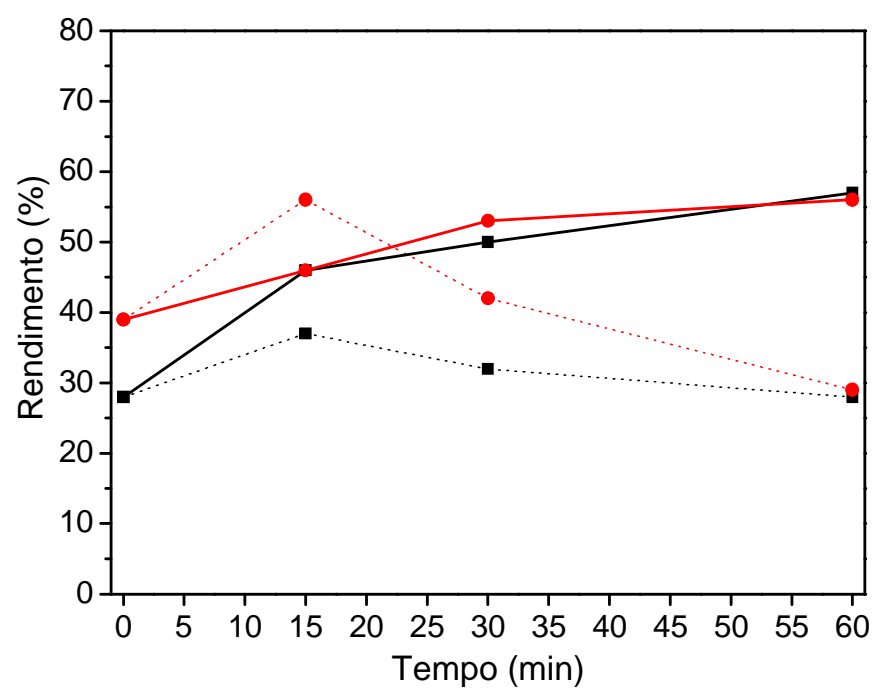

Figura 64. Rendimentos para ROMP na presença de luz branca, a $25^{\circ} \mathrm{C}$ por 5 minutos na

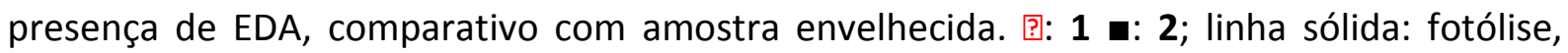
linha tracejada: solução envelhecida.

\subsection{Caracterização dos polímeros por GPC e RMN ${ }^{13} \mathrm{C}$}

A Figura 66 Abaixo apresenta o espectro de $\mathrm{RMN}{ }^{13} \mathrm{C}$ para o polímero formado com 1 na razão molar $[\mathrm{NBE}] /[\mathrm{Ru}]=5000$ à $50^{\circ} \mathrm{C}$ e 5 minutos. Os sinais são atribuídos (Tabela 13) segundo a literatura ${ }^{39,55}$ seguindo a identificação dos átomos de carbono apresentados na Figura 66. 


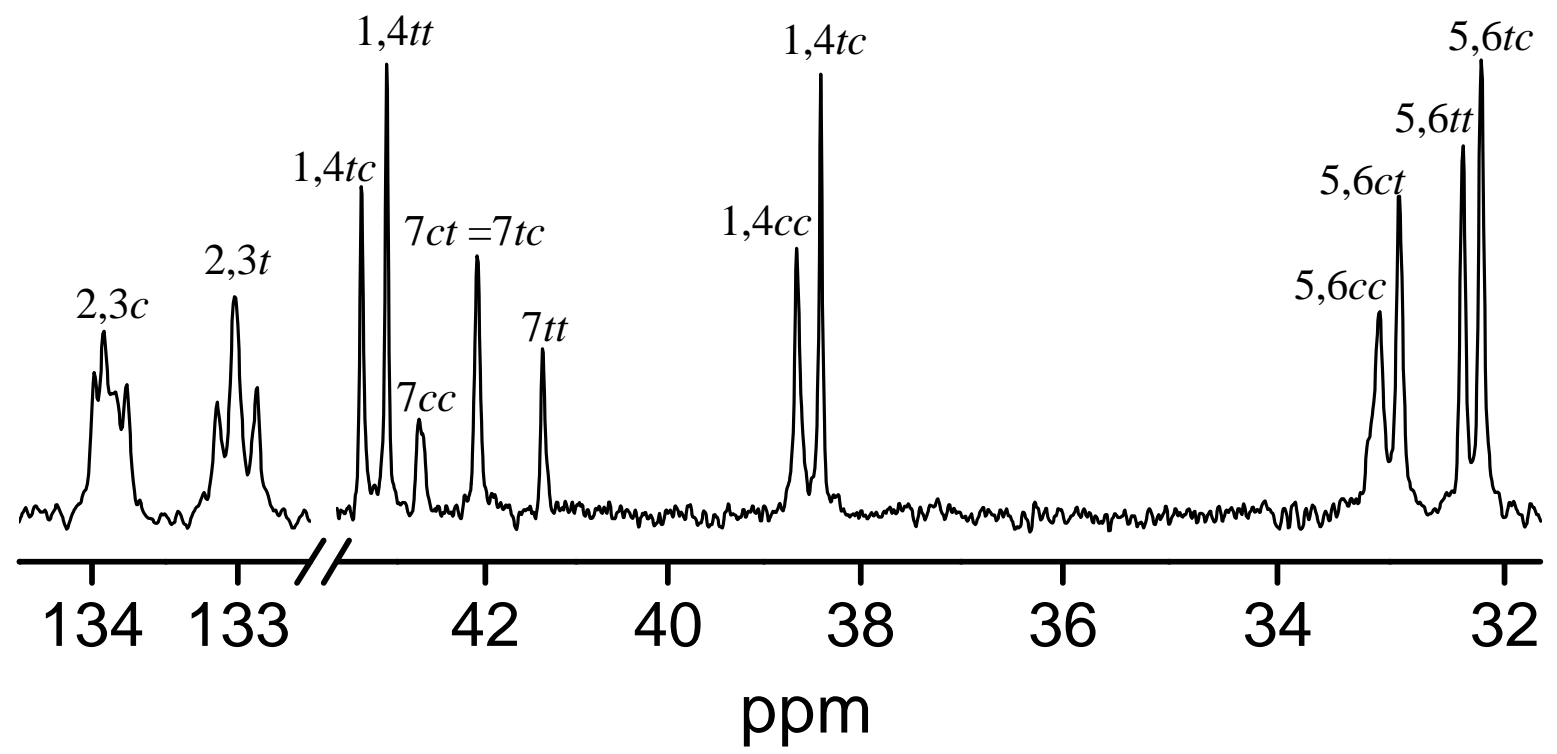

Figura 65. Espectro de $\mathrm{RMN}{ }^{13} \mathrm{C}$ para polinorborneno formado com 1.

Tabela 13 - Deslocamento químico, atribuições e área relativa dos picos (\%) e $\sigma_{c}$ do polímero formado utilizando 1.

\begin{tabular}{|c|c|c|c|}
\hline Deslocamento químico (ppm) & Atribuições & Área relativa dos picos (\%) & $\sigma_{c}$ \\
\hline 32.20 & $c^{5,6}-t t$ & 7,68 & \multirow{4}{*}{0,49} \\
\hline 32.36 & $c^{5,6}-t c$ & 9,06 & \\
\hline 32.92 & $c^{5,6}-c t$ & 8,16 & \\
\hline 33.09 & $c^{5,6}-c c$ & 8,23 & \\
\hline 38.40 & $C^{1,4}-c c$ & 7,45 & \multirow{4}{*}{0,50} \\
\hline 38.65 & $c^{1,4}-c t$ & 7,80 & \\
\hline 43.12 & $c^{1,4}-t t$ & 8,35 & \\
\hline 43.41 & $c^{1,4}-t c$ & 6,54 & \\
\hline 41.36 & $C^{7}-t t$ & 3,94 & \multirow{3}{*}{0,50} \\
\hline 42.09 & $c^{7}-c t: t c$ & 6,7 & \\
\hline 42.75 & $C^{7}-c c$ & 3,94 & \\
\hline 133.02 & $c^{2,3}-t$ & 11,43 & \multirow{2}{*}{0,49} \\
\hline 133.92 & $c^{2,3}-c$ & 11,19 & \\
\hline
\end{tabular}

Através de cálculos utilizando os valores de integral de cada pico presente no polímero, é possível obter o valor de $\sigma_{c}$ das porções cis-trans presentes no polímero formado ${ }^{1,5,39,55}$. Seguindo a equação 1. 


$$
\sigma_{c}=(c c+c t) /(c c+c t+t c+t t)
$$

(Equação 1)
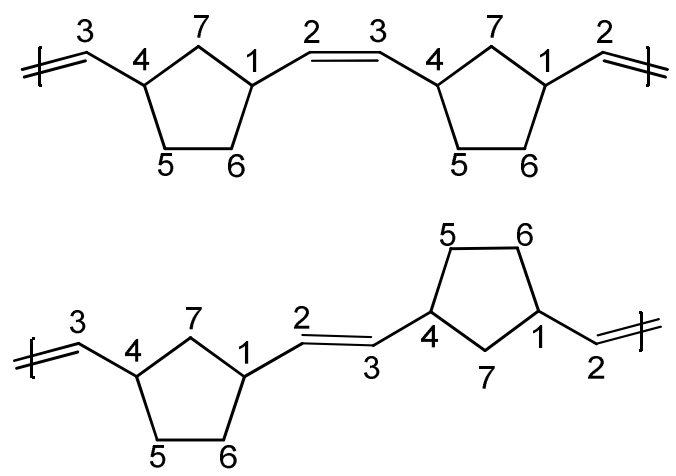

Figura 66. Numeração dada aos carbonos do polinorborneno para uso nos cálculos de integral para obtenção do valor de $\sigma_{c}^{39,55}$.

A Figura 67 apresenta o espectro de $\mathrm{RMN}{ }^{13} \mathrm{C}$ para o polímero formado com 2 na razão molar $[\mathrm{NBE}] /[\mathrm{Ru}]=5000$ à $50^{\circ} \mathrm{C}$ e 5 minutos. Os sinais estão na Tabela 14 , assim como os dados de $\sigma_{\mathrm{c}}$.

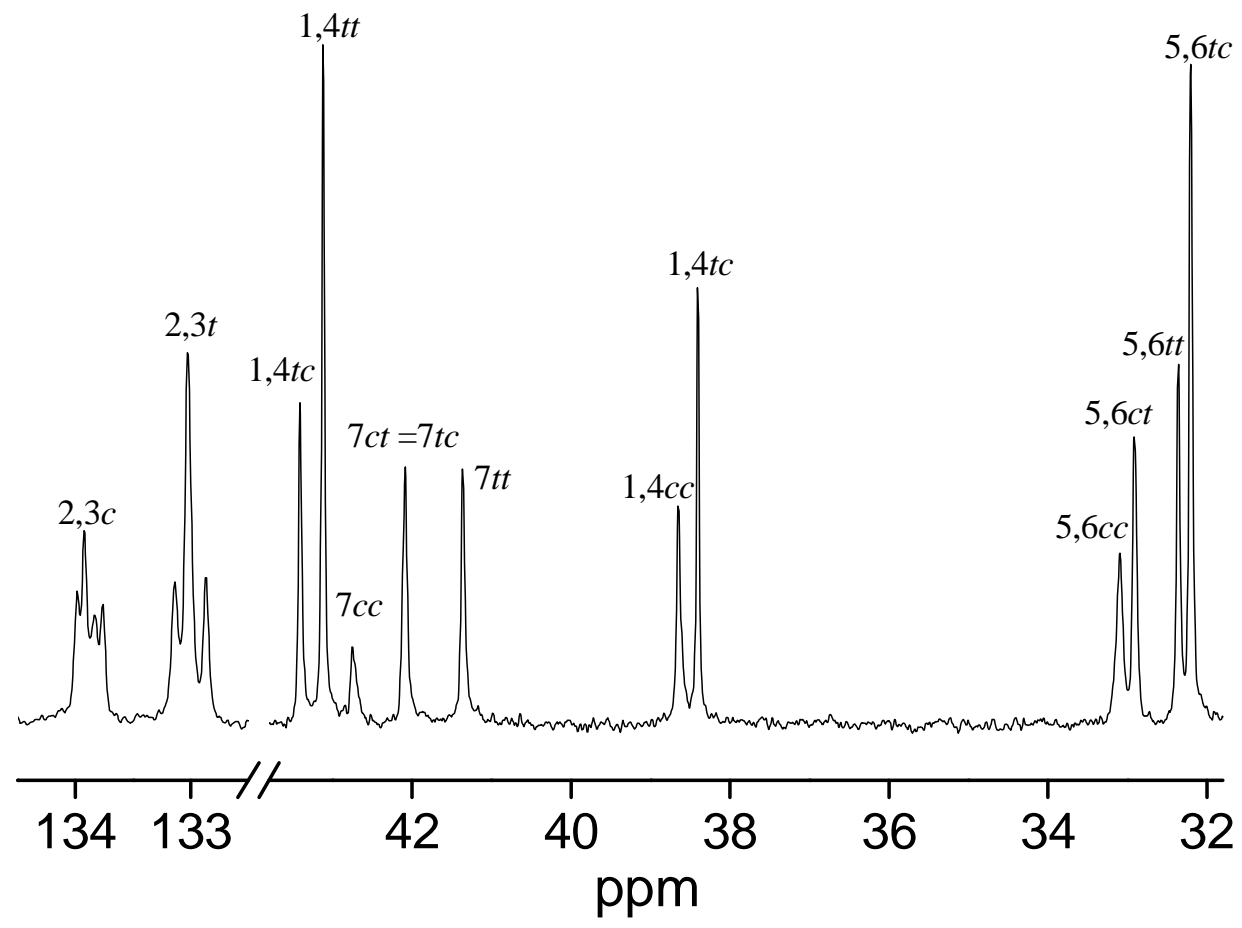

Figura 67. Espectro de $\mathrm{RMN}{ }^{13} \mathrm{C}$ para polinorborneno formado com $\mathbf{2}$. 
Tabela 14 - Deslocamento químico, atribuições e área relativa dos picos (\%) e $\sigma_{c}$ do polímero formado utilizando 2.

\begin{tabular}{|c|c|c|c|}
\hline Deslocamento químico (ppm) & Atribuições & Área relativa dos picos (\%) & $\sigma_{c}$ \\
\hline 32.21 & $C^{5,6}-t t$ & 6,26 & \multirow{4}{*}{0,40} \\
\hline 32.36 & $c^{5,6}-t c$ & 11,74 & \\
\hline 32.92 & $c^{5,6}-c t$ & 7,06 & \\
\hline 33.10 & $c^{5,6}-c c$ & 5,11 & \\
\hline 38.41 & $C^{1,4}-c c$ & 4,95 & \multirow{4}{*}{0,40} \\
\hline 38.65 & $C^{1,4}-c t$ & 6,05 & \\
\hline 43.12 & $C^{1,4}-t t$ & 10,69 & \\
\hline 43.41 & $c^{1,4}-t c$ & 5,74 & \\
\hline 41.36 & $C^{7}-t t$ & 5,27 & \multirow{3}{*}{0,42} \\
\hline 42.09 & $c^{7}-c t: t c$ & 5,69 & \\
\hline 42.75 & $C^{7}-c c$ & 2,37 & \\
\hline 133.03 & $C^{2,3}-t$ & 13,7 & \multirow{2}{*}{0,41} \\
\hline 133.92 & $c^{2,3}-c$ & 9,85 & \\
\hline
\end{tabular}

A Figura 68 apresentado o espectro de $\mathrm{RMN}^{13} \mathrm{C}$ para o polímero formado com 3 na razão molar $[\mathrm{NBE}] /[\mathrm{Ru}]=5000$ à $25^{\circ} \mathrm{C}$ e 5 minutos. Os sinais estão na Tabela 14 , assim como os dados de $\sigma_{\mathrm{c}}$.

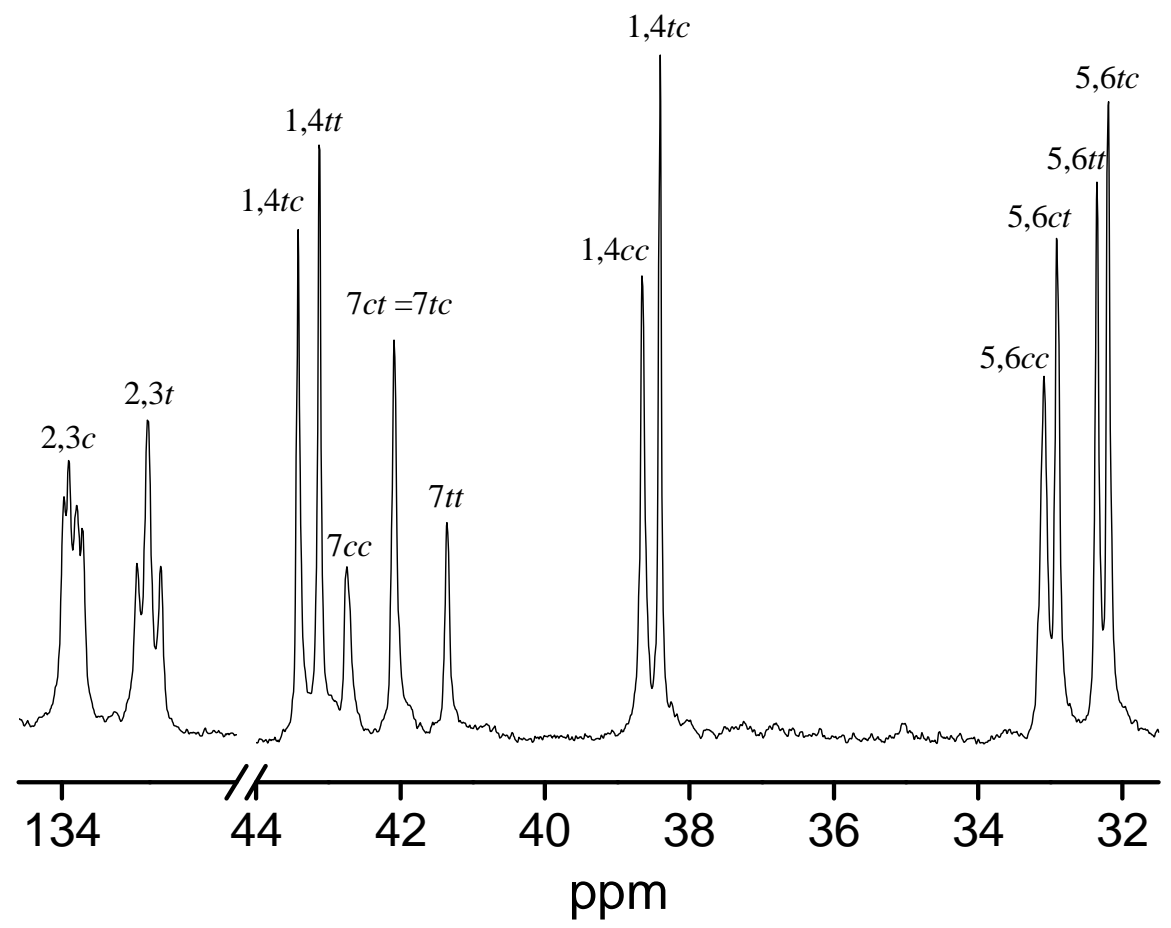

Figura 68. Espectro de $\mathrm{RMN}^{13} \mathrm{C}$ para polinorborneno formado com 3. 
Tabela 15 - Deslocamento químico, atribuições e área relativa dos picos (\%) e $\sigma_{c}$ do polímero formado utilizando 3.

\begin{tabular}{|c|c|c|c|}
\hline Deslocamento químico (ppm) & Atribuições & Área relativa dos picos (\%) & $\sigma_{\mathrm{c}}$ \\
\hline 32.20 & $c^{5,6}-t t$ & 6,57 & \multirow{4}{*}{0,50} \\
\hline 32.35 & $c^{5,6}-t c$ & 8,34 & \\
\hline 32.91 & $c^{5,6}-c t$ & 7,64 & \\
\hline 33.09 & $C^{5,6}-c c$ & 7,27 & \\
\hline 38.41 & $C^{1,4}-c c$ & 6,79 & \multirow{4}{*}{0,51} \\
\hline 38.65 & $c^{1,4}-c t$ & 7,38 & \\
\hline 43.12 & $C^{1,4}-t t$ & 7,34 & \\
\hline 43.42 & $c^{1,4}-t c$ & 6,24 & \\
\hline 41.36 & $C^{7}-t t$ & 3,67 & \multirow{3}{*}{0,50} \\
\hline 42.09 & $c^{7}-c t: t c$ & 6,79 & \\
\hline 42.74 & $C^{7}-c c$ & 3,82 & \\
\hline 133.02 & $c^{2,3}-t$ & 10,14 & \multirow{2}{*}{0,52} \\
\hline 133.92 & $C^{2,3}-c$ & 11,20 & \\
\hline
\end{tabular}

Dos dados de $\sigma_{c}$ nos três espectros analisados, observa-se que os polímeros são equivalentes nas razões cis/trans, com pequeno favorecimento da forma trans no caso com $2^{1,54,55}$ 


\section{CONCLUSÕES}

Os complexos sintetizados combinando as aminas acíclicas $\mathrm{NH}_{2} \mathrm{Ph}, \mathrm{NH}_{2} \mathrm{CH}_{2} \mathrm{Ph}$ e $\mathrm{NH}^{\mathrm{n}} \mathrm{BuPh}$ com $\mathrm{PPh}_{3}$, a partir de reações com $\left[\mathrm{RuCl}_{2}\left(\mathrm{PPh}_{3}\right)_{3}\right]$, foram isolados e caracterizados. As caracterizações foram realizadas por análise elementar de $\mathrm{CHN}$, espectroscopia na região do infravermelho, $\mathrm{RMN}{ }^{31} \mathrm{P}\left\{{ }^{1} \mathrm{H}\right\}$, espectroscopia na região do uv-vis e voltametria cíclica. Com os dados analíticos conclui-se que ocorre a saída de uma molécula de $\mathrm{PPh}_{3}$ no precursor e coordenação de 1 ou 2 aminas à esfera de coordenação dos centros de rutênio. Os complexos com $\mathrm{NH}_{2} \mathrm{Ph}$ (1) e com $\mathrm{NH}_{2} \mathrm{CH}_{2} \mathrm{Ph}$ (2) são hexacoordenados e o complexo com $\mathrm{NH}^{\mathrm{n}} \mathrm{BuPh}$ (3) é uma espécie pentacoordenada do tipo pirâmide de base quadrada. Em 1 e em 3, tanto os ligantes $\mathrm{PPh}_{3}$ quanto os ligantes cloro estão trans-posicionados entre si. Já em 2 tanto ligantes cloro quanto ligantes $\mathrm{PPh}_{3}$ estão cis-posicionados.

Nas reações de ROMP de NBE, os três complexos foram ativos. No caso com 1 obteve-se rendimento quantitativo a $50^{\circ} \mathrm{C}$ por 30 minutos, enquanto que com $\mathbf{2}$, na mesma temperatura obteve-se rendimento quantitativo por 5 minutos. Já o complexo 3 polimerizou NBE com rendimento quantitativo à $25^{\circ} \mathrm{C}$ por 5 minutos.

As reações de ROMP de NBD com 1 e $\mathbf{2}$ foram pouco efetivas, mesmo a $50{ }^{\circ} \mathrm{C}$ por até 240 minutos; obteve-se no máximo $12 \%$ com 1 e $25 \%$ com 2. O complexo 3 polimerizou quantitativamente $\mathrm{NBD}$ a $50^{\circ} \mathrm{C}$ por 30 minutos. Somente 3 proporcionou a polimerização de DCPD com valor de rendimento em torno de $26 \%$.

Variando-se as razões molares $[\mathrm{NBE}] /[\mathrm{Ru}]$ foi possível observar que os complexos foram ativos para concentrações molares de NBE de até 10.000 vezes em relação à de 
rutênio. Observou-se também que a temperatura favoreceu a atividade dos complexos entre $25^{\circ} \mathrm{C}$ e $50^{\circ} \mathrm{C}$, e com tempos de reação de 5 a 240 minutos.

O complexo 3 apresentou atividade para copolimerizações de NBE/NBD ou NBD/NBE, com rendimentos de até $60 \%$. Esse complexo foi ativo com NBE/DCPD e NBD/DCPD com até 35\% de rendimento. O catalisador foi sensível a variações nas razões molares dos comonômeros.

Os poliNBE formados obtiveram $\sigma_{c}$ entre 0,41 a 0,52 , com valores de $M_{w}$ em torno $10^{4}$ e $10^{5}$ com IPDs na faixa de 1,6 a $3,5$.

Os estudos por RMN ${ }^{13} \mathrm{C}$ serão realizados para os copolímeros, bem como os estudos cinéticos para medir as constantes de velocidades das reações de iniciação e propagação.

Dos resultados obtidos, os estudos com aminas acíclicas são promissores dentro da perspectivas de se obterem catalisadores alternativos para ROMP. Observou-se que aminas simples podem modular a reatividade de catalisadores ao variar os efeitos estéricos e eletrônicos junto ao centro metálico. 


\section{REFERÊNCIAS BIBLIOGRÁFICAS}

[1] IVIN, K.J.; MOL, J.C. Olefin metathesis and metathesis polymerization. New York: Academic Press. 1997. p. 472-496.

[2] MOL, J.C. Industrial applications of olefin metathesis. Journal of Molecular Catalysis A: Chemical, v. 213, p. 39-45, 2004.

[3] GRUBBS, R. H. Olefin metathesis. Tetrahedron, v. 60, p. 7117-7140, 2004.

[4] BIELAWISKI, C. W.; GRUBBS, R. H. Living ring-opening metathesis polymerization. Progress in Polymer Science, v. 32, p. 1-29, 2007.

[5] GRUBBS, R. H. Handbook of Metathesis. New York: Wiley, 2003. v. 3.

[6] CHAUVIN, Y. Olefin Metathesis: the early days (Nobel Lecture). Angewandte Chemie International Edition, v. 45, 3747, 2006.

[7] GRUBBS, R. H. Olefin-metathesis catalysts for the preparation of molecules and materials (Nobel Lecture). Angewandte Chemie International Edition, v. 45, p. 37603765, 2006.

[8] SCHROCK, R. R. Multiple metal-carbon bonds for catalytic metathesis reaction (Nobel lecture). Angewandte Chemie International Edition , v. 45, 3759, 2006.

[9] HERISSON, J.L.; CHAUVIN, Y. Makrolmol Chemistry. v. 141, p. 161, 1971.

[10] GRUBBS, R. G.; CHANG, S. Recent advances in olefin metathesis and its application in inorganic synthesis. Tetrahedron, v. 54, p. 4413-4450, 1998

[11] FRANCE, M. B., UFFELMAN, E. S. Ring-opening metathesis polymerization with a well-defined ruthenium carbene complex: an experiment for the undergraduate inorganic of polymer laboratory. Journal of Chemical Education, v. 76, n. 5, p. 661-665, 1999. 
[12] BRESLOW, D. S. Metathesis polymerization. Progress in Polymer Science, v. 18, p. 1141-1195, 1993.

[13] CHERUMUTTATHU, H.S.; NOBUAKI, K. Orbital Interactions in the Ruthenium Olefin Metathesis Catalysts. Organometallics, v. 23, p. 76-80, 2004.

[14] ROSSI, A.R.; EISENSTEIN, O.; HOFFMANN, R. Some Geometrical and Electronic Features of the Intermediate Stages of Olefin Metathesis. Journal of American Chemical Society, v. 103, p. 5582-5584, 1981.

[15] MASTERS, C. Homogeneous Transition-Metal Catalysis, Champman and Hall, London, 1981.

[16] CETINKAYA, S.; OZKER, T; BAYRAM, R. Application of well-defined ruthenium alkylidenes to the ROMP of norbornene derivatives: Methoxyphenyl- substituted polynorbornene dicarboximides. Applied Catalysis A: General, v. 393, p. 24-28, 2011.

[17] YANG, D.; HUANG, W.; YU, J.; JIANG, J.; ZHANG, L.; XIE, M. A novel shape memory polynorbornene functionalized with poly( $\varepsilon$-caprolactone) side chain and cyano group through ring-opening metathesis polymerization. Polymer, v. 51, p. 5100-5106, 2010.

[18] NGUYEN, S. T.; GRUBBS, R. H.; ZILLER, J.W. Syntheses and activities of new single component, ruthenium-based olefin metathesis catalysts. Journal of the American Chemical Society, v. 115, p. 9858-9859, 1993

[19] SCHWAB, P.; GRUBBS, R.H.; ZILLER, J.W. Synthesis and application of $\mathrm{RuCl}_{2}(\mathrm{CHR})\left(\mathrm{PR}_{3}\right)_{2}$ : The influence of the alkylidene moiety on metathesis activity. Journal of the American Chemical Society, v. 118, p. 100-110, 1996.

[20] TRNKA, T. M.; GRUBBS, R. H. The development of $L_{2} X_{2} R u=C H R$ olefin metathesis catalysts: an organometallic success story. Accounts of Chemical Research, v. 34, p.18-29, 2001.

[21] SCHOLL, M.; DING, S.; LEE, C. W.; GRUBBS, R. H. Synthesis and activity of a new generation of ruthenium-based olefin metathesis catalysts coordinated with 1,3dimesityl-4,5- dihydroimidazol-2-ylidene ligands. Organic Letters, v. 1, p. 953-956, 1999 
[22] LEITGEB, A.; WAPPEL, J.; SLUGOVC, C. The ROMP toolbox upgraded. Polymer, v. 51, n. 14, p. 2927-2946, 2010.

[23] ALLAERT, B.; DIELTIENS, N.; LEDOUX, N.; VERCAEMST, C.; VAN DER VOORT, P; STEVENS, C. V.; LINDEN, A.; VERPOORT, F. Synthesis and activity for ROMP of bidentate Schiff base substituted second generation Grubbs catalysts. Journal of Molecular Catalysis A: Chemical, v. 260, p. 221-226, 2006.

[24] WESKAMP; T.; SCHATTENMANN; W.C.; SPIEGLER; M.; HERMANN; W.A. A novel class of ruthenium catalysts for olefin metathesis. Angewandte Chemie International Edition, v.37, p. 2490-2492, 1998

[25] FRENZEL, U.; NUYKEN, O. Ruthenium-based metathesis initiators: development and use in ring-opening metathesis polymerization. Journal of Polymer Science, Part A: Polymer Chemistry, v. 60, p. 2895-2916, 2002.

[26] NOVAK, B. M.; GRUBBS, R. H. Catalytic organometallic chemistry in water: the aqueous ring-opening metathesis polymerization of 7-oxanorbornene derivatives. Journal of the American Chemical Society, v. 110, n. 22, p. 7542-7543, 1988.

[27] NGUYEN, S. T.; JOHNSON, L. K.; GRUBBS, R. H. Ring-opening metathesis polymerization (ROMP) of norbornene by a Group VIII carbene complex in protic media. Journal American Chemical Society, v.114 , p. 3974-,1992.

[28] FU, G.C.; NGUYEN, S.T.; GRUBBS, R.H. Catalytic ring-closing metathesis of functionalized dienes by a ruthenium carbene complex. Journal of the AmericanChemical Society, v. 115, p. 9856-9857, 1993.

[29] RAHMAN, M. M., LIU, H., ERIKS, K., PROCK, A. E GIERING, W.P.; Separation of Phosphorous(III) Ligands into Pure s-Donors and s-Donors/p-Acceptors: Comparison of Basicity and s-Donicity. Organometallics

[30] MCAULIFFE, C. A., LEVASON, W. Phosphine, Arsine and Stibine Complexes of the Transition Elements, Elsevier, Amsterdam, 1979.

[31] PIGNOLET. L. H. Homogeneous Catalysis With Metal Phosphine Complexes. Plenium, New York, 1993. 
[32] SA, J. L. S.; LIMA-NETO, B. S. Ability of Ru complexes for ROMP tuned through a combination of phosphines and amines. Journal of Molecular Catalysis A: Chemical, v. 304, p. 187-190, 2009.

[33] COLLMAN, J. P., HEGEDUS, L. S., NORTON, J. R., FINK, R. L. Principles and Aplications of Organotransitions Metal Chemistry, Mill Valley, University Science Books, 1987.

[34] COTTON, F.A.; WILKINSON, G.; MURILLO, C. A.; BOCHMANN, M., Advanced Inorganic Chemistry, $6^{\text {th }}$ Ed., Wiley, New York, 1999.

[35] PARSHALL, G. W., ITTEL, S. D. Homogeneous Catalysis. The Application and Chemistry of Catalysts by Soluble Transition Metal Complexes, $2^{\text {th }}$ Ed., Willey Interscience, New York, 1992.

[36] LIMA NETO, B. S., "Efeito e influência trans de ligantes apresentando P(III), As(III) e $\mathrm{Sb}$ (III) como átomos doadores, em tetraaminas de Ru(II)", Dissertação de Mestrado, Instituto de Física e Química de São Carlos-USP, 1987.

[37] MATOS, J. M. E.; BATISTA, N. C.; CARVALHO, R. M.; SANTANA, S. A. A.; PUZZI, P. N.; SANCHES, M.; LIMA-NETO, B. S. Metátese de olefinas no Brasil: - "Brazil is ROMPing it!". Química Nova, v. 30, p. 431-435, 2007.

[38] MATOS, J. M. E.; LIMA-NETO, B. S. Piperidine as ancillary ligand in the novel $\left[\mathrm{RuCl}_{2}\left(\mathrm{PPh}_{3}\right)_{2}\right.$ (piperidine)] complex for methatesis polymerization of norbornene and norbornadiene. Journal of Molecular Catalysis. A: Chemical, v. 222, p. 81-85, 2004.

[39] SA, J. L. S.; VIEIRA, L. H.; NASCIMENTO, E. S. P; LIMA-NETO, B. S. The influence of perhydroazepine and piperidine as further ancillary ligands on $\mathrm{Ru}-\mathrm{PPh}_{3}$-based catalysts for ROMP of norbornene and norbornadiene. Applied Catalysis A: General, v. 374, p. 194-200, 2010.

[40] MATOS, J. M. E.; LIMA-NETO, B. S. Development of easily accessible ruthenium based catalysts for metathesis polimerization using 4-X-pyridine as ancillary ligands.

Catalysis Today, v. 107-108, p. 282-288, 2005.

[41] MATOS, J. M. E.; LIMA-NETO, B. S. Acyclic amines as ancillary ligands in Ru-based catalysts for ring-opening metathesis polymerization: Probing the electronic and 
steric aspects of cyclic and acyclic amines. Journal of Molecular Catalysis A:

Chemical, v. 259, p. 286- 291, 2006.

[42] HALL Jr, H.K. Correlations of the base strengths of amines. Journal of American Chemical Society, v. 79, p. 5441-5444, 1957

[43] STEPHENSON, T. A.; WILKINSON, G. New complexes of ruthenium (II) and (III) with triphenilphosphine, triphenilarsine, triclorostannate, pyridine and other ligands. Journal of Inorganic Nuclear Chemistry, v. 28, p. 945-956, 1966.

[44] ARMIT, P. W.; BOYD, A. S. F.; STEPHESON, T. A. Synthesis and rearrangement reactions of dihalogenotris- and dihalogenotetrakis-(tertiary phosphine) ruthenium(II) compounds. Journal of the American Chemical Society, n. 16/17, p. 1663-1672, 1975.

[45] SOCRATES, G. Infrared and Raman characteristic group frequencies. New York: John Wiley, 2001. p. 211

[46] SILVERSTEIN, R. M.; WEBSTER, F. X.; KIEMLE, D. J. Identificação Espectrométrica de Compostos Orgânicos. 7. ed. Sao Paulo: Editora LTC, 2006. p. 101.

[47] ALBERS, J.; CADIERNO, V.; CROCHET, P.; GARCÍA-GARRIDO, S.E.; GIMENO, J. Octahedral ruthenium(II) complexes cis,cis-[RuX $\left.(\mathrm{CNR})(\mathrm{CO})\left(\mathrm{P}^{\wedge} \mathrm{P}\right)\right]$ and cis,cis,cis$\left[\operatorname{RuX}_{2}(C O) 2\left(P^{\wedge} P\right)\right]\left(X=C l, B r ; P^{\wedge} P=1,10\right.$-bis(diphenylphosphino) ferrocene, 1,10-bis (diisopropylphosphino) ferrocene): Synthesis and catalytic applications in transfer hydrogenation of acetophenone and cycloisomerization of (Z)-3-methylpent-2-en-4yn-1-ol. Journal of Organometallic Chemistry, v. 692, p. 5234-5244, 2007.

[48] GRAMINHA, A. E.; BATISTA, A. A.; MENDES, I. C.; TEIXEIRA, L. R.; BERALDO,.H. Ruthenium(II) complexes containing 2-pyridineformamide- and 2-benzoylpyridinederived thiosemicarbazones and $\mathrm{PPh}_{3}$ : NMR and electrochemical studies of cis-transisomerization. Spectrochimica Acta Part A, v. 69, p. 1277-1282, 2008.

[49] CADIERNO, V.; CROCHET, P.; DÍEZ, J.; GARCÍA-GARRIDO, S. E.; GIMENO, J. An Easy Entry to Dimers $\left[\left\{R u X(\mu-X)(C O)\left(P^{\wedge} P\right)\right\}_{2}\right]\left(X=C l, B r ; P^{\wedge} P=1,1^{\prime}-\right.$

Bis(diphenylphosphino)ferrocene, 1,1'-Bis(diisopropylphosphino) ferrocene) from $\eta^{3}$ Allylruthenium(II) Derivatives $\left[\mathrm{RuX}\left(\eta^{3}-2-\mathrm{C}_{3} \mathrm{H}_{4} \mathrm{R}\right)(\mathrm{CO})(\mathrm{P} \wedge \mathrm{P})\right](\mathrm{R}=\mathrm{H}, \mathrm{Me})$ : Efficient Catalyst Precursors in Transfer Hydrogenation of Ketones. Organometallics, v. 22, p. 5226-5234, 2003. 
[50] MOODY, C.J.; WHITHAM, G.H. Reactive Intermediates. New York: Oxford University Press Inc. 1995. p. 26-50.

[51] USÓN, R.; ORO, L. A.; CIRIANO, M. A.; NAVAL, M. M. Cyclopentadienylruthenium complexes with chelating diamines and diolefins, crystal structures of $\left[\mathrm{Ru}(\mathrm{NBD})\left(\mathrm{PPh}_{3}\right)\left(\eta-\mathrm{C}_{5} \mathrm{H}_{5}\right)\right] \mathrm{ClO}_{4}$ and $\left[\mathrm{Ru}\left\{\left(\eta^{6}-\mathrm{C}_{6} \mathrm{H}_{5}\right) \mathrm{Ph}_{2} \mathrm{PO}\right\}\left(\eta-\mathrm{C}_{5} \mathrm{H}_{5}\right)\right] \mathrm{ClO}_{4}$. A new mode of coordination of triphenylphosphine. Journal of Organometallic Chemistry, v. 256, p. 3312-347, 1983.

[52] SZYMAŃSKA-BUZAR, T.; GLOWIAK, T.; CZELUŚNIAK, I. Reactivity of $\left[\mathrm{Mo}(\mu-\mathrm{Cl})\left(\mathrm{SnCl}_{3}\right)(\mathrm{CO})_{3}(\mathrm{NCMe})_{2}\right]$ towards norbornadieno. X-ray crystal structure of $\left[\mathrm{Mo}(\mu-\mathrm{Cl})\left(\mathrm{SnCl}_{3}\right)(\mathrm{CO})_{2}\left(\mathrm{~h}^{4}-\mathrm{C}_{7} \mathrm{H}_{8}\right)(\mathrm{NCMe})\right]$. Polyhedron, v. 21, p. 2505-2513, 2002.

[53] DAVIDSON, T.A.; WAGENER, K.B.; PRIDDY, D.B. Polymerization of dicyclopentadiene: A tale of two mechanisms. Macromolecules, v. 29, p. 786-788, 1996.

[54] DAVIS, F. J. Polymer Chemistry: A Practical Approach. New York: Oxford University Press, 2004.

[55] CZELUŚNIAK, I.; SZYMAŃSKA-BUZAR, T. Ring-opening metathesis polymerization of norbornene and norbornadiene by tungsten(II) and molybdenum(II) complexes.

Journal of Molecular Catalysis A: Chemical, v. 190, p. 131-143, 2002. 
ANEXO I

Cromatogramas obtidos por GPC para os complexos 1, 2 e 3.
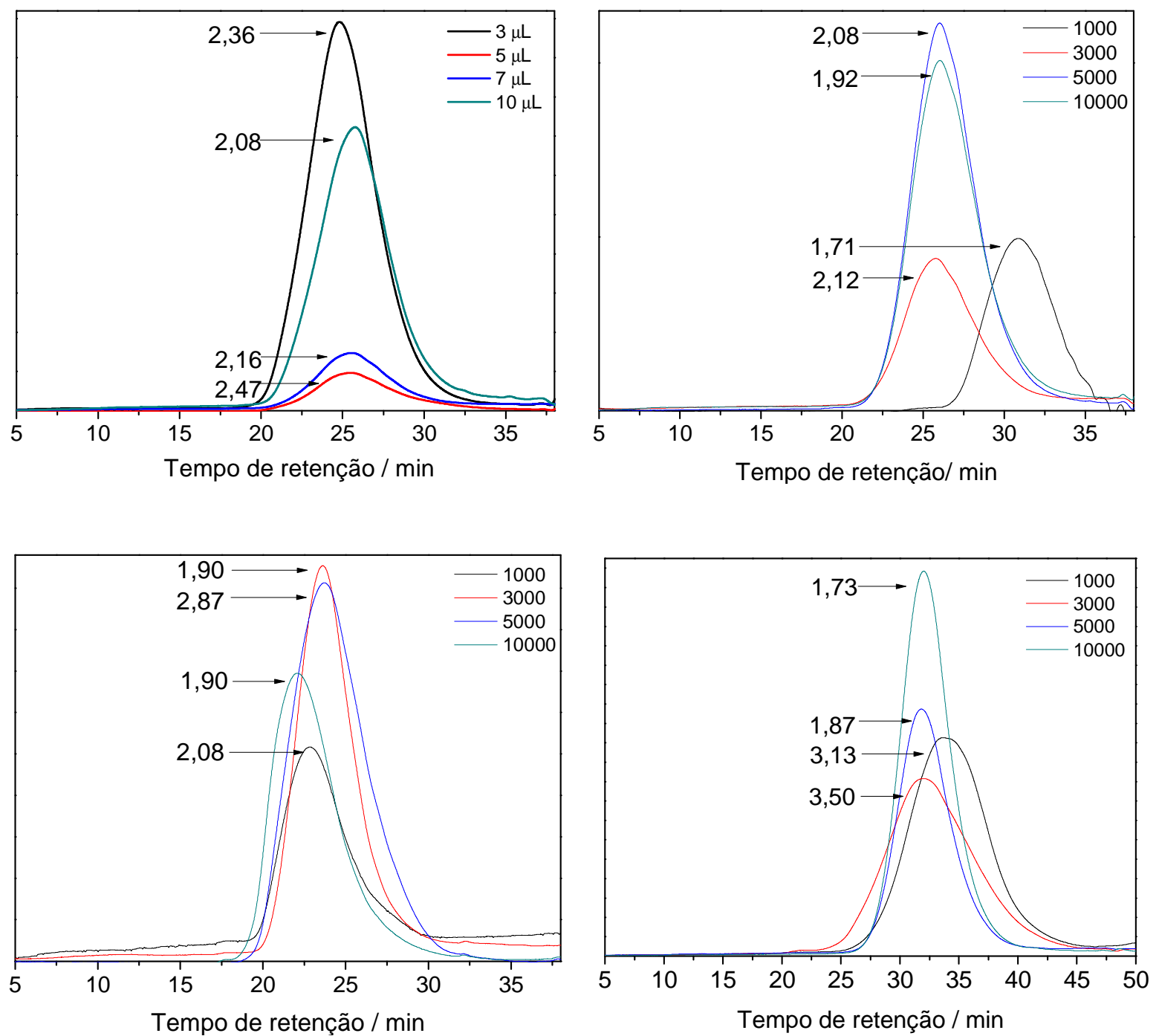

Figura 69. Cromatogramas com IPD para ROMP de NBE utilizando 1 em: (a) EDA; (b) $25^{\circ} \mathrm{C} \mathrm{em}$ $5 \mathrm{~min}$; (c) $50^{\circ} \mathrm{C} \mathrm{em} 5 \mathrm{~min}$ e (d) $50^{\circ} \mathrm{C}$ em $30 \mathrm{~min}$. 


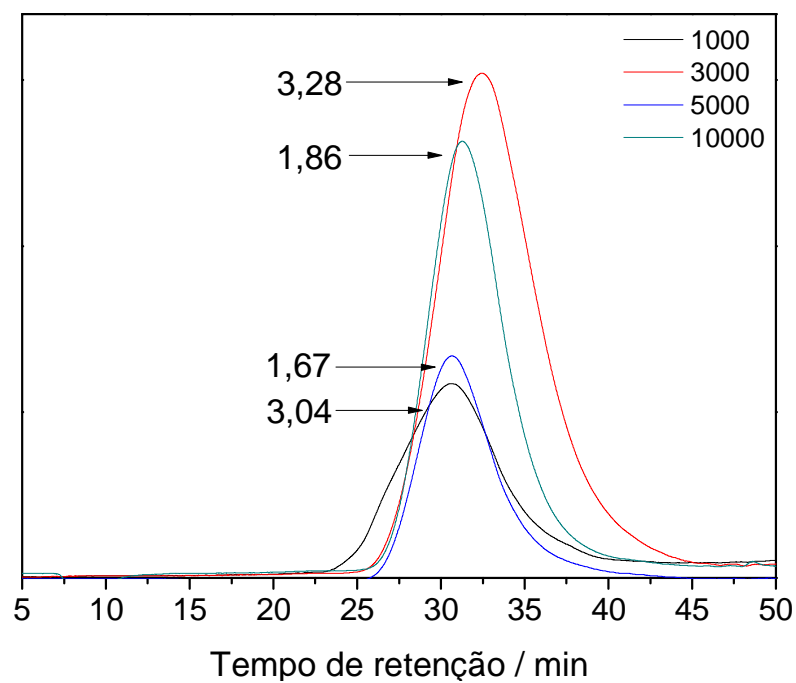

Figura 70. Cromatograma com IPD para ROMP de NBE utilizando 2 a $50^{\circ} \mathrm{C}$ em $5 \mathrm{~min}$.

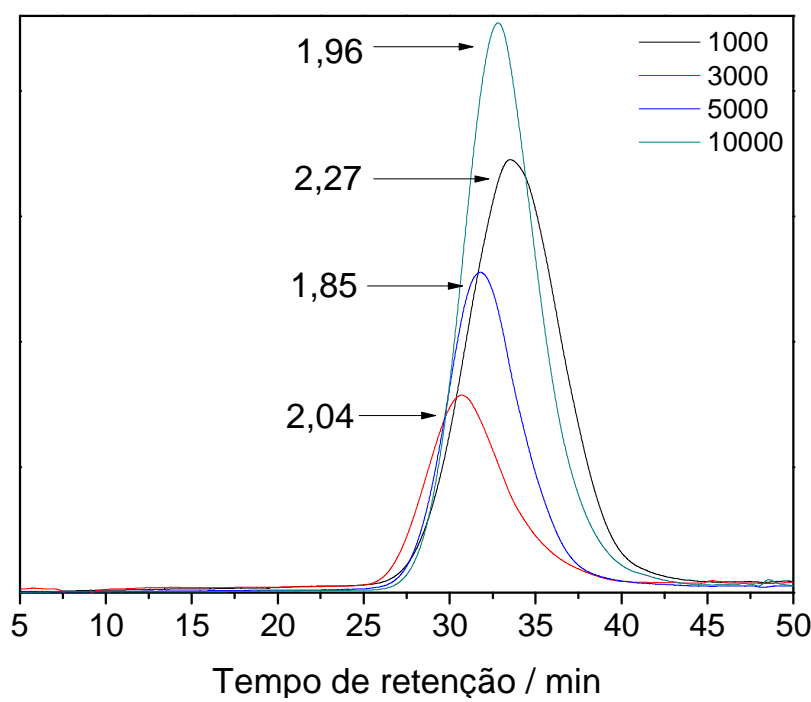

Figura 71. Cromatograma com IPD para ROMP de NBE utilizando 3 a $25^{\circ} \mathrm{C}$ em 5 min. 